NBER WORKING PAPER SERIES

\title{
NONPARAMETRIC COUNTERFACTUAL PREDICTIONS IN NEOCLASSICAL MODELS OF INTERNATIONAL TRADE
}

\author{
Rodrigo Adao \\ Arnaud Costinot \\ Dave Donaldson \\ Working Paper 21401 \\ http://www.nber.org/papers/w21401 \\ NATIONAL BUREAU OF ECONOMIC RESEARCH \\ 1050 Massachusetts Avenue \\ Cambridge, MA 02138 \\ July 2015
}

For useful comments we thank Ariel Burstein, Penny Goldberg, Andres Rodriguez-Clare, Bob Staiger, Jon Vogel, and Ivan Werning as well as seminar participants at Brown University, the New York Federal Reserve, Northwestern, Princeton, UC Berkeley, University of Oregon, and Yale. We are grateful to Joe Shapiro for helping us to access data on freight costs. The views expressed herein are those of the authors and do not necessarily reflect the views of the National Bureau of Economic Research.

NBER working papers are circulated for discussion and comment purposes. They have not been peerreviewed or been subject to the review by the NBER Board of Directors that accompanies official NBER publications.

(C) 2015 by Rodrigo Adao, Arnaud Costinot, and Dave Donaldson. All rights reserved. Short sections of text, not to exceed two paragraphs, may be quoted without explicit permission provided that full credit, including $\odot$ notice, is given to the source. 
Nonparametric Counterfactual Predictions in Neoclassical Models of International Trade Rodrigo Adao, Arnaud Costinot, and Dave Donaldson

NBER Working Paper No. 21401

July 2015

JEL No. F10,F11,F14,F15,F17

\begin{abstract}
$\underline{\text { ABSTRACT }}$
We develop a methodology to construct nonparametric counterfactual predictions, free of functional-form restrictions on preferences and technology, in neoclassical models of international trade. First, we establish the equivalence between such models and reduced exchange models in which countries directly exchange factor services. This equivalence implies that, for an arbitrary change in trade costs, counterfactual changes in the factor content of trade, factor prices, and welfare only depend on the shape of a reduced factor demand system. Second, we provide sufficient conditions under which estimates of this system can be recovered nonparametrically. Together, these results offer a strict generalization of the parametric approach used in so-called gravity models. Finally, we use China's recent integration into the world economy to illustrate the feasibility and potential benefits of our approach.
\end{abstract}

Rodrigo Adao

Department of Economics, MIT

77 Massachusetts Avenue

Cambridge, MA, 02139

rradao@mit.edu

Arnaud Costinot

Department of Economics, E17-232

MIT

77 Massachusetts Avenue

Cambridge MA 02139

and NBER

costinot@mit.edu
Dave Donaldson

Department of Economics

Stanford University

579 Serra Mall

Stanford, CA 94305

and NBER

ddonald@stanford.edu 


\section{Introduction}

Many interesting questions in international economics are counterfactual ones. Consider China's recent export boom. In the last two decades, its share of world exports has increased from 3\% in 1995 to $11 \%$ in 2011. What if it had not? What would have happened to other countries around the world?

Given the challenges inherent in isolating quasi-experimental variation in general equilibrium settings, the standard approach to answering such questions has been to proceed in three steps. First, fully specify a parametric model of preferences, technology and trade costs around the world. Second, estimate the model's supply- and demand-side parameters. And finally, armed with this complete knowledge of the world economy, predict what would happen if some of the model's parameters were to change. Such Computational General Equilibrium (CGE) models have long been used to answer a stream of essential counterfactual questions; see e.g. Hertel (2013) for a survey of the influential GTAP model. Over the last ten years or so, this tradition has been enhanced by an explosion of quantitative work based on gravity models, triggered in large part by the seminal work of Eaton and Kortum (2002).

A key difference between old CGE models, like GTAP, and new CGE models, like Eaton and Kortum (2002), is parsimony. The latest version of the GTAP model described in Hertel, McDougall, Narayanan and Aguiar (2012) has more than 13,000 structural parameters. Counterfactual analysis in the Eaton and Kortum (2002) model can be conducted using knowledge of only one: the trade elasticity. Parsimony is valuable. But it hinges on strong functional form assumptions that may hinder the credibility of counterfactual predictions. The goal of this paper is to explore the extent to which one may maintain parsimony, but dispense with functional-form assumptions. In a nutshell, can we relax Eaton and Kortum's (2002) strong functional-form assumptions without circling back to GTAP's 13,000 parameters?

Our starting point is the equivalence between neoclassical economies and reduced exchange economies in which countries simply trade factor services. Formally, we consider a world economy comprising a representative agent in each country, constant returns to scale in production, and perfect competition in all markets. In this general environment we show that for any competitive equilibrium there is an equilibrium in a reduced exchange economy that is equivalent in terms of welfare, factor prices and the factor content of trade-and further, that the converse is also true.

This equivalence is important for its simplifying power: a reduced exchange economy in which countries act as if they trade factor services can be characterized fully by an 
analysis of the reduced factor demand system that summarizes all agents' preferences over factor services. Thus for a number of counterfactual questions, like the effects of uniform changes in trade costs, one does not need the complete knowledge of demand and production functions across countries and industries. For instance, one does not need to know the cross-price elasticity between French compact cars and Italian cotton shirts or between Korean flat screen TVs and Spanish heirloom tomatoes. Similarly, one does not need to know productivity in these various economic activities around the world. All one needs to know is the cross-price elasticity between factors from different countries. This basic observation encapsulates how we propose to reduce the dimensionality of what needs to be estimated for counterfactual analysis-the reduced factor demand system-without imposing strong functional-form assumptions. ${ }^{1}$

Our second theoretical result establishes that, as long as the reduced factor demand system is invertible, knowledge of this demand system as well as measures of the factor content of trade and factor payments in some initial equilibrium are sufficient to construct counterfactual predictions about the effect of changes in trade costs and factor endowments. This result provides a nonparametric generalization of the methodology popularized by Dekle, Eaton and Kortum (2008). Their analysis focuses on a Ricardian economy in which the reduced labor demand system takes the Constant Elasticity of Substitution (CES) form. This functional form assumption, however, is not a critical condition for the previous approach to succeed; only the invertibility of the reduced factor demand is.

The procedure that we propose to make counterfactual predictions relies on knowledge of the reduced factor demand system. In gravity models, such systems are implicitly assumed to be CES. Hence, a single trade elasticity can be estimated by regressing the log of bilateral flows on an exogenous shifter of the log of bilateral trade costs, like tariffs or freight costs. Our final set of theoretical results demonstrates that this approach can be pushed further than previously recognized. Namely, we provide sufficient conditions under which, given measures of the factor content of trade and observable shifters of trade costs, reduced factor demand systems can be nonparametrically identified using the same exclusion restrictions. As with our counterfactual results, the invertibility of the reduced factor demand remains the critical assumption; strong functional form assumptions can be dispensed with.

\footnotetext{
${ }^{1}$ It is worth emphasizing that this approach to dimensionality-reduction does not hinge on any assumption about the number of goods and factors in the world. Regardless of whether there are more goods than factors, the point is that one can estimate a single reduced demand system for factors rather than estimate multiple production functions-that determine how factors are demanded by producers of goods-and utility functions - that determine how goods are demanded by consumers. Of course, the fewer factors there are, the easier the estimation of the reduced factor demand system is.
} 
We conclude our paper by applying our general results to one particular counterfactual question: What would have happened to other countries if China had remained closed? In practice, data limitations are severe-Leamer's (2010) elusive land of "Asymptopia" is far away - and estimation of a reduced factor demand system must, ultimately, proceed parametrically. So the final issue that needs to be tackled is how to parametrize and estimate a reduced factor demand system without taking a stance on particular microfoundations. We offer the following rules of thumb: (i) be as flexible as possible given data constraints; (ii) allow flexibility along the dimensions that are more likely to be relevant for counterfactual question of interest; and (iii) use the source of variation in the data under which demand is nonparametrically identified. ${ }^{2}$

Towards this goal in the present context, we introduce a strict generalization of CES, which we refer to as mixed CES, inspired by the work of Berry (1994) and Berry, Levinsohn and Pakes (1995) in industrial organization. Like in a standard gravity model, we assume the existence of a composite factor in each country so that the factor content of trade between any pair of countries is equal to their bilateral trade flow. Compared to a standard gravity model, however, our demand system features two new structural parameters that measure the extent to which exporters that are closer in terms of either market shares or some observable characteristic, which we take to be GDP per capita, tend to be closer substitutes. Under CES, when China gains market share, Indian and French exports must be affected equally. By contrast, the mixed CES demand system allows data to speak to whether this "independence of irrelevant alternatives" embodied in CES holds empirically or not.

After estimating our mixed CES demand system for 37 large exporters using data on bilateral trade flows and freight costs from 1995 to 2011, we conclude that rich countries tend to gain relatively more than poor countries from China's integration with the rest of the world-that is, rich countries would have been relatively worse off if Chinese trade costs had counterfactually remained at their 1995 value from 1995 to 2011 . Under the restriction that demand is CES, no such pattern emerges.

Up to this point, we have emphasized the feasibility and potential benefits of our new approach to counterfactual and welfare analysis. It should be clear that our approach also has important limitations. We discuss these further below but four deserve emphasis here. First, the equivalence result on which we build heavily relies on the efficiency of perfectly competitive markets. This does not mean that our approach will necessarily

\footnotetext{
${ }^{2}$ In their original paper on the CES function, Arrow, Chenery, Minhas and Solow (1961) note that one of its attractive features is that it is "the most general function which can be computed on a suitable slide rule." Computing power has since improved.
} 
fail if one were to relax the assumption of perfect competition or introduce distortionsindeed, Arkolakis et al. (2012a) and Arkolakis et al. (2012b) offer examples in this vein that cover a number of influential modeling approaches-but it is fair to say that it is much less likely to be useful in such circumstances. Second, the scope of the counterfactual exercises that we consider is limited by the restriction that the shape of the reduced demand system remains stable. Uniform changes in iceberg trade costs satisfy this condition, but many interesting shocks do not, a point we come back to in Section 4.3. Third, the restriction that the demand system is invertible implicitly excludes zeros in bilateral factor trade. So our nonparametric approach does not solve the "zeros issue" in standard gravity models. ${ }^{3}$ Fourth, the estimation of a reduced factor demand system requires that the factor content of trade be measured accurately. Since the seminal work of Leontief (1953), multiple generations of trade economists have combined input-output matrices with trade data to do so, but the high-level of aggregation of such matrices leaves open the possibility of mis-measurement, a point emphasized more recently by Burstein and Vogel (2010). ${ }^{4}$

The rest of our paper is organized as follows. Section 2 discusses the related literature. Section 3 establishes our main equivalence result. Section 4 uses this result to conduct counterfactual and welfare analysis. Section 5 provides sufficient conditions for nonparametric identification. Section 6 estimates factor demand. Section 7 uses these estimates to study the consequences of China's integration with the rest of the world. Section 8 offers some concluding remarks.

\footnotetext{
${ }^{3}$ This is a version of the "new goods problem" that is common in many demand settings (Bresnahan and Gordon, 2008). Just as in those settings, one can typically place a lower bound on the welfare effects of a counterfactual by requiring that zeros cannot become positive. For our purposes, the more specific question is whether the challenge posed by zeros in the data is alleviated or worsened by the study of reduced factor demand relative to standard gravity approaches. The answer depends on the assumptions that one makes about the number of goods and factors. If one assumes the existence of a composite factor in each country, as we do in our empirical analysis, then focusing on factor demand reduces the prevalence of zeros relative to any analysis that would focus on trade in goods.

${ }^{4}$ In particular, national input-output matrices do not disaggregate factor payments by destination within each producing country-times-industry cell. The implicit assumption used to measure the factor content of trade in the empirical literature therefore is that factor intensity is constant across destinations. Since micro-level evidence, e.g. Bernard and Jensen (1999), suggests systematic variation in factor intensity between firms that serve domestic and foreign markets, one could potentially improve on the measurement of the factor content of trade by combining aggregate data from the national accounts and micro-level data in a consistent way. We do not attempt to do so in this paper, but we note that, according to our theoretical results, any researcher interested in our counterfactual exercises would also be affected by this issue, albeit perhaps less explicitly.
} 


\section{Related Literature}

This paper combines old ideas from general equilibrium theory with recent methods from industrial organization and international trade to develop a new way of constructing counterfactual predictions in an open economy.

From the general equilibrium literature, we borrow the idea that, for many purposes, production economies may be reduced to exchange economies; see e.g. Taylor (1938), Rader (1972), and Mas-Colell (1991). Early applications of this idea to international trade can be found in Meade (1952), Helpman (1976), Woodland (1980), Wilson (1980), and Neary and Schweinberger (1986). Among those, Helpman (1976), Wilson (1980), and Neary and Schweinberger (1986) are most closely related. Helpman (1976) shows how to reduce computation time necessary to solve for trade equilibria by focusing on the excess demand for factors, whereas Neary and Schweinberger (1986) introduce the concept of direct and indirect factor trade utility functions and use revealed-preference arguments to generalize the Heckscher-Ohlin Theorem. Finally, Wilson (1980) demonstrates that the analysis of the Ricardian model can be reduced to the analysis of an exchange model in which each country trades its own labor for the labor of other countries.

One can think of the starting point of our paper as a generalization of Wilson's (1980) equivalence result to any neoclassical trade model. Compared to the aforementioned papers, our main contribution is to show how the equivalence between neoclassical trade models and exchange models can be used as a tool for counterfactual and welfare analysis using commonly available data on trade flows, factor payments, and trade costs. Here, reduced exchange models are a first step towards measurement and estimation, not an analytical device for studying the theoretical properties of competitive equilibria.

We view our paper as a bridge between the recent gravity literature, reviewed in Costinot and Rodríguez-Clare (2013) and Head and Mayer (2013), and the older neoclassical trade literature, synthesized in Dixit and Norman (1980). ${ }^{5}$ With the former, we share an interest in combining theory and data to shed light on counterfactual questions. With the latter, we share an interest in robust predictions, free of strong functional form assumptions. Since data is limited, there is a tension between these two goals. To make progress on the first, without giving up on the second, we therefore propose to use factor demand as a sufficient, albeit potentially high dimensional, statistic. This strategy can be thought of as a nonparametric generalization of Arkolakis, Costinot and RodríguezClare's (2012a) approach to counterfactual and welfare analysis. Ultimately, there is noth-

\footnotetext{
${ }^{5}$ Further results about the theoretical properties of gravity models, including sufficient conditions for existence and uniqueness of equilibria, can be found in Allen, Arkolakis and Takahashi (2014).
} 
ing special about gravity models. They are factor demand systems, like any other neoclassical trade model. And like any demand system, factor demand systems can be estimated using data on quantities, prices, and some instrumental variables. Once this basic econometric issue is recognized, it becomes natural to turn to the recent results on the nonparametric identification of demand in differentiated markets; see e.g. Berry, Gandhi and Haile (2013) and Berry and Haile (2014).

Our analysis is also related to the large empirical literature on the determinants of the factor content of trade. A long and distinguished tradition-e.g. Bowen, Leamer and Sveikauskas (1987), Trefler (1993), Trefler (1995), and Davis and Weinstein (2001) —aims to test the Heckscher-Ohlin-Vanek model by comparing the factor content of trade measured in the data to the one predicted by the model under various assumptions about technology, preferences, and trade costs (or lack thereof). Our goal is instead to estimate a factor demand system and use these estimates to conduct counterfactual and welfare analysis. In order to test or assess the fit of the Heckscher-Ohlin-Vanek model in some observed equilibrium, one does not need to know the cross-price elasticities between factors from different countries. Indeed, such tests are often conducted under the assumption that factor price equalization holds, up to some factor-augmenting productivity differences, so that factors from different countries are assumed to be perfect substitutes. For our purposes, knowledge of cross-price elasticities is critical.

Finally, our work has implications for the debate about the extent to which the factor content of trade observed in one equilibrium can be used (or not) for measuring the consequences of international trade on inequality; see e.g. Deardorff and Staiger (1988), Krugman (2000) and Leamer (2000). Such a discussion implicitly boils down to the question of what shape factor demand systems take and whether factors from different countries are perfect substitutes (or not). Our analysis points towards estimating these systems as a way to settle such debates.

\section{Neoclassic Trade Models as Exchange Models}

\subsection{Neoclassical Trade Model}

Consider a world economy comprising $i=1, \ldots, I$ countries, $k=1, \ldots, K$ goods, and $n=$ $1, \ldots, N$ primary factors of production. Factor supply is inelastic. $\boldsymbol{v}_{i} \equiv\left\{v_{i}^{n}\right\}$ denotes the vector of factor endowments in country $i$. 
Preferences. In each country $i$, there is a representative agent with utility,

$$
u_{i}=u_{i}\left(\boldsymbol{q}_{i}\right)
$$

where $\boldsymbol{q}_{i} \equiv\left\{q_{j i}^{k}\right\}$ is the vector of quantities consumed in country $i$ and $u_{i}$ is strictly increasing, quasiconcave, and differentiable. The previous notation allows, but does not require, $u_{i}$ to depend only on $\left\{\sum_{j} q_{j i}^{k}\right\}$. Hence, we explicitly allow, but do not require, goods produced in different countries to be imperfect substitutes. Compared to recent quantitative work in the field, we impose no functional-form assumptions on $u$, though the assumption of a representative agent is by no means trivial.

Technology. Production is subject to constant returns to scale. Output of good $k$ in country $i$ that is available for consumption in country $j$ is given by

$$
q_{i j}^{k}=f_{i j}^{k}\left(\boldsymbol{l}_{i j}^{k}\right)
$$

where $\boldsymbol{l}_{i j}^{k} \equiv\left\{l_{i j}^{n k}\right\}$ is the vector of factors used to produce good $k$ in country $i$ for country $j$, and $f_{i j}^{k}$ is strictly increasing, concave, differentiable, and homogeneous of degree one.

Compared to recent quantitative work in the field, we again impose no functionalform assumptions on $f_{i j}^{k}$. For instance, it is standard in the existing literature to assume that the difference between production functions across different destinations derive from iceberg trade costs. This special case corresponds to the existence of Hicks-neutral productivity shifters, $\tau_{i j}^{k}$, such that

$$
f_{i j}^{k}\left(l_{i j}^{k}\right) \equiv f_{i}^{k}\left(l_{i j}^{k}\right) / \tau_{i j}^{k} .
$$

In an Arrow-Debreu sense, a good in our economy formally corresponds to a triplet $(i, j, k)$, whereas a factor formally corresponds to a pair $(i, n)$, with the usual wide interpretation. Though we impose constant returns to scale, decreasing returns in production can be accommodated in the usual way by introducing additional primary factors of production. Endogenous labor supply can be dealt with by treating leisure as another nontradable good. Multinational production, as in Ramondo and Rodríguez-Clare (2013), can also be accommodated by expanding the set of goods and using a different index $k$ for goods whose "technologies" originate in different countries. Finally, the assumption of no joint production can be relaxed substantially. The key requirement for our equivalence result is that there is no component of production that is joint across destination markets, as would be the case in the presence of fixed costs of production. ${ }^{6}$ Besides the absence of

\footnotetext{
${ }^{6}$ This implies that our theoretical framework can accomodate economies in which there are multiple
} 
increasing returns in each sector, the only substantial restriction imposed on technology is the absence of intermediate goods. We discuss how to incorporate such goods in Section 4.3 .

Competitive equilibrium. Goods markets and factor markets are perfectly competitive. We let $p_{i j}^{k}$ denote the price of good $k$ from country $i$ in country $j$ and $w_{i}^{n}$ denote the price of factor $n$ in country $i$. Letting $\boldsymbol{q} \equiv\left\{\boldsymbol{q}_{i}\right\}, \boldsymbol{l} \equiv\left\{\boldsymbol{l}_{i j}^{k}\right\}, \boldsymbol{p} \equiv\left\{p_{i j}^{k}\right\}$, and $\boldsymbol{w} \equiv\left\{w_{i}^{n}\right\}$, we can then define a competitive equilibrium as follows.

Definition 1. A competitive equilibrium corresponds to $(\boldsymbol{q}, \boldsymbol{l}, \boldsymbol{p}, \boldsymbol{w})$ such that:

i. consumers maximize their utility:

$$
\begin{aligned}
& \boldsymbol{q}_{i} \in \operatorname{argmax}_{\tilde{\boldsymbol{q}}_{i}} u_{i}\left(\tilde{\boldsymbol{q}}_{i}\right) \\
& \sum_{j, k} p_{j i}^{k} \tilde{q}_{j i}^{k} \leq \sum_{n} w_{i}^{n} v_{i}^{n} \text { for all } i
\end{aligned}
$$

ii. firms maximize their profits:

$$
\boldsymbol{l}_{i j}^{k} \in \operatorname{argmax}_{\tilde{I}_{i j}^{k}} p_{i j}^{k} f_{i j}^{k}\left(\tilde{l}_{i j}^{k}\right)-\sum_{n} w_{i}^{n} \tilde{l}_{i j}^{n k} \text { for all } i, j, \text { and } k \text {; }
$$

iii. goods markets clear:

$$
q_{i j}^{k}=f_{i j}^{k}\left(l_{i j}^{k}\right) \text { for all } i, j \text {, and } k \text {; }
$$

iv. factors markets clear:

$$
\sum_{j, k} l_{i j}^{f k}=v_{i}^{n} \text { for all } i \text { and } n
$$

\subsection{Reduced Exchange Model}

An old idea in general equilibrium theory is that it is often simpler to analyze the competitive equilibrium of a neoclassical model with production by studying instead a fictitious endowment economy in which consumers directly exchange factor services; see e.g. Taylor (1938), Rader (1972), and Mas-Colell (1991). Although this idea is often associated in the trade literature with the Heckscher-Ohlin model, it applies equally well to the Ricardian model of trade; see e.g. Wilson (1980). We now offer a formal proof of the equivalence between a general neoclassical trade model and an exchange economy, in terms of

regions within a country and firms in each region jointly produce goods and amenities. 
the factor content of trade, factor prices, and welfare. This equivalence result will be the backbone of our approach to counterfactual and welfare analysis in Section 4.

Starting from the neoclassical trade model of Section 3.1, we can define the reduced utility function over primary factors of production in country $i$ as

$$
\begin{aligned}
& U_{i}\left(\boldsymbol{L}_{i}\right) \equiv \max _{\tilde{\boldsymbol{q}}_{i}, \tilde{l}_{i}} u_{i}\left(\tilde{\boldsymbol{q}}_{i}\right) \\
& \tilde{q}_{j i}^{k} \leq f_{j i}^{k}\left(\tilde{\boldsymbol{l}}_{j i}^{k}\right) \text { for all } j \text { and } k, \\
& \sum_{k} \tilde{l}_{j i}^{n k} \leq L_{j i}^{n} \text { for all } j \text { and } n,
\end{aligned}
$$

where $\boldsymbol{L}_{i} \equiv\left\{L_{j i}^{n}\right\}$ denotes the vector of total factor demands from country $i$. It describes the maximum utility that a consumer in country $i$ would be able to achieve if she were endowed with $L_{i}$ and had access to the technologies of all firms around the world. ${ }^{7}$ One can check that $U_{i}(\cdot)$ is strictly increasing and quasiconcave, though not necessarily strictly quasiconcave, even if $u_{i}(\cdot)$ is. ${ }^{8}$ In particular, $U_{i}(\cdot)$ is likely to be linear whenever production functions are identical around the world. While this situation is obviously knifeedge, this is the special case on which the Heckscher-Ohlin model of trade focuses. We therefore explicitly allow for such situations below.

Letting $\boldsymbol{L} \equiv\left\{\boldsymbol{L}_{i}\right\}$, we can define a competitive equilibrium of the reduced exchange model or, in short, a reduced equilibrium.

Definition 2. A reduced equilibrium corresponds to $(\boldsymbol{L}, \boldsymbol{w})$ such that:

i. consumers maximize their reduced utility:

$$
\begin{aligned}
& \boldsymbol{L}_{i} \in \operatorname{argmax}_{\tilde{L}_{i}} U_{i}\left(\tilde{\mathbf{L}}_{i}\right) \\
& \qquad \sum_{j, n} w_{j}^{n} \tilde{L}_{j i}^{n} \leq \sum_{n} w_{i}^{n} v_{i}^{n} \text { for all } i ;
\end{aligned}
$$

\footnotetext{
${ }^{7}$ The above definition is closely related to, but distinct from, the notion of the "direct factor trade utility function" introduced in Neary and Schweinberger (1986). The distinction comes from the fact that Neary and Schweinberger's (1986) factor trade utility function measures the maximum utility attainable if all consumption must be produced using the techniques of the home country. In our definition, each country is assumed to have access to the techniques in all other countries, inclusive of trade costs. This distinction is important. As we will show in a moment, the factor content of trade derived from solving (6) coincides with the factor content of trade in the competitive equilibrium. This would no longer be true if one were to maximize Neary and Schweinberger's (1986) factor trade utility function.

${ }^{8}$ The fact $U_{i}$ is strictly increasing in $L_{i}$ is trivial. To see that $U_{i}$ is quasi-concave, take two vectors of factor demand, $\boldsymbol{L}_{i}$ and $\tilde{\boldsymbol{L}}_{i}$, and $\alpha \in[0,1]$. Let $(\boldsymbol{q}, \boldsymbol{l})$ and $(\tilde{\boldsymbol{q}}, \tilde{\boldsymbol{l}})$ be the solution of (6) associated with $\boldsymbol{L}_{i}$ and $\tilde{\boldsymbol{L}}_{i}$, respectively. Now consider $(\overline{\boldsymbol{q}}, \overline{\boldsymbol{l}}) \equiv \alpha(\boldsymbol{q}, \boldsymbol{l})+(1-\alpha)(\tilde{\boldsymbol{q}}, \tilde{\boldsymbol{l}})$. By construction, $\bar{l}$ trivially satisfies (8). Since $f_{j i}^{k}$ is concave, we also have $\bar{q}_{j i}^{k} \leq \alpha f_{j i}^{k}\left(\boldsymbol{l}_{j i}^{k}\right)+(1-\alpha) f_{j i}^{k}\left(\tilde{l}_{j n}^{k}\right) \leq f_{j i}^{k}\left(\bar{l}_{j n}^{k}\right)$ for all $j$ and $k$. This implies $U_{i}\left(\alpha \boldsymbol{L}_{i}+(1-\alpha) \tilde{\boldsymbol{L}}_{i}\right) \geq u_{i}(\overline{\boldsymbol{q}}) \geq \min \left\{u_{i}(\boldsymbol{q}), u_{i}(\tilde{\boldsymbol{q}})\right\}=\min \left\{U_{i}\left(\boldsymbol{L}_{i}\right), U_{i}\left(\tilde{\boldsymbol{L}}_{i}\right)\right\}$ where the second inequality follows from the quasiconcavity of $u_{i}$.
} 
ii. factor markets clear:

$$
\sum_{j} L_{i j}^{n}=v_{i}^{n} \text { for all } i \text { and } n .
$$

Our main equivalence result can be stated as follows.

Proposition 1. For any competitive equilibrium, $(\boldsymbol{q}, \boldsymbol{l}, \boldsymbol{p}, \boldsymbol{w})$, there exists a reduced equilibrium, $(\boldsymbol{L}, \boldsymbol{w})$, with: $(i)$ the same factor prices, $\boldsymbol{w}$; (ii) the same factor content of trade, $L_{i j}^{n}=\sum_{k} l_{i j}^{n k}$ for all $i, j$, and $n$; and (iii) the same welfare levels, $U_{i}\left(\boldsymbol{L}_{i}\right)=u_{i}\left(\boldsymbol{q}_{i}\right)$ for all $i$. Conversely, for any reduced equilibrium, $(\boldsymbol{L}, \boldsymbol{w})$, there exists a competitive equilibrium, $(\boldsymbol{q}, \boldsymbol{l}, \boldsymbol{p}, \boldsymbol{w})$, such that conditions (i)-(iii) hold.

The formal proof of Proposition 1 can be found in Appendix A.1. The basic arguments are similar to those used in proofs of the First and Second Welfare Theorems. This should be intuitive. In the reduced equilibrium, each representative agent solves a country-specific planning problem, as described in (6). Thus, showing that any competitive equilibrium is associated with an equivalent reduced equilibrium implicitly relies on the efficiency of the original competitive equilibrium, which the First Welfare Theorem establishes. Similarly, showing that any reduced equilibrium is associated with an equivalent competitive equilibrium implicitly relies on the ability to decentralize efficient allocations, which the Second Welfare Theorem establishes. The key distinction between Proposition 1 and standard Welfare Theorems is that the reduced equilibrium is not a global planner's problem; it remains a decentralized equilibrium in which countries fictitiously trade factor services and budgets are balanced country by country. Broadly speaking, we do not go all the way from the decentralized equilibrium to the global planner's problem, but instead stop at a hybrid reduced equilibrium, which combines country-specific planner's problems with perfect competition in factor markets. ${ }^{9}$

According to Proposition 1, if one is interested in the factor content of trade, factor prices, or welfare, then one can always study a reduced equilibrium-whose primitives are the reduced utility functions, $\left\{U_{i}\right\}$, and the endowments, $\left\{\boldsymbol{v}_{i}\right\}$-rather than a competitive equilibrium-whose primitives are the utility functions, $\left\{u_{i}\right\}$, the endowments, $\left\{\boldsymbol{v}_{i}\right\}$, and the production functions, $\left\{f_{i j}^{k}\right\}$. In order to do counterfactual and welfare analysis, one does not need to have direct knowledge of both the utility functions, $\left\{u_{i}\right\}$, and the production functions, $\left\{f_{i j}^{k}\right\}$. Instead, one merely needs to know how they indirectly

\footnotetext{
${ }^{9}$ This implies, in particular, that the convexity of preferences and technology, which is central in the proof of the Second Welfare Theorem, plays no role in the proof of Proposition 1. In the Second Welfare Theorem, convexity is invoked for Lagrange multipliers, and in turn, competitive prices to exist. Here, competitive prices for goods can be directly constructed from factor prices in the reduced equilibrium using zero-profit conditions.
} 
shape, $\left\{U_{i}\right\}$, and in turn global factor demand-that is, the solution of the reduced utility maximization problem (9). ${ }^{10}$

\section{Counterfactual and Welfare Analysis}

We start by considering counterfactual shocks to preferences and factor endowments in a reduced exchange model. In this context, we show how to extend the exact algebra popularized by Dekle, Eaton and Kortum (2008) in the context of a CES demand system to general, non-CES environments. Perhaps surprisingly, the critical assumption required for the previous approach to succeed is not strong functional form assumptions on the structure of factor demand, it is merely its invertibility. Using the equivalence result from Section 3, we then show how the previous counterfactual predictions can be used to study the effect of changes in endowments and technology in a general neoclassical model of trade.

\subsection{Reduced Counterfactuals}

Consider a reduced exchange model in which the reduced utility function over primary factors can be expressed as

$$
U_{i}\left(\boldsymbol{L}_{i}\right) \equiv \bar{U}_{i}\left(\left\{L_{j i}^{n} / \tau_{j i}^{n}\right\}\right),
$$

where $\bar{U}_{i}$ is a strictly increasing and quasi-concave utility function and $\tau_{j i}^{n}>0$ are exogenous preference shocks. The counterfactual question that we are interested in here is: What are the effects of a change from $(\boldsymbol{\tau}, \boldsymbol{v}) \equiv\left\{\tau_{j i}^{n}, v_{i}^{n}\right\}$ to $\left(\boldsymbol{\tau}^{\prime}, \boldsymbol{v}^{\prime}\right) \equiv\left\{\left(\tau_{j i}^{n}\right)^{\prime},\left(v_{i}^{n}\right)^{\prime}\right\}$ on trade flows, factor prices, and welfare?

\subsubsection{Trade Flows and Factor Prices}

For each country $i$, let $\boldsymbol{L}_{i}\left(\boldsymbol{w}, y_{i} \mid \boldsymbol{\tau}\right)$ denote the set of solutions to the utility maximization problem (9) as a function of factor prices, $\boldsymbol{w}$, income, $y_{i} \equiv \sum_{n} w_{i}^{n} v_{i}^{n}$, and preference parameters, $\tau$. This corresponds to the Marshallian demand for factor services in the reduced

\footnotetext{
${ }^{10}$ This is true regardless of whether the competitive and reduced equilibria are unique. Formally, Proposition 1 establishes that the set of factor prices, factor content of trade, and welfare levels that can be observed in a competitive equilibrium is the same as the set of factor prices, factor content of trade, and welfare levels that can be observed in a reduced equilibrium. Whether the previous sets are singletons is irrelevant for our equivalence result.
} 
equilibrium. The associated vectors of factor expenditure shares are then given by

$$
\chi_{i}\left(\boldsymbol{w}, y_{i} \mid \boldsymbol{\tau}\right) \equiv\left\{\left\{x_{j i}^{n}\right\} \mid x_{j i}^{n}=w_{j}^{n} L_{j i}^{n} / y_{i} \text { for some } \boldsymbol{L}_{i} \in \boldsymbol{L}_{i}\left(\boldsymbol{w}, y_{i} \mid \boldsymbol{\tau}\right)\right\}
$$

Since preference shocks are multiplicative, expenditure shares must depend only on the "effective" factor prices, $\omega_{i} \equiv\left\{w_{j}^{n} \tau_{j i}^{n}\right\}$. We can therefore write, with a slight abuse of notation and without risk of confusion, $\chi_{i}\left(\boldsymbol{w}, y_{i} \mid \boldsymbol{\tau}\right) \equiv \chi_{i}\left(\boldsymbol{\omega}_{i}, y_{i}\right)$. Using the previous notation, the equilibrium conditions (9) and (10) can then be expressed compactly as

$$
\begin{aligned}
x_{i} & \in \chi_{i}\left(\boldsymbol{\omega}_{i}, y_{i}\right) \text { for all } i, \\
\sum_{j} x_{i j}^{n} y_{j} & =y_{i}^{n}, \text { for all } i \text { and } n,
\end{aligned}
$$

where $x_{i} \equiv\left\{x_{j i}^{n}\right\}$ denotes the vector of factor expenditure shares in country $i$ and $y_{i}^{n} \equiv$ $w_{i}^{n} v_{i}^{n}$ denotes payments to factor $n$.

A standard gravity model, such as the one developed by Anderson and Van Wincoop (2003) and Eaton and Kortum (2002), corresponds to the special case in which there is only one factor of production in each country and factor demand is CES. Omitting the index for factors, $n$, such models require

$$
\chi_{j i}\left(\omega_{i}, y_{i}\right)=\frac{\left(\omega_{j i}\right)^{\epsilon}}{\sum_{l}\left(\omega_{l i}\right)^{\epsilon}} \text {, for all } j \text { and } i
$$

for some trade elasticity $\epsilon>1$; see Arkolakis, Costinot and Rodríguez-Clare (2012a) and Costinot and Rodríguez-Clare (2013) for further discussion. ${ }^{11}$ We now proceed under the assumption that $\chi_{i}$ is known, but dispense with any functional-form restriction.

In what follows we refer to $\chi_{i}$ as the factor demand system in country $i$. The only assumption that we impose on the factor demand system is its invertibility.

A1 [Invertibility]. In any country $i$, for any vector of expenditure shares, $x>0$, and any income level, $y>0$, there exists a unique vector of factor prices (up to a normalization) such that $x \in \chi_{i}(\omega, y)$, which we denote $\chi_{i}^{-1}(x, y)$.

In line with $\mathrm{A} 1$, we restrict ourselves from now on to equilibria such that $x_{i}>0$ for all $i{ }^{12}$ Let $x_{i}^{\prime} \equiv\left\{\left(x_{j i}^{n}\right)^{\prime}\right\}$ and $w^{\prime}$ denote the counterfactual expenditure shares and factor prices in the counterfactual equilibrium with preference parameters and endowments

\footnotetext{
${ }^{11}$ In this case, total income, $y_{i}$, has no effect on factor expenditure shares because of homotheticity.

${ }^{12} \mathrm{By} \boldsymbol{x}_{i}>0$, we formally mean $x_{j i}^{n}>0$ for all $j$ and $n$. Zero expenditure shares create two issues. First, factor prices can no longer be inferred from expenditure shares. Typically, they can only be bounded from below. Second, proportional changes between the initial and counterfactual equilibrium, on which our analysis focuses, are no longer well-defined. Empirically, zeros are irrelevant for the sample of countries
} 
given by $\left(\tau^{\prime}, v^{\prime}\right)$. The basic idea behind the exact hat algebra of Dekle, Eaton and Kortum (2008) is twofold: $(i)$ focus on the proportional changes in expenditure shares and factor prices, $\hat{\boldsymbol{x}}_{i} \equiv\left\{\left(x_{j i}^{n}\right)^{\prime} / x_{j i}^{n}\right\}$ and $\hat{\boldsymbol{w}} \equiv\left\{\left(w_{j}^{n}\right)^{\prime} / w_{j}^{n}\right\}$, caused by proportional changes in preferences and endowments, $\hat{\boldsymbol{\tau}} \equiv\left\{\left(\tau_{i j}^{n}\right)^{\prime} / \tau_{i j}^{n}\right\}$ and $\hat{\boldsymbol{v}} \equiv\left\{\left(v_{i}^{n}\right)^{\prime} / v_{i}^{n}\right\}$; and (ii) use data on expenditure shares, $x_{i j}^{n}$, as well as factor payments, $y_{i}^{n}$, in the initial equilibrium to extract information about the underlying structural parameters of the model. There is nothing in this general strategy that hinges on the demand system being CES. Invertibility of factor demand is the critical assumption.

Let us start by rewriting the equilibrium conditions (12) and (13) at the counterfactual values of the preference and endowment parameters, $\left(\tau^{\prime}, v^{\prime}\right)$ :

$$
\begin{aligned}
x_{i}^{\prime} & \in \chi_{i}\left(\boldsymbol{\omega}_{i}^{\prime}, y_{i}^{\prime}\right) \text { for all } i, \\
\sum_{j}\left(x_{i j}^{n}\right)^{\prime} y_{j}^{\prime} & =\left(y_{i}^{n}\right)^{\prime}, \text { for all } i \text { and } n .
\end{aligned}
$$

These two conditions, in turn, can be expressed in terms of proportional changes,

$$
\begin{aligned}
\left\{\hat{x}_{j i}^{n} x_{j i}^{n}\right\} & \in \chi_{i}\left(\left\{\hat{w}_{j}^{n} \hat{\tau}_{j i}^{n} \omega_{j i}^{n}\right\}, \sum_{n} \hat{w}_{i}^{n} \hat{v}_{i}^{n} y_{i}^{n}\right) \text { for all } i, \\
\sum_{j} \hat{x}_{i j}^{n} x_{i j}^{n}\left(\sum_{n} \hat{w}_{j}^{n} \hat{v}_{j}^{n} y_{j}^{n}\right) & =\hat{w}_{i}^{n} \hat{v}_{i}^{n} y_{i}^{n}, \text { for all } i \text { and } n,
\end{aligned}
$$

where we have used the fact that total income in the counterfactual equilibrium is equal to the sum of total factor income, $y_{i}^{\prime}=\sum_{n}\left(y_{i}^{n}\right)^{\prime}$. Finally, using A1, we can eliminate the effective factor prices in country $i, \omega_{j i}^{n}$, from the previous expression using initial expenditure shares, $x_{i}$, and income levels, $y_{i}$. This leads to the following proposition.

Proposition 2. Suppose that A1 holds and the reduced utility function satisfies (11). Then the proportional changes in expenditure shares and factor prices, $\hat{\boldsymbol{x}}_{i} \equiv\left\{\left(x_{i j}^{n}\right)^{\prime} / x_{i j}^{n}\right\}$ and $\hat{\boldsymbol{w}} \equiv$ $\left\{\left(w_{j}^{n}\right)^{\prime} / w_{j}^{n}\right\}$, caused by the proportional changes in preferences and endowments, $\hat{\boldsymbol{\tau}} \equiv\left\{\left(\tau_{i j}^{n}\right)^{\prime} / \tau_{i j}^{n}\right\}$ and $\hat{v} \equiv\left\{\left(v_{i}^{n}\right)^{\prime} / v_{i}^{n}\right\}$, solve

$$
\begin{aligned}
\left\{\hat{x}_{j i}^{n} x_{j i}^{n}\right\} & \in \chi_{i}\left(\left\{\hat{w}_{j}^{n} \hat{\tau}_{j i}^{n}\left(\chi_{j i}^{n}\right)^{-1}\left(x_{i}, y_{i}\right)\right\}, \sum_{n} \hat{w}_{i}^{n} \hat{v}_{i}^{n} y_{i}^{n}\right) \text { for all } i, \\
\sum_{j} \hat{x}_{i j}^{n} x_{i j}^{n}\left(\sum_{n} \hat{w}_{j}^{n} \hat{v}_{j}^{n} y_{j}^{n}\right) & =\hat{w}_{i}^{n} \hat{v}_{i}^{n} y_{i}^{n}, \text { for all } i \text { and } n .
\end{aligned}
$$

Once proportional changes in expenditure shares and factor prices have been solved for, the value of imports of factor $n$ from country $i$ in country $j$ in the counterfactual and the level of aggregation at which we will conduct our estimation and counterfactual simulation. 
equilibrium, $\left(X_{i j}^{n}\right)^{\prime}$, can be simply computed as

$$
\left(X_{i j}^{n}\right)^{\prime}=\hat{x}_{i j}^{n} x_{i j}^{n}\left(\sum_{n} \hat{w}_{j}^{n} \hat{v}_{j}^{n} y_{j}^{n}\right) \text { for all } i, j \text {, and } n
$$

To sum up, if we know the factor demand system in all countries, $\left\{\chi_{i}\right\}$, and have access to data on expenditure shares and factor payments, $\left\{x_{i j}^{n}\right\}$ and $\left\{y_{j}^{n}\right\}$, then one can compute counterfactual changes in factor trade and factor prices. Using standard arguments from consumer theory, we establish next that the knowledge of $\chi_{i}$ is also sufficient for computing welfare changes in country $i$.

\subsubsection{Welfare}

Consider an arbitrary country $i$. We are interested in computing the equivalent variation, $\Delta W_{i}$, associated with a shock from $(\tau, v)$ to $\left(\tau^{\prime}, v^{\prime}\right)$. When expressed as a fraction of country $i$ 's initial income, this is given by

$$
\Delta W_{i}=\left(e_{i}\left(\omega_{i}, U_{i}^{\prime}\right)-y_{i}\right) / y_{i}
$$

where $U_{i}^{\prime}$ denotes the utility level of country $i$ in the counterfactual equilibrium and $e_{i}\left(\cdot, U_{i}^{\prime}\right)$ denotes the expenditure function,

$$
e_{i}\left(\boldsymbol{\omega}_{i}, U_{i}^{\prime}\right) \equiv \min _{\tilde{\boldsymbol{L}}_{i}}\left\{\sum_{n, j} \omega_{j i}^{n} \tilde{L}_{j i}^{n} \mid \bar{U}_{i}\left(\tilde{\boldsymbol{L}}_{i}\right) \geq U_{i}^{\prime}\right\}
$$

By construction, $\Delta W_{i}$ measures the percentage change in income that the representative agent in country $i$ would be indifferent about accepting in lieu of the counterfactual change from $(\tau, v)$ to $\left(\tau^{\prime}, v^{\prime}\right)$. Note that when preference shocks occur in country $i-$ i.e. when there is a change from $\tau_{j i}^{n}$ for some $j$ and $n$ - the expenditure function implicitly measures the amount of income necessary to reach $U_{i}^{\prime}$ given the original preferences, i.e. given utility $\bar{U}_{i}\left(\left\{L_{j i}^{n} / \tau_{j i}^{n}\right\}\right)$, taking into account that after the shock, the consumer maximizes $\bar{U}_{i}\left(\left\{L_{j i}^{n} /\left(\tau_{j i}^{n}\right)^{\prime}\right\}\right)$. Since preference shocks are multiplicative, this is equivalent to a change in effective factor prices from $\omega_{i} \equiv\left\{w_{j}^{n} \tau_{j i}^{n}\right\}$ to $\omega_{i}^{\prime} \equiv\left\{\left(w_{j}^{n}\right)^{\prime}\left(\tau_{j i}^{n}\right)^{\prime}\right\}$.

To compute $\Delta W_{i}$, we can solve a system of Ordinary Differential Equations (ODEs), as in Hausman (1981) and Hausman and Newey (1995). Since the expenditure function $e_{i}\left(\cdot, U_{i}^{\prime}\right)$ is concave in the effective factor prices, it must be differentiable almost everywhere. The Envelope Theorem (e.g. Milgrom and Segal (2002), Theorem 1) therefore 
implies

$$
d e_{i}\left(\boldsymbol{\omega}, U_{i}^{\prime}\right) / d \omega_{j}^{n}=L_{j i}^{n}\left(\boldsymbol{\omega}, e_{i}\left(\boldsymbol{\omega}, U_{i}^{\prime}\right)\right) \text { for all } j \text { and } n \text { and almost all } \boldsymbol{\omega},
$$

with $\left\{L_{j i}^{n}\left(\omega, e_{i}\left(\omega, U_{i}^{\prime}\right)\right)\right\}$ that solves (9) at the effective factor prices, $\omega$. Given our focus on expenditure shares, it is convenient to rearrange the previous expression in logs. For any selection $\left\{x_{j i}^{n}(\omega, y)\right\} \in \chi_{i}(\omega, y)$, we must have

$$
d \ln e_{i}\left(\omega, U_{i}^{\prime}\right) / d \ln \omega_{j}^{n}=x_{j i}^{n}\left(\omega, e_{i}\left(\omega, U_{i}^{\prime}\right)\right) \text { for all } j \text { and } n \text { and almost all } \omega \text {. }
$$

By budget balance in the counterfactual equilibrium, we also know that

$$
e_{i}\left(\omega_{i}^{\prime}, U_{i}^{\prime}\right)=y_{i}^{\prime}
$$

where $\omega_{i}^{\prime}$ is the vector of effective factor prices in the counterfactual equilibrium.

The expenditure function $e_{i}\left(\cdot, U_{i}^{\prime}\right)$ must be equal to the unique solution of (18) satisfying (19). This solution can be computed given knowledge of any selection $\left\{x_{j i}^{n}(\cdot, \cdot)\right\} \in$ $\chi_{i}(\cdot, \cdot)$, country $i^{\prime}$ s income level in the counterfactual equilibrium, $y_{i}^{\prime}=\sum_{n} \hat{w}_{i}^{n} \hat{v}_{i}^{n} y_{i}^{n}$, and the effective factor prices in the counterfactual equilibrium, $\omega_{i}^{\prime}=\left\{\hat{w}_{j}^{n} \hat{\tau}_{j i}^{n}\left(\chi_{j i}^{n}\right)^{-1}\left(\boldsymbol{x}_{i}, y_{i}\right)\right\}$, with $\hat{\boldsymbol{w}}$ given by (15) and (16). Once $e_{i}\left(\cdot, U_{i}^{\prime}\right)$ has been solved for, we can again use the invertibility of demand to substitute for the initial effective factor prices in equation (17). This leads to our next proposition.

Proposition 3. Suppose that A1 holds and the reduced utility function satisfies (11). Then the equivalent variation associated with a change from $(\tau, v)$ to $\left(\boldsymbol{\tau}^{\prime}, \boldsymbol{v}^{\prime}\right)$, expressed as a fraction of country i's initial income, is

$$
\Delta W_{i}=\left(e\left(\left\{\left(\chi_{j i}^{n}\right)^{-1}\left(x_{i}, y_{i}\right)\right\}, U_{i}^{\prime}\right)-y_{i}\right) / y_{i}
$$

where $e\left(\cdot, U_{i}^{\prime}\right)$ is the unique solution of (18) and (19).

\subsection{Application to Neoclassical Trade Models}

Our goal now is to find structural shocks in a neoclassical trade model that are isomorphic to preference and endowment shocks in a reduced exchange model. By Propositions 13 , counterfactual predictions about factor content of trade, factor prices, and welfare in neoclassical model can then be computed using equations (15)-(20). 
Consider a neoclassical trade model in which technology can be expressed as

$$
f_{i j}^{k}\left(l_{i j}^{k}\right) \equiv \bar{f}_{i j}^{k}\left(\left\{l_{i j}^{n k} / \tau_{i j}^{n}\right\}\right), \text { for all } i, j \text {, and } k \text {, }
$$

where $\tau_{i j}^{n}$ denotes factor-augmenting productivity shocks, that are common to all goods for a given exporter-importer pair. Since these productivity shocks are bilateral in nature, we simply refer to them as trade cost shocks from now on. ${ }^{13}$

Given equation (21), the reduced utility function over primary factors of production associated with the present neoclassical trade model can be written as

$$
\begin{aligned}
& U_{i}\left(\boldsymbol{L}_{i}\right) \equiv \max _{\tilde{q}_{i}, \tilde{l}_{i}} u_{i}\left(\tilde{\boldsymbol{q}}_{i}\right) \\
& \tilde{q}_{j i}^{k} \leq \bar{f}_{j i}^{k}\left(\left\{\tilde{l}_{j i}^{n k} / \tau_{j i}^{n}\right\}\right) \text { for all } j \text { and } k, \\
& \sum_{k} \tilde{l}_{j i}^{n k} \leq L_{j i}^{n} \text { for all } j \text { and } n .
\end{aligned}
$$

A simple change of variable then implies

$$
U_{i}\left(\boldsymbol{L}_{i}\right) \equiv \bar{U}_{i}\left(\left\{L_{j i}^{n} / \tau_{j i}^{n}\right\}\right),
$$

with

$$
\begin{array}{r}
\bar{U}_{i}\left(\boldsymbol{L}_{i}\right) \equiv \max _{\tilde{\boldsymbol{q}}_{i} \tilde{l}_{i} u_{i}\left(\tilde{\boldsymbol{q}}_{i}\right)} \\
q_{j i}^{k} \leq \bar{f}_{j i}^{k}\left(\tilde{\boldsymbol{l}}_{j i}^{k}\right) \text { for all } j \text { and } k, \\
\sum_{k} \tilde{l}_{j i}^{n k} \leq L_{j i}^{n} \text { for all } j \text { and } n .
\end{array}
$$

Thus, if technology satisfies (21), $U_{i}(\cdot)$ satisfies (11). Not surprisingly, trade cost shocks in a neoclassical trade model are equivalent to preference shocks in the associated reduced exchange model. Since endowment shocks are identical in neoclassical trade models and reduced exchange models, we arrive at the following corollary of Propositions 1-3.

Corollary 1. Suppose that A1 holds and that technology satisfies (21). Then the proportional

\footnotetext{
${ }^{13}$ Formally, a change in iceberg trade costs between countries $i$ and $j$ corresponds to the special case in which productivity shocks are Hicks-neutral for a given exporter-importer pair, i.e., $\tau_{i j}^{n}=\tau_{i j}$. Note that while the productivity shocks considered in equation (21) may not vary across goods, equation (21) does allow for a very rich set of heterogeneous trading frictions in the initial equilibrium: $\bar{f}_{i j}^{k}$ may vary with both $i$ and $j$ for all $k$. Thus, some goods may be more costly to trade than others. Similarly, goods that are exported may have different factor intensity than goods that are sold domestically, as in Matsuyama (2007). Note also that the productivity shocks considered in equation (21) may vary across factors $n$. Hence, our model can accommodate economies in which only a subset of individuals get access to foreign markets.
} 
changes in the factor content of trade, factor prices, and welfare caused by trade cost shocks and endowment shocks in a neoclassical trade models, $\hat{\boldsymbol{\tau}} \equiv\left\{\left(\tau_{i j}^{n}\right)^{\prime} / \tau_{i j}^{n}\right\}$ and $\hat{\boldsymbol{v}} \equiv\left\{\left(v_{i}^{n}\right)^{\prime} / v_{i}^{n}\right\}$, are given by (15)-(20).

To sum up, equations (15)-(20) provide a system of equations that can be used for counterfactual and welfare analysis. It generalizes the exact hat algebra of Dekle, Eaton and Kortum (2008) developed in the case of Constant Elasticity of Substitution (CES) factor demands to any invertible factor demand system. Namely, given data on expenditure shares and factor payments, $\left\{x_{j i}^{n}\right\}$ and $\left\{y_{i}^{n}\right\}$, if one knows the factor demand system, $\chi_{i}$, then one can compute counterfactual changes in factor prices, aggregate trade flows, and welfare. ${ }^{14}$ Sections 5 and 6 discuss identification and estimation, respectively, of the factor demand system, $\chi_{i}$. Before doing so, we briefly discuss some extensions of the previous results.

\subsection{Extensions}

\subsubsection{Sector-specific trade cost shocks}

Our approach emphasizes that in any neoclassical trade model, it is as if countries were directly trading factor services. As we have shown in the previous subsection, this approach is well-suited to study factor-augmenting productivity shocks, in general, and uniform changes in iceberg trade costs, in particular. While such shocks are of independent interest, they are restrictive. For instance, one may want to study trade cost shocks that only affect a subset of sectors in the economy. Here, we demonstrate how our analysis can be extended to cover such cases.

Consider the same neoclassical economy as in Section 4.2 with technology satisfying (21). For expositional purposes, consider a counterfactual shock that only affects productivity, $\tau_{i j}^{n k}$, of one factor, $n$, for one country pair, $i$ and $j$, in a single sector, $k$. To study such a counterfactual scenario, we only need to add one factor and one non-arbitrage condition to our previous analysis. Namely, instead of only having "factor $n$ in country $i$," we can define "factor $n$ from country $i$ that is used to produce good $k$ for country $j$ " and "factor $n$ from country $i$ that is not." The price of both factors in a competitive equilibrium, of course, should be the same. Given this new set of factors, all shocks remain uniform across goods. Thus, the results of Section 4.2 still apply.

\footnotetext{
${ }^{14}$ Like Proposition 1, the above corollary holds whether or not a competitive equilibrium is unique. If there are multiple equilibria, then there is a set of proportional changes in the factor content of trade, factor prices, and welfare caused by $\hat{\boldsymbol{\tau}}$ and $\hat{\boldsymbol{v}}$, but this set remains characterized by (15)-(20).
} 
Of course, as trade cost shocks become more and more heterogeneous across sectors, our emphasis on the factor content of trade becomes less and less useful. In the extreme case where all goods are subject to a different shock, it is no simpler to study a reduced exchange model with $K \times N$ factors in each country than the complete neoclassical trade model with $K$ goods and $N$ factors. The flip-side of this observation is that, away from this extreme case, our approach is always useful in the sense that it reduces the dimensionality of what needs to be estimated, i.e., the factor demand system.

\subsubsection{Tariffs}

Historically, an important application of CGE models has been the analysis of regional trade agreements, such as NAFTA and the European Union, in which the counterfactual shocks of interest were not productivity shocks but rather changes in trade policy; see e.g. Baldwin and Venables (1995) for a survey. We now discuss how our analysis can be extended to analyze the effects of changes in ad-valorem trade taxes. For pedagogical purposes, it is useful to start from a reduced exchange model, as in Section 4.1, but one in which a factor $n$ being traded between country $i$ and country $j$ is subject to an ad-valorem import tax or subsidy, $t_{i j}^{n}$. Once this case has been dealt with, the empirically relevant case in which tariffs vary across sectors, not factors, can be dealt with by redefining factors appropriately, as in Section 4.3.1.15

The key difference between the reduced equilibrium with and without trade taxes is that taxes raise revenue. This needs to be added to factor income in equations (15) and (16) when computing changes in factor prices and the factor content of trade. Formally, consider a change in trade taxes from $\boldsymbol{t} \equiv\left\{t_{i j}^{n}\right\}$ to $\boldsymbol{t}^{\prime} \equiv\left\{\left(t_{i j}^{n}\right)^{\prime}\right\}$. The counterparts of equations (15) and (16) in this situation become

$$
\begin{aligned}
\left\{\hat{x}_{j i}^{n} x_{j i}^{n}\right\} & \in \chi_{i}\left(\left\{\hat{w}_{j}^{n}\left(1 \hat{+} t_{j i}^{n}\right)\left(\chi_{j i}^{n}\right)^{-1}\left(x_{i}, y_{i}\right)\right\}, \hat{y}_{i} y_{i}\right) \text { for all } i, \\
\sum_{j} \hat{x}_{i j}^{n} x_{i j}^{n} \hat{y}_{j} y_{j} & =\hat{w}_{i}^{n} \hat{v}_{i}^{n} w_{i}^{n} v_{i}^{n}, \text { for all } i \text { and } n,
\end{aligned}
$$

with total income, inclusive of tax revenues, such that

$$
\begin{aligned}
y_{i} & =\sum_{n} y_{i}^{n} /\left(1-\sum_{j} \sum_{n} t_{j i}^{n} x_{j i}^{n} /\left(1+t_{j i}^{n}\right)\right) \text { for all } i, \\
\hat{y}_{i} y_{i} & =\sum_{n} \hat{w}_{i}^{n} \hat{v}_{i}^{n} y_{i}^{n} /\left(1-\sum_{j} \sum_{n}\left(t_{j i}^{n}\right)^{\prime} \hat{x}_{j i}^{n} x_{j i}^{n} /\left(1+t_{j i}^{n}\right)^{\prime}\right) \text { for all } i .
\end{aligned}
$$

\footnotetext{
${ }^{15}$ Wilson (1980) discusses this issue in the context of the Ricardian model.
} 
Equations (18)-(20) are unchanged. So, given information on tariffs, $\boldsymbol{t}$ and $\boldsymbol{t}^{\prime}$, changes in the factor content of trade, factor prices, and welfare can still be computed using only: (i) data on initial expenditure shares and factor payments, $\left\{x_{i j}^{n}\right\}$ and $\left\{y_{j}^{n}\right\}$, and (ii) an estimate of the factor demand system, $\chi_{i}$, in each country.

\subsubsection{Intermediate Goods}

The neoclassical trade model of Section 3 rules out intermediate goods. We conclude by discussing how our theoretical analysis can be extended to environments with inputoutput linkages. Consider an economy in which gross output of good $k$ produced in country $i$ that is available in country $j$ - either as a final good for consumers or an intermediate good for firms-is given by

$$
q_{i j}^{k}=f_{i j}^{k}\left(l_{i j}^{k}, m_{i j}^{k}\right),
$$

where $\boldsymbol{l}_{i j}^{k} \equiv\left\{l_{i j}^{n k}\right\}$ still denotes the vector of factor demands and $\boldsymbol{m}_{i j}^{k} \equiv\left\{m_{o i j}^{g k}\right\}$ is the vector of input demands, with $m_{o i j}^{g k}$ being the amount of good $g$ from the origin country $o$ that is used as an intermediate good in country $i$ to produce good $k$ and deliver it to country $j$. In a competitive equilibrium, gross output must then be equal to the total demand by consumers and firms,

$$
c_{i j}^{k}+\sum_{l, d} m_{i j d}^{k l}=q_{i j}^{k} \text { for all } i, j, \text { and } k,
$$

where $c_{i} \equiv\left\{c_{j i}^{k}\right\}$ denotes the vector of final demand in country $i$. All other assumptions are the same as in Section 3.1.

In this more general environment, we can still define a reduced utility function over primary factors of production,

$$
\begin{aligned}
& U_{i}\left(\boldsymbol{L}_{i}\right) \equiv \max _{\tilde{\tilde{q}}, \tilde{m}, \tilde{c}, \tilde{l}} \tilde{l}_{i}\left(\tilde{\boldsymbol{c}}_{i}\right) \\
& \left.\tilde{q}_{j d}^{k} \leq f_{j d}^{k} \tilde{\boldsymbol{l}}_{j d}^{k}, \tilde{\boldsymbol{m}}_{j d}^{k}\right) \text { for all } d, j, \text { and } k, \\
& \sum_{d, k} \tilde{l}_{j d}^{n k} \leq L_{j i}^{n} \text { for all } j \text { and } n, \\
& \tilde{c}_{j d}^{k}+\sum_{g, r} \tilde{m}_{j d r}^{k g} \leq \tilde{q}_{j d}^{k} \text { for all } d, j, \text { and } k,
\end{aligned}
$$

with $\tilde{\boldsymbol{q}} \equiv\left\{\tilde{q}_{j d}^{k}\right\}, \tilde{\boldsymbol{m}} \equiv\left\{\tilde{m}_{j d r}^{k g}\right\}, \tilde{\boldsymbol{c}} \equiv\left\{\tilde{c}_{j d}^{k}\right\}$, and $\tilde{\boldsymbol{l}} \equiv\left\{\tilde{l}_{j d}^{n k}\right\}$. Compared to the definition of Section 3.2, the control variables now include gross output, intermediate goods, final demands, and primary factors for all destination countries, $d$, not just country $i$. This 
reflects the potential existence of global supply chains in which factors from country $j$ may be used to produce intermediate goods for country $d$, which are then used to produce final goods for country $i .^{16}$

One can show that Proposition 1 still holds in this economy, with the factor content of trade being computed as in Johnson and Noguera (2012). The only technicality is that the proof now requires the Nonsubstitution Theorem to construct good prices in a competitive equilibrium from factor prices in a reduced equilibrium. Conditional on the new definition of the reduced utility function, Propositions 2 and 3 are unchanged. They can be applied directly to study endowment shocks in a neoclassical model. When intermediate goods are not traded or traded but their factor content is not re-exported, as in Grossman and Rossi-Hansberg (2008), Propositions 2 and 3 can also be applied directly to the analysis of changes in trade costs. When the factor content of intermediate goods is re-exported, as in Yi (2003), Propositions 2 and 3 can still be used, but they require the space of factors to be augmented, as in Section 4.3.1. Specifically, one needs to treat factors that are imported directly and indirectly differently since they are subject to different (vectors of) iceberg trade costs.

\section{Identification}

\subsection{Assumptions}

In order to go from the economic model of Section 3.1 to an econometric model that can be estimated, we need to make additional assumptions on which variables are unobservable and which ones are not as well as the origins of the exogenous shocks generating the observable variables.

Exogenous shocks. Consider a dataset generated by the model of Section 3.1 at different dates indexed by $t$. At each point in time, we assume that preferences and technology in the original neoclassical trade model satisfy

$$
\begin{aligned}
u_{i}\left(\boldsymbol{q}_{i, t}\right) & =\bar{u}\left(\left\{q_{j i, t}^{k} / \theta_{j i}\right\}\right), \text { for all } i, \\
f_{i j, t}^{k}\left(\boldsymbol{l}_{i j, t}^{k}\right) & =\bar{f}_{i}^{k}\left(\left\{l_{i j, t}^{n k} / \tau_{i j, t}^{n}\right\}\right), \text { for all } i, j, \text { and } k .
\end{aligned}
$$

Factor endowments, $\left\{v_{i, t}^{n}\right\}$, and trade costs, $\left\{\tau_{i j, t}^{n}\right\}$, are allowed to vary over time, but utility and production functions, $\left\{u_{i}\right\}$ and $\left\{\bar{f}_{i}^{k}\right\}$, are assumed to be fixed. Differences

\footnotetext{
${ }^{16}$ Obviously, a solution to the previous maximization problem must always feature $c_{j d}^{k}=0$ for all $d \neq i$ since country $i$ cannot benefit from final consumption in other countries.
} 
in preferences across countries take the form of exporter-importer taste shifters, $\left\{\theta_{j i}\right\}$, that are common across all goods. ${ }^{17}$ In line with the analysis of Section 4 , equations (22) and (23) lead to the following restriction on the heterogeneity in factor demands across countries.

A2. [Price heterogeneity] In any country $i$ and at any date $t$, there exists a vector of effective factor prices, $\boldsymbol{\omega}_{i, t} \equiv\left\{w_{j, t}^{n} \theta_{j i} \tau_{j i, t}^{n}\right\}$, such that factor demand can be expressed as $\bar{\chi}\left(\boldsymbol{\omega}_{i, t}, y_{i, t}\right)$.

Under A2, reduced utility functions over primary factors of production in the reduced exchange model are allowed to vary across countries and over time-either because of primitive differences in preferences or technology—but this heterogeneity can be reduced to differences in effective factor prices, i.e., factor prices adjusted by the relevant preference and trade cost shocks. This implies that in order to identify the shape of factor demand around the world, we only need to identify the shape of $\bar{x}$.

An obvious benefit of A2 is that it reduces the dimensionality of the demand system that we want to estimate by a factor $I$, equal to the number of countries in the world economy. A more subtle, but crucial benefit of A2 is that the global factor demand, $\bar{\chi}$, can be estimated using both time series and cross-sectional variation. This will allow us to control for variations in endogenous factor prices, $w_{j, t}^{n}$, by including exporter-factor-year dummies when estimating $\bar{x}$. Finally, note that A2 holds trivially in a gravity model, as can be seen directly from (14).

Observables and unobservables. For any country $i$ and for any date $t$, we assume that effective factor prices, $\omega_{i, t} \equiv\left\{\omega_{j i, t}^{n}\right\}$, are unobservable and normalized so that:

$$
\begin{aligned}
\ln \omega_{1 i, t}^{1} & =0, \text { for all } i \text { and } t, \\
E\left[\ln \omega_{j i, t}^{n}\right] & =0, \text { for all } j \text { and } n .
\end{aligned}
$$

The first normalization amounts to expressing effective factor prices relative to factor 1 from country 1 in all markets $(i, t)$. The second normalization is necessary to identify separately effective factor prices from factor-specific taste shifters. ${ }^{18}$ The only observables

\footnotetext{
${ }^{17}$ For expositional purposes, we ignore time-varying preference shocks, $\theta_{j i, t}$. They could be dealt with in the exact same way as we dealt with preference shocks in the reduced exchange model of Section 4.1. Note also that the absence of sector-specific productivity shocks is sufficient, but not necessary. What is crucial for the analysis below is that sector-specific productivity shocks do not affect the shape of factor demand. For example, if all goods enter symmetrically in the utility function, then a weaker sufficient condition is that the distribution of productivity across sectors is stable over time, though productivity in particular sectors may go up or down at particular points in time. Hanson, Lind and Muendler (2014) offer empirical evidence consistent with that weaker condition.

${ }^{18}$ One can always start from $\bar{\chi}\left(\boldsymbol{\omega}_{i, t}, y_{i, t}\right)$ and define $\tilde{\chi}\left(\tilde{\boldsymbol{\omega}}_{i, t}, y_{i, t}\right) \equiv \bar{\chi}\left(\left\{\tilde{\omega}_{j i, t}^{n} / \alpha_{j}^{n}\right\}, y_{i, t}\right)$ with $\tilde{\omega}_{j i, t}^{n}=\alpha_{j}^{n} \omega_{j i, t}^{n}$ for some $\alpha_{j}^{n}>0$. By construction, $\bar{\chi}$ and $\tilde{\chi}$ must generate the exact same observables. However, $\omega_{i, t}$ and
} 
are: (i) factor expenditure shares, $x_{i, t} \equiv\left\{x_{j i, t}^{n}\right\} ;$ (ii) factor payments, $\boldsymbol{y}_{i, t} \equiv\left\{y_{i, t}^{n}\right\}$; and (iii) trade cost shifters, $z_{i, t} \equiv\left\{z_{j i, t}^{n}\right\} .{ }^{19}$ We assume that trade cost shocks in the model, $\tau_{j i, t}^{n}$ are related to trade cost shifters in the data through

$$
\ln \tau_{j i, t}^{n}=\ln z_{j i, t}^{n}+\tilde{\varphi}_{j i}^{n}+\tilde{\xi}_{j, t}^{n}+\varepsilon_{j i, t}^{n}
$$

where $\tilde{\varphi}_{j i}^{n}$ and $\tilde{\xi}_{j, t}^{n}$ are exporter-importer-factor and exporter-factor-year fixed-effects, respectively, and $\varepsilon_{i, t} \equiv\left\{\varepsilon_{j i, t}^{n}\right\}$ are idiosyncratic shocks. In Section 6, we will use data on bilateral freight costs as trade cost shifters for (all) factors from a given destination. Combining the previous equation with the definition of effective factor prices, $\omega_{j i, t}^{n} \equiv w_{j, t}^{n} \theta_{j i} \tau_{j i, t}^{n}$ we then obtain

$$
\ln \omega_{j i, t}^{n}=\ln z_{j i, t}^{n}+\varphi_{j i}^{n}+\xi_{j, t}^{n}+\varepsilon_{j i, t}^{n} \text { for all } i, j, n, \text { and } t,
$$

with $\varphi_{j i}^{n} \equiv \tilde{\varphi}_{j i}^{n}+\ln \theta_{j i}$ and $\tilde{\xi}_{j, t}^{n} \equiv \tilde{\xi}_{j, t}^{n}+\ln w_{j, t}^{n}$. The first set of fixed-effects, $\left\{\varphi_{j i}^{n}\right\}$, capturesamong other things-any source of trading frictions between country $i$ and $j$ that is stable over time. This includes common proxies for trade costs like bilateral distance, whether $i$ and $j$ share a common language, or whether they have colonial ties; see e.g. Anderson and Van Wincoop (2003). Crucially, the second set of fixed effects, $\left\{\xi_{j, t}^{n}\right\}$, captures the variations in factor prices, $\left\{w_{j, t}^{n}\right\}$, which are the key endogenous variables in our model.

Throughout our analysis, we impose the following exogeneity restriction on the vector of idiosyncratic shocks.

A3. [Exogeneity] $E\left[\boldsymbol{\varepsilon}_{i, t} \mid \ln \boldsymbol{z}_{i, t}, \boldsymbol{d}_{i, t}\right]=0$, where $\boldsymbol{d}_{i, t}$ is a full vector of importer-exporter-factor and exporter-factor-year dummies, with $i$ as the importer and $t$ as the year for all dummies.

Because of equation (26), A3 is stronger than assuming that trade cost shifters, $z_{i, t}$, can be used as instruments for effective factor prices, $\omega_{i, t}$, after controlling for all factors that are either exporter-importer-factor or exporter-factor-year specific. If we think of equation (26) as a first-stage, it implies that reduced-form and IV estimates should coincide. Hence, we can infer the impact on factor demand of effective factor prices, which are not observable, by tracing out the impact of trade cost shifters, which are observable. This

$\tilde{\boldsymbol{\omega}}_{i, t}$ cannot both satisfy (25).

${ }^{19}$ In principle, data on factor expenditure shares, $x_{i, t} \equiv\left\{x_{j i, t}^{n}\right\}$, and factor payments, $y_{i, t} \equiv\left\{y_{i, t}^{n}\right\}$, can be obtained from sources such as the World Input-Output Database. As already discussed in the Introduction, a practical limitation of such datasets is that they implicitly assume that factor intensity is constant across destinations within the same industry. For the empirical application of Section 6, such considerations will be irrelevant since we will assume the existence of a composite factor in each country. Note also that for the purposes of identifying the shape of factor demand, we will only need information on total income, $y_{i, t}=\sum_{n} y_{i, t}^{n}$, in each country. Data on factor payments, $y_{i, t} \equiv\left\{y_{i, t}^{n}\right\}$, are only necessary for counterfactual analysis, as shown in Section 4. 
is the same strategy used for the estimation of (constant) trade elasticities in the gravity literature; see Head and Mayer (2013). ${ }^{20}$

Following Newey and Powell (2003), we conclude by imposing the following completeness condition.

A4. [Completeness] For any $g\left(\boldsymbol{x}_{i, t}, \boldsymbol{d}_{i, t}, y_{i, t}\right)$ with finite expectation, $E\left[g\left(\boldsymbol{x}_{i, t}, \boldsymbol{d}_{i, t}, y_{i, t}\right) \mid \ln \boldsymbol{z}_{i, t}, \boldsymbol{d}_{i, t}\right]=$ 0 implies $g\left(\boldsymbol{x}_{i, t}, \boldsymbol{d}_{i, t}, y_{i, t}\right)=0$.

A4 is the equivalent of a rank condition in the estimation of parametric models. ${ }^{21}$

\subsection{Identifying Factor Prices and Factor Demand}

We are now ready to establish that factor prices and factor demand are identified. The argument follows the same steps as in Berry and Haile (2014). Because our demand system is invertible, we can express each effective factor price as a function of the vector market share plus some error term. Once the estimating equations have been transformed in this way, the completeness condition of Newey and Powell (2003) provides non-parametric identification.

By A1, we can invert our factor demand system to express effective factor prices, $\omega_{i, t}$ faced by country $i$ at date $t$ as a function of expenditure shares, $x_{i, t}$, and total income, $y_{i, t}$,

$$
\omega_{j i, t}^{n}=\left(\chi_{j i}^{n}\right)^{-1}\left(x_{i, t}, y_{i, t}\right) \text {, }
$$

with the level of effective factor prices in country $i$ and year $t$ pinned down by (24). Taking logs and using equation (26), we then have

$$
\varepsilon_{j i, t}^{n}=\ln \left(\chi_{j i}^{n}\right)^{-1}\left(x_{i, t}, y_{i, t}\right)-\ln z_{j i, t}^{n}-\varphi_{j i}^{n}-\xi_{j, t}^{n} .
$$

\footnotetext{
${ }^{20} \mathrm{~A}$ common finding in the international macro literature is that exporters' costs shocks tend to be incompletely passed through into consumer prices; see e.g. Burstein and Gopinath (2013). This observation does not by itself invalidate the previous strategy. Within the context of a neoclassical model, such findings can be rationalized by assuming that foreign goods need to be distributed, which requires local factors of production, as in Burstein, Neves and Rebelo (2003). In such a model, there is incomplete pass-through into consumer prices, as observed in the data, yet complete pass-through into effective factor prices, as assumed in equation (26).

${ }^{21}$ Going from a finite to an infinite dimensional space of parameters leads to non-trivial issues. Newey (2013) notes that "In fully nonparametric models (that are infinite dimensional), completeness is not testable, as pointed out by Canay, Santos and Shaikh (2013). In these models the reduced form is like an infinite dimensional matrix with eigenvalues that have a limit point at zero. Nonidentification occurs when at least one of the eigenvalues equals zero. The problem with testing this hypothesis is that one cannot distinguish empirically a model with a zero eigenvalue from one where the eigenvalues have a limit point of zero. However, completeness is generic, in the sense that it holds for "most" if it holds for one [...]. This is like the discrete, finite support case where most matrices have full column rank if the order condition is satisfied." We have little to add to this discussion.
} 
By A2, the inverse demand is the same for all importer $i$ and period $t$,

$$
\varepsilon_{j i, t}^{n}=\ln \left(\bar{\chi}_{j}^{n}\right)^{-1}\left(x_{i, t}, y_{i, t}\right)-\ln z_{j i, t}^{n}-\varphi_{j i}^{n}-\xi_{j, t}^{n}
$$

where $\left(\bar{\chi}_{j}^{n}\right)^{-1}(\cdot)$ is the inverse demand for factor $n$ from country $j$. Combining this expression with $\mathrm{A} 3$, we obtain the following moment condition

$$
E\left[\ln \left(\bar{\chi}_{j}^{n}\right)^{-1}\left(x_{i, t}, y_{i, t}\right)-\varphi_{j i}^{n}-\xi_{j t}^{n} \mid \ln z_{i, t}, d_{i, t}\right]=\ln z_{j i, t}^{n} .
$$

By A4, there is at most one function $g_{j}^{n}$ that satisfies $E\left[g_{j}^{n}\left(\boldsymbol{x}_{i, t}, y_{i, t}, \boldsymbol{d}_{i, t}\right) \mid \ln z_{i, t}, \boldsymbol{d}_{i, t}\right]=\ln z_{j i, t}^{n}{ }^{22}$ Thus if two inverse demand functions, $\left(\bar{\chi}_{j}^{n}\right)^{-1}$ and $\left(\tilde{\chi}_{j}^{n}\right)^{-1}$, satisfy (28) for some $\left(\varphi_{j i}^{n}, \xi_{j t}^{n}\right)$ and $\left(\tilde{\varphi}_{j i}^{n}, \tilde{\zeta}_{j t}^{n}\right)$, then we must have

$$
\begin{aligned}
& \ln \left(\bar{\chi}_{j}^{n}\right)^{-1}\left(\boldsymbol{x}_{i, t}, y_{i, t}\right)=g_{j}^{n}\left(\boldsymbol{x}_{i, t}, y_{i, t}, \boldsymbol{d}_{i, t}\right)+\varphi_{j i}^{n}+\tilde{\xi}_{j t}^{n}, \\
& \ln \left(\tilde{\chi}_{j}^{n}\right)^{-1}\left(\boldsymbol{x}_{i, t}, y_{i, t}\right)=g_{j}^{n}\left(\boldsymbol{x}_{i, t}, y_{i, t}, \boldsymbol{d}_{i, t}\right)+\tilde{\varphi}_{j i}^{n}+\tilde{\xi}_{j t}^{n} .
\end{aligned}
$$

Taking the difference between these two equations, we obtain

$$
\ln \left(\bar{\chi}_{j}^{n}\right)^{-1}\left(x_{i, t}, y_{i, t}\right)-\ln \left(\tilde{\chi}_{j}^{n}\right)^{-1}\left(x_{i, t}, y_{i, t}\right)=\varphi_{j i}^{n}+\xi_{j t}^{n}-\tilde{\varphi}_{j i}^{n}-\tilde{\xi}_{j t}^{n} .
$$

Holding $x_{i, t}$ and $y_{i, t}$ fixed, the left-hand side does not vary with $i$ or $t$. So, $\varphi_{j i}^{n}+\xi_{j t}^{n}-\tilde{\varphi}_{j i}^{n}-$ $\tilde{\xi}_{j t}^{n}$ cannot vary with $i$ or $t$ either. This establishes that $\ln \left(\bar{\chi}_{j}^{n}\right)^{-1}$ is identified up to some constant, which equation (25) and (27) pin down for all $j$ and $n$. Finally, note that once the inverse factor demand is known, then both factor demand and effective factor prices are known as well, with prices being uniquely pinned down by equation (27).

We summarize the previous discussion in the next proposition.

Proposition 4. Suppose that A1-A4 hold. Then effective factor prices and factor demand are identified, up to the two normalizations (24) and (25).

\subsection{Ricardian Example}

The invertibility of demand plays a key role throughout our analysis. We use it to conduct counterfactual and welfare analysis in Section 4 and we use it again to establish Proposition 4. We now provide sufficient conditions on the primitives of a neoclassical trade model such that A1 holds. We also show that under the same conditions, a competitive

\footnotetext{
${ }^{22}$ To see this, suppose that $g_{j}^{n}\left(\boldsymbol{x}_{i, t}, y_{i, t}, \boldsymbol{d}_{i, t}\right)$ and $\tilde{g}_{j}^{n}\left(\boldsymbol{x}_{i, t}, y_{i, t}, \boldsymbol{d}_{i, t}\right)$ satisfy equation (28). Then they must also satisfy $E\left[g_{j}^{n}\left(\boldsymbol{x}_{i, t}, y_{i, t}, \boldsymbol{d}_{i, t}\right)-\tilde{g}_{j}^{n}\left(\boldsymbol{x}_{i, t}, y_{i, t}, \boldsymbol{d}_{i, t}\right) \mid \ln \boldsymbol{z}_{i, t}, \boldsymbol{d}_{i, t}\right]=0$, which requires $g_{j}^{n}=\tilde{g}_{j}^{n}$ by A4.
} 
equilibrium is unique. Hence, counterfactual changes in factor prices and welfare are also nonparametrically identified in this environment. We will come back to the same environment for our empirical application in Sections 6 and 7.

Consider an economy in which utility and productions functions satisfy

$$
\begin{aligned}
& u_{i}\left(\boldsymbol{q}_{i}\right)=\bar{u}\left(\left\{\sum_{j} q_{j i}^{k}\right\}\right), \text { for all } i, \\
& f_{i j}^{k}\left(\boldsymbol{l}_{i j}^{k}\right)=\alpha_{i}^{k} \bar{f}_{i}\left(\boldsymbol{l}_{i j}^{k}\right) / \tau_{i j}, \text { for all } i, j, \text { and } k,
\end{aligned}
$$

where $\bar{u}$ is a homothetic utility function that satisfies standard Inada conditions; $\alpha_{i j}^{k}$ is total factor productivity in country $i$ and sector $k$ when selling to country $j ; \bar{f}_{i}$ is a production function, common to all sectors and destinations; and $\tau_{i j}$ is a bilateral iceberg trade cost. Given equation (29), the Inada conditions are imposed to rule out zero expenditure shares on all goods. ${ }^{23}$ The crucial restriction is imposed in equation (30). It states that all goods from country $i$ use factors with the same intensity. Hence, everything is as if there was only one factor per country with price $c_{i} \equiv \min _{\tilde{l}}\left\{\sum w_{i}^{n} \tilde{l}_{i}^{n} \mid \bar{f}_{i}(\tilde{\boldsymbol{l}})=1\right\}$ and endowment $\bar{f}_{i}\left(\boldsymbol{v}_{i}\right)$.

In light of the previous discussion, we refer to an economy that satisfies (29) and (30) as a Ricardian economy. In such an environment, homotheticity and no differences in factor intensity imply that we can write the demand for factors in country $i$ as $\bar{\chi}\left(\boldsymbol{\omega}_{i}\right)$, with $\omega_{i} \equiv\left\{\tau_{j i} c_{j}\right\}$ the vector of effective prices for the composite factors.

As discussed in Berry, Gandhi and Haile (2013), a sufficient condition for a demand function to be invertible over its support is that it satisfies the connected substitute property. ${ }^{24}$ This property has a long tradition in general equilibrium theory where it is used to establish the uniqueness of competitive equilibrium prices, through the injectivity of the excess demand function; see Arrow and Hahn (1971), p. 227. For the purposes of this paper, we need a slightly more general version of this property that applies to demand

\footnotetext{
${ }^{23}$ By itself, the assumption that goods from different exporting countries are perfect substitutes, as described in equation (29), is without loss of generality. To see this, note that by assuming that each good $k$ can only be produced in one country, the present model still nests the Armington model. We only impose equation (29) to weaken the Inada conditions. Namely, we require all countries to consume all goods, not all goods from all origins.

${ }^{24}$ If we were able to observe the quantities of factor services demanded by each country directly, rather than factor expenditure shares, invertibility would be a straightforward issue in the context of this paper. From Proposition 1, we know that there must be a representative agent whose factor demand solves (9). Whenever the reduced utility function is differentiable at the optimum, the first-order conditions of the utility maximization problem (9) immediately imply that factor prices are determined (up to a normalization) by the gradient of the reduced utility function, evaluated at the optimal quantities of factor demanded. The case of Cobb-Douglas utility is an extreme example that shows that the previous argument does not carry over to expenditure shares. In that case, there is is uniqueness of prices conditional on quantities demanded, but not conditional on expenditure shares.
} 
correspondences, not just functions. We focus on the following generalization adapted from Howitt (1980).

Definition 3 [Connected Substitutes]. A correspondence $\bar{\chi}: \mathbb{R}_{++}^{m} \rightarrow P\left(\mathbb{R}_{++}^{m}\right)$ satisfies the connected substitute property if for any $\omega$ and $\boldsymbol{\omega}^{\prime} \in \mathbb{R}_{++}^{m}$, any $x \in \bar{\chi}(\boldsymbol{\omega})$, any $x^{\prime} \in \bar{\chi}\left(\boldsymbol{\omega}^{\prime}\right)$, and any non-trivial partition $\left\{M_{1}, M_{2}\right\}$ of $M \equiv\{1, \ldots, m\}, \omega_{j}^{\prime}>\omega_{j}$ for all $j \in M_{1}$ and $\omega_{j}^{\prime}=\omega_{j}$ for all $j \in M_{2}$ imply $\sum_{j \in M_{2}} x_{j}^{\prime}>\sum_{j \in M_{2}} x_{j}$.

Our first lemma provides sufficient conditions under which the factor demand system of a Ricardian economy is invertible over its support.

Lemma 1. Consider a Ricardian economy. If good expenditure shares satisfy the connected substitute property, then for any vector of factor expenditure shares, $x>0$, there is at most one vector (up to a normalization) of effective factor prices, $\omega$, such that $x \in \bar{\chi}(\omega)$.

The formal proof can be found in Appendix A.2. The general strategy is similar to the one used by Scarf and Wilson (2005) to establish the uniqueness of competitive equilibria in a Ricardian model. The key idea is to show that if expenditure shares on goods satisfy the connected property, then the expenditure shares on factors must satisfy the same property. At that point, the invertibility of the factor demand system follows from standard arguments; see e.g. Proposition 17.F.3 in Mas-Colell, Whinston and Green (1995). The only minor technicality is that the demand function may be a correspondence, which Definition 3 is designed to address.

In light of the above discussion, it should not be surprising that the same sufficient conditions lead to the uniqueness of the competitive equilibrium.

Lemma 2. Consider a Ricardian economy. If good expenditure shares satisfy the connected substitute property, then the vector of equilibrium factor prices, $\left(c_{1}, \ldots, c_{I}\right)$, is unique (up to a normalization).

Let us take stock. Proposition 4 and Lemma 1 imply that factor demand is nonparametrically identified in a Ricardian economy if A2-A4 hold and good expenditure shares satisfy the connected substitute property. Since all the assumptions of Section 4 are satisfied, Proposition 2, Proposition 3, and Lemma 2 further imply that proportional changes in factor prices and welfare are uniquely determined given data on initial expenditure shares and factor payments, $\left\{x_{i j}^{n}\right\}$ and $\left\{y_{j}^{n}\right\}$, and an estimate of factor demand, $\bar{\chi}^{25}$ This leads to our final observation.

\footnotetext{
${ }^{25}$ Proportional changes in the factor content of trade are also unique if factor demand, $\bar{\chi}$, is single-valued at the initial and counterfactual equilibria.
} 
Corollary 2. Consider a Ricardian economy. If A2-A4 hold and good expenditure shares satisfy the connected substitute property, then proportional changes in factor prices and welfare caused by trade cost shocks and endowment shocks are nonparametrically identified.

\section{Estimation}

The above results highlight two important features of neoclassical trade models. First, counterfactual changes in trade costs and factor endowments can be studied with only the knowledge of a reduced factor demand system. Second, this reduced demand system can be nonparametrically identified from standard data sources on international trade in goods and standard exclusion restrictions. Armed with these theoretical results we now turn to a strategy for estimating the reduced demand system, in practice.

\subsection{From Asymptopia to Mixed CES}

Nonparametric identification results, like those presented in Section 5, are asymptotic in nature. They answer the question of whether one could point identify each of the potentially infinite-dimensional parameters of a model with a dataset whose sample size tends to infinity-formally, whether there exists a unique mapping from population data to model parameters. As noted by Chiappori and Ekeland (2009), such results are useful because they can help select the most adequate moment conditions; that is, the source of variation in the data directly related to the economic relation of interest.

Of course, datasets in the real world often feature a small number of observations and little exogenous variation. So estimation must inevitably proceed parametrically. Our goal here is to do so in a flexible manner, drawing on recent advances in the area of applied demand estimation; see e.g. Nevo (2011). In the spirit of dimensionality-reduction, we start by making three assumptions. Like in Section 5.3, we assume that: (i) preferences are homothetic, so that we can ignore the effect of income on expenditure shares; (ii) all goods have the same factor intensity in each country, so that we can focus on a single composite factor per country; and (iii) cross-country differences in factor demand can be reduced to differences in effective factor prices, so that we can focus on estimating a unique global factor demand. All three assumptions are restrictive, but standard in the existing gravity literature. ${ }^{26}$

\footnotetext{
${ }^{26}$ Fajgelbaum and Khandelwal (2014) is a recent exception that introduces non-homothetic preferences to study how gains from trade vary across income groups. As discussed below, our dataset only includes two importing countries: the United States and Australia. So, there is very little variation that we can use to estimate non-homotheticies. Similarly, introducing differences in factor intensity across sectors would
} 
Since there is one composite factor in each country, we drop superscripts $n$ from now on. Hence, $\omega_{j i, t}$ stands for the effective price of the composite factor from country $j$ in country $i$ in year $t$, with $\omega_{i, t} \equiv\left\{\omega_{j i, t}\right\}$ being the associated vector of effective prices. Taking inspiration from Berry (1994) and Berry, Levinsohn and Pakes (1995), we posit that the expenditure share that country $i$ devotes to the factor from country $j$ in year $t$ can be expressed as

$$
\bar{\chi}_{j}\left(\boldsymbol{\omega}_{i, t}\right)=\int \frac{\left(\kappa_{j}\right)^{\sigma_{\alpha} \alpha}\left(\omega_{j i, t}\right)^{-\left(\bar{\epsilon} \cdot \epsilon^{\sigma_{\epsilon}}\right)}}{\sum_{l=1}^{N}\left(\kappa_{l}\right)^{\sigma_{\alpha} \alpha}\left(\omega_{l i, t}\right)^{-\left(\bar{\epsilon} \cdot \epsilon^{\sigma_{\epsilon}}\right)}} d F(\alpha, \epsilon)
$$

where $\kappa \equiv\left\{\kappa_{j}\right\}$ is a vector of observable country characteristics and $\left\{\bar{\epsilon}, \sigma_{\alpha}, \sigma_{\epsilon}\right\}$ are structural parameters. The random draws $(\alpha, \epsilon)$ can be interpreted as unobserved heterogeneity across goods in the elasticities with respect to effective factor prices, $\omega_{j i, t}$, and exporter characteristic, $\kappa_{j}$. We come back to this point below when discussing the relationship between mixed and nested CES.

In our baseline analysis, we assume that $\kappa_{j}$ is the per-capita GDP of country $j$ relative to the per-capita GDP of the United States $(j=1)$ in the pre-sample period. ${ }^{27}$ We also assume that the joint distribution $F(\alpha, \epsilon)$ is such that $\alpha$ and $\ln \epsilon$ have a joint standard normal distribution with an identity covariance matrix. ${ }^{28}$ As a function of effective factor prices, the demand system is completely characterized by three structural parameters: $\bar{\epsilon}$, $\sigma_{\alpha}$ and $\sigma_{\epsilon}$.

This particular functional form is attractive for two reasons. First, it nests the case of CES demand. That is, in the special case of $\sigma_{\alpha}=\sigma_{\epsilon}=0$, we recover a standard gravity model with trade elasticity $\bar{\epsilon}$, as in Eaton and Kortum (2002) or Anderson and Van Wincoop (2003). When $\sigma_{\alpha} \neq 0$ or $\sigma_{\epsilon} \neq 0$, the demand system in equation (31) becomes a random coefficients version of CES demand, in the same way that the mixed logit demand system in Berry, Levinsohn and Pakes (1995) is a random coefficients version of logit demand. For this reason, we refer to our demand system as "mixed CES."

Second, the demand system in equation (31) captures flexibly and parsimoniously a

then require estimates of the extent to which multiple factors are substitutable for one another within each country. While in principle this can be achieved with supply-side shifters of relative factor prices, finding such shifters in practice has proven difficult; see, e.g., Oberfield and Raval (2014) for a recent discussion of the capital-labor case.

${ }^{27}$ More generally, one could incorporate a multivariate set of time-varying characteristics by setting $\kappa_{j, t} \equiv \boldsymbol{\gamma} \cdot \boldsymbol{u}_{j, t}$ where $\boldsymbol{u}_{j, t}$ is a vector of characteristics for exporter $j$ at year $t$ and $\gamma$ is the parameter vector that intermediates the effect of these characteristics on market shares. An alternative modeling strategy would be to organize countries into groups, based on some observed characteristic, and then estimate a nested CES system. This is much like the nested logit approach in Goldberg (1995).

${ }^{28}$ We incorporate the heterogeneity in $\epsilon$ with a positive multiplicative shifter to guarantee no sign variation in the trade elasticity. In other words, the sign of the trade elasticity is entirely determined by $\bar{\epsilon}$ but its magnitude is affected the multiplicative shifter, $\epsilon^{\sigma_{\epsilon}}$, whose distribution is log-normal with mean zero and variance $\sigma_{\epsilon}$. 
number of natural features of demand substitution patterns through the structural parameters $\sigma_{\alpha}$ and $\sigma_{\epsilon}$. To see this, define the share of the factor from country $j$ in expenditures of country $i$ conditional on $(\alpha, \epsilon)$ :

$$
x_{j i, t}(\alpha, \epsilon) \equiv \frac{\left(\kappa_{j}\right)^{\sigma_{\alpha} \alpha}\left(\omega_{j i, t}\right)^{-\left(\bar{\epsilon} \cdot \epsilon^{\sigma_{\epsilon}}\right)}}{\sum_{l=1}^{N}\left(\kappa_{l}\right)^{\sigma_{\alpha} \alpha}\left(\omega_{l i, t}\right)^{-\left(\bar{\epsilon} \cdot \epsilon^{\sigma_{\epsilon}}\right)}} .
$$

Now take three exporter countries $j, l$ and $r$ competing in the same importing market $i$ in year $t$. Consider how the demand for the factor from country $j$ relative to the factor from the reference country $r$ depends on the effective price of factor from country $l$ relative to that of country $r$. This elasticity of relative demand shares to relative prices is given by

$$
\frac{\partial \ln \left(\frac{\bar{\chi}_{j}\left(\omega_{i, t}\right)}{\bar{\chi}_{r}\left(\omega_{i, t}\right)}\right)}{\partial \ln \left(\frac{\omega_{l i, t}}{\omega_{r i t}}\right)}=\int\left(\bar{\epsilon} \cdot \epsilon^{\sigma_{\epsilon}}\right)\left(\frac{x_{j i, t}(\alpha, \epsilon)}{\bar{\chi}_{j}}-\frac{x_{r i, t}(\alpha, \epsilon)}{\bar{\chi}_{r}}\right) x_{l i, t}(\alpha, \epsilon) d F(\alpha, \epsilon)
$$

This expression highlights key features of the demand system in equation (31). As expected, setting $\sigma_{\alpha}=\sigma_{\epsilon}=0$ recovers the well-know property of independence of irrelevant alternatives (IIA) embedded in the CES demand system: the cross-price elasticity is zero. ${ }^{29}$ Departures from this special case yield richer patterns of substitution. The cross-price elasticity is relatively larger when $x_{j i, t}(\alpha, \epsilon)$ and $x_{l i, t}(\alpha, \epsilon)$ co-move more than $x_{r i, t}(\alpha, \epsilon)$ and $x_{l i, t}(\alpha, \epsilon)$ in the $(\alpha, \epsilon)$ space. From equation (32), we can see that such a pattern is generated by two channels. Whenever $\sigma_{\alpha} \neq 0$ and $\sigma_{\epsilon}=0$, this is the case if countries $j$ and $l$ are more similar in terms of their characteristics, $\kappa$, than countries $r$ and $l$ are (i.e., $\left.\left|\kappa_{j}-\kappa_{l}\right|<\left|\kappa_{r}-\kappa_{l}\right|\right)$. Alternatively, whenever $\sigma_{\alpha}=0$ and $\sigma_{\epsilon} \neq 0$, this pattern occurs if countries $j$ and $l$ are more similar in terms of their effective factor price than countries $r$ and $l$ are-this is then intrinsically related to market shares (i.e., $\left|\bar{\chi}_{j}-\bar{\chi}_{l}\right|<\left|\bar{\chi}_{r}-\bar{\chi}_{l}\right|$ ).

One particular set of micro-foundations that would lead to the factor demand system in equation (31) is that stemming from: (i) a Cobb-Douglas utility with equal weights over a continuum of sectors, with a lower-level CES nest over a continuum of varieties in each sector and (ii) country-and-sector-specific Fréchet distributions of productivity across varieties. Under this interpretation, each sector is fully characterized by its corresponding pair $(\alpha, \epsilon)$ with $F(\alpha, \epsilon)$ representing the distribution of sector attributes. In this sense, the factor demand system in equation (31) is closely related to the nested CES demand implied by standard multi-sector models in the field; see e.g. Costinot, Donaldson and Komunjer (2012) and Caliendo and Parro (2015).

\footnotetext{
${ }^{29}$ This follows immediately form the observation that $x_{j i, t}(\alpha, \epsilon)=\bar{\chi}_{j}$ for all $j$ if $\sigma_{\alpha}=\sigma_{\epsilon}=0$. Also, it is straightforward to verify that, in this case, the own-price elasticity is constant and equal to $-\bar{\epsilon}$.
} 
The crucial distinction here concerns the source of variation used for estimation. The results in Section 5 demonstrate that the aggregate factor demand system-which, as we have argued, is all that is required to study the counterfactual scenarios we consider here-is nonparametrically identified from aggregate data on factor spending shares. This is the variation that we will use next. Multi-sector level models, in contrast, are estimated using within-sector variation. And while sector-level factor demand relations are identified with sector-level data, the aggregate factor demand function, along with its essential aggregate cross-price elasticities, is not. ${ }^{30}$

Summarizing the above discussion, the "mixed CES" demand in equation (31) not only nests commonly used functional forms in the literature but also captures in a parsimonious manner the natural feature that factors similar in the $\kappa$-space are closer substitutes. ${ }^{31}$ Given the essential role played by these cross-price elasticities of substitution in many counterfactual scenarios of interest, we consider of paramount importance the ability of an estimator to let the data speak directly to these phenomena.

\subsection{Estimation Procedure}

We now turn to the estimation of the structural parameters $\left\{\bar{\epsilon}, \sigma_{\alpha}, \sigma_{\epsilon}\right\}$ in equation (31). Building on the identification result of Section 5, the estimator is based on the existence of an observed and exogenous component of effective factor prices. Later, we take this cost shifter, $z_{j i, t}$, to be the reported freight charges between trading partners.

In order to use the estimation procedure developed by Berry, Levinsohn and Pakes (1995) in the mixed logit case, it is convenient to focus on the following log-transformation of effective factor prices, $\delta_{j i, t} \equiv-\bar{\epsilon} \ln \left(\omega_{j i, t} / \omega_{1 i, t}\right)$, where $\omega_{1 i, t}$ is the effective price of U.S. factor in country $i$ at year $t$. Expressed in terms of $\delta_{i, t} \equiv\left\{\delta_{j i, t}\right\}$, the demand system in

\footnotetext{
${ }^{30}$ To see why this distinction may matter in practice, suppose that the true factor demand system is CES. In that case, the researcher using sector-level data and positing a nested-CES utility function with an upper-level Cobb-Douglas aggregator would uncover the true lower-level elasticity of substitution, but would wrongly assume that the upper-level elasticity is equal to one. In contrast, the researcher assuming mixed CES would rightly conclude that factor demand is CES. Of course, one could relax the assumption that the aggregator is Cobb-Douglas and attempt to estimate it as well; see e.g. Costinot, Donaldson and Smith (2015). But at that point, given the dimensionality of the demand system across goods that needs to be estimated, it is not clear what the benefit is compared to estimating the factor demand system directly.

${ }^{31}$ The translog demand system-as used in the Armington context by Novy (2013) — is an important exception not covered by the demand system in (31). One way to nest both CES and translog would be to use the CES-Translog demand system introduced by Pollak, Sickles and Wales (1984). While it is attractive to consider a demand system that nests both CES and translog, the main difficulty with using such a system is designing moment conditions that directly relate to the non-linear parameters of this extended CESTranslog system. One advantage of the "mixed CES" system is the clear connection between parameters and the structure of cross-price elasticities. As discussed below, this provides guidance for the choice of moment conditions.
} 
equation (31) becomes

$$
\bar{\chi}_{j}\left(\delta_{i, t} \mid \boldsymbol{\theta}_{2}\right)=\int \frac{\exp \left(\alpha \sigma_{\alpha} \ln \kappa_{j}+\epsilon^{\sigma_{\epsilon}} \delta_{j i, t}\right)}{1+\sum_{l=2}^{N} \exp \left(\alpha \sigma_{\alpha} \ln \kappa_{l}+\epsilon^{\sigma_{\epsilon}} \delta_{l i, t}\right)} d F(\alpha, \epsilon),
$$

where $\boldsymbol{\theta}_{2} \equiv\left(\sigma_{\alpha}, \sigma_{\epsilon}\right)$ is the sub-vector of "non-linear" parameters of the model, by which we mean those that will enter non-linearly in the estimation procedure below.

Conditional on the vector $\boldsymbol{\theta}_{2}$, Berry, Levinsohn and Pakes (1995) establish the existence of a unique vector $\delta_{i, t}$ that rationalizes expenditure shares in country $i$ and year $t$, i.e.,

$$
\bar{\chi}_{j}\left(\delta_{i, t} \mid \theta_{2}\right)=x_{j i, t}, \text { for all } j .
$$

In line with the notation of the previous sections, let $\bar{\chi}^{-1}\left(\boldsymbol{x}_{i, t} \mid \boldsymbol{\theta}_{2}\right) \equiv\left\{\bar{\chi}_{j}^{-1}\left(\boldsymbol{x}_{i, t} \mid \boldsymbol{\theta}_{2}\right)\right\}$ denote the solution of this system. By definition, $\bar{\chi}_{j}^{-1}\left(\boldsymbol{x}_{i, t} \mid \boldsymbol{\theta}_{2}\right)=-\bar{\epsilon} \ln \left(\omega_{j i, t} / \omega_{1 i, t}\right)$. Thus, we can use equation (26) to write

$$
\bar{\chi}_{j}^{-1}\left(\boldsymbol{x}_{i, t} \mid \boldsymbol{\theta}_{2}\right)=-\bar{\epsilon} \ln \left(z_{j i, t} / z_{1 i, t}\right)+\phi_{j i}+s_{j t}+e_{j i, t}
$$

with $\phi_{j i} \equiv-\bar{\epsilon}\left(\varphi_{j i}-\varphi_{1 i}\right), \varsigma_{j t} \equiv-\bar{\epsilon}\left(\xi_{j t}-\xi_{1 t}\right)$, and $e_{j i, t} \equiv-\bar{\epsilon}\left(\varepsilon_{j i, t}-\varepsilon_{1 i, t}\right)$, or more compactly,

$$
\bar{\chi}_{j}^{-1}\left(\boldsymbol{x}_{i, t} \mid \boldsymbol{\theta}_{2}\right)=\boldsymbol{Z}_{j i, t}^{1} \cdot \boldsymbol{\theta}_{1}+e_{j i, t}
$$

where $\boldsymbol{\theta}_{1} \equiv\left(-\bar{\epsilon},\left\{\phi_{j i}\right\},\left\{s_{j t}\right\}\right)$ denotes the sub-vector of "linear" parameters of the model and $\boldsymbol{Z}_{j i, t}^{1} \equiv\left[\ln \left(z_{j i, t} / z_{1 i, t}\right), \boldsymbol{d}_{i, t}\right]$ with $\boldsymbol{d}_{i, t}$ denoting a full vector of exporter-importer dummies and exporter-year dummies, with $i$ as the importer and $t$ as the year for all dummies.

Given a vector of instruments $Z_{j i, t}$ that is mean-independent from the structural error term, $E\left[e_{j i, t} \mid \boldsymbol{Z}_{j i, t}\right]=0$, one can then obtain a consistent GMM estimator of $\boldsymbol{\theta} \equiv\left[\boldsymbol{\theta}_{1} \mid \boldsymbol{\theta}_{2}\right]$ by constructing the structural error term $e_{j i, t}(\boldsymbol{\theta}) \equiv \bar{\chi}_{j}^{-1}\left(\boldsymbol{x}_{i, t} \mid \boldsymbol{\theta}_{2}\right)-\boldsymbol{Z}_{j i, t}^{1} \cdot \boldsymbol{\theta}_{1}$ and solving for

$$
\hat{\boldsymbol{\theta}}=\arg \min _{\theta} \mathbf{e}(\boldsymbol{\theta})^{\prime} \mathbf{Z} \Phi \mathbf{Z}^{\prime} \mathbf{e}(\boldsymbol{\theta}),
$$

where $\Phi$ is a matrix of moment weights. The details of the estimation procedure (as well as our procedure for computing standard errors for $\hat{\boldsymbol{\theta}}_{2}$ ) can be found in Appendix B.

To build instruments for the estimation of $\boldsymbol{\theta}$, we rely on the exogeneity restrictions described in Assumption A3. First, the structural error $e_{j i, t}$ is uncorrelated with the exporter's own freight cost $\ln z_{j i, t}$ and the dummy vector $\boldsymbol{d}_{i, t}$, making $Z_{j i, t}^{1}$ a natural vector of instruments. This is the usual set of regressors included in the estimation of CES demand. Second, Assumption A3 also entails that $e_{j i, t}$ is uncorrelated with the freight cost 
of all other competitors in the market, $\left\{\ln z_{l i, t}\right\}_{l \neq j}$. Following the intuition for the IIA violation implied by $\left(\sigma_{\alpha}, \sigma_{\epsilon}\right)$, we propose additional instruments for exporter $j$ that are based on the interaction between freight cost of competitors, $\ln z_{l i, t}$, and their per-capita GDP difference, $\left|\kappa_{j}-\kappa_{l}\right|$. Specifically, define the instrument vector $\mathbf{Z}_{j i, t}^{2} \equiv\left\{\left|\kappa_{j}-\kappa_{l}\right| \ln z_{l i, t}\right\}_{l \neq j}$. Intuitively, this choice of instruments is designed to explore the extent to which distance in the characteristic space, $\left|\kappa_{j}-\kappa_{l}\right|$, affects cross-price elasticities. The final instrument vector combines these two components: $\mathbf{Z}_{j i, t} \equiv\left[\mathbf{Z}_{j i, t}^{1} \mid \mathbf{Z}_{j i, t}^{2}\right]$.

\subsection{Data}

As described above, our estimation procedure draws on four types of data: $(i)$ data on the total value of bilateral trade in goods, which can then be converted into expenditure shares, denoted by $x_{j i, t} ;(i i)$ data on bilateral freight costs, denoted by $z_{j i, t} ;(i i i)$ data on total income by country, denoted by $y_{j, t}$; and (iv) data on per-capita GDP, denoted by $\kappa_{j}$.

We obtain data on $x_{j i, t}$ and $y_{j, t}$ from the World Input-Output Database for all years between 1995 and 2011. Following Shapiro (2012), data on $z_{j i, t}$ are available from the publicly available import data for two importers $i$, Australia and the United States, in all years $t$ from 1990 to 2010. ${ }^{32}$ To avoid the possibility of zero trade flows, we focus on the 36 largest exporters to Australia and the United States, and aggregate all other countries up to a single "Rest-of-the-World" unit. In the estimation of $\boldsymbol{\theta}$, we use all years with available information on trade flows and freight costs, 1995-2010. Finally, we obtain the information on per-capita GDP necessary to construct $\kappa_{j}$ from the Penn World Table, version 8.0. ${ }^{33}$ The list of exporters along with their per-capita GDP values is presented on Table A1 in Appendix C

\subsection{Estimation Results}

\subsubsection{Reduced-Form Evidence}

Before turning to our estimates of the structural parameters, we begin with a simpler approach that builds directly on the standard gravity model. Our goal is twofold. First, we illustrate that the deviations from IIA motivated in Section 6.1 are a systematic feature

\footnotetext{
${ }^{32}$ We are grateful to Joe Shapiro for making these data easily accessible to us. For each exporter and year, we compute the freight cost by dividing reported values of total exports CIF by total exports FOB. For domestic sales, we input a freight cost of zero - this is equivalent to assuming a constant (over time) transport cost of domestic sales in the presence of exporter-importer fixed effects.

${ }^{33}$ For each exporter, we compute per-capita GDP by dividing the expenditure-side real GDP at current PPP (USD 2005) by the total population. We then construct $\kappa_{j}$ as the average per-capita GDP between 1992 and 1995.
} 
Table 1: Reduced-Form estimates and violation of IIA in gravity estimation

\begin{tabular}{lcccc}
\hline Dependent variable: $\log ($ exports $)$ & $(1)$ & $(2)$ & $(3)$ & $(4)$ \\
\hline $\log$ (freight cost) & $-6.103^{* *}$ & $-6.347^{* *}$ & $-1.301^{* *}$ & $-1.277^{* *}$ \\
& $(1.046)$ & $(1.259)$ & $(0.392)$ & $(0.381)$ \\
test for joint significance of interacted competitors' & freight costs: & $\gamma_{l}=0$ for all $l$ \\
F-stat & \multicolumn{2}{c}{$42.60^{* *}$} & \\
p-value & \multicolumn{2}{c}{$<0.001$} & $<0.24^{* *}$ \\
Disaggregation level & exporter-importer & exp.-imp.-industry \\
Observations & \multicolumn{2}{c}{1,184} & \multicolumn{2}{c}{18,486} \\
\hline
\end{tabular}

Notes: Sample of exports from 37 countries to Australia and USA between 1995 and 2010 (aggregate and 2-digit industry-level). All models include a full set of dummies for exporter-importer(-industry), importeryear(-industry), and exporter-year(-industry). Standard errors clustered by exporter-importer. ${ }^{* *} \mathrm{p}<0.01$.

of the data. Second, we document that these deviations are directly related to the similarity of competitors in terms of per-capita GDP. To this end, we estimate the following equation:

$$
\ln \left(x_{j i, t}\right)=\beta \ln z_{j i, t}+\sum_{l \neq j} \gamma_{l}\left(\left|\kappa_{j}-\kappa_{l}\right| \ln z_{l i, t}\right)+\phi_{j i}+\zeta_{j t}+v_{i t}+\varepsilon_{j i, t} .
$$

In this specification, $x_{j i, t}$ is the share of country $j$ exports in expenditures of country $i$ at year $t$ and $z_{j i, t}$ is the bilateral freight cost from country $j$ to country $i$ at year $t$. The terms $\phi_{j i}, \zeta_{j t}$ and $v_{i t}$ represent exporter-importer, exporter-year and importer-year fixed-effects, respectively.

The IIA property implies that competitors' costs affect the spending share of exporter $j$ solely through the importer price index, being fully absorbed by the importer-year fixed effect. In specification (36), the IIA property is equivalent to $\gamma_{l}=0$ for all $l$. Alternatively, IIA is violated if the demand for the factor from country $j$ depends also on the price of the factor from country $l$ conditional on the importer-year fixed effect; that is, $\gamma_{l} \neq 0$ for some exporter $l$. The interaction between $\ln z_{l, t,}$ and $\left|\kappa_{j}-\kappa_{l}\right|$ relate this third country effect to the proximity of competitors in terms of per-capita GDP.

Table 1 reports estimates of various versions of equation (36). Column (1) begins by restricting attention to the standard CES case in which $\gamma_{l}=0$ for all $l$. We obtain an estimate of -6.1 for the trade elasticity in line with a vast literature that has estimated such a specification; see e.g. Head and Mayer (2013). Column (2) then includes the interaction terms to estimate the set of coefficients $\gamma_{l}$. Because there are 37 such coefficients and we are only interested in testing whether at least one of them is non-zero, we simply report the 
value of the F-test for the hypothesis that $\gamma_{l}=0$ for all $l$. This test is comfortably rejected at the one percent level, while clustering standard errors at the exporter-importer level. Columns (3)-(4) estimate the same specification using trade data disaggregated by 2-digit industry. This exercise investigates whether the IIA violation is simply related to industry aggregation. Accordingly, we allow all fixed effects to be industry-specific which implies that parameters are estimated from within-industry variation. For exposition purposes, we impose the same coefficients $\beta$ and $\gamma_{l}$ across sectors. The hypothesis that $\gamma_{l}=0$ for all $l$ is again rejected..$^{34}$

To summarize, Table 1 supports the relevance of third-country effects as captured by the interaction between competitor's freight costs and distance between per-capita GDPs, $\left|\kappa_{j}-\kappa_{l}\right| \ln z_{l i, t}$. In the structural estimation below, we rely on exactly this variation to obtain estimates of the parameters controlling the cross-price elasticity, $\sigma_{\alpha}$ and $\sigma_{\epsilon}$.

\subsubsection{Structural Estimation}

We now turn to our estimates of $\boldsymbol{\theta}$ obtained from the GMM procedure described in Section 6.2. These parameters are reported in Table 2 along with their accompanying standard errors clustered by exporter-importer pair. ${ }^{35}$ In Panel A, we restrict $\sigma_{\alpha}=\sigma_{\epsilon}=0$ in which case we estimate $\bar{\epsilon}$ to be approximately -6 . As expected, this value is very similar to the estimate in column (1) of Table $1 .^{36}$

Panel B reports our estimates with unobserved heterogeneity only in $\alpha$, whereas Panel $C$ focuses on our preferred specification with unobserved heterogeneity in both $\alpha$ and $\epsilon$. As can be seen from Panel $\mathrm{C}$, we estimate a value of $\sigma_{\epsilon}$ close to zero, indicating that deviations from IIA based on market shares are not important. However, the estimate of $\sigma_{\alpha}$ is statistically significant which suggests the importance of IIA deviations related to per-capita GDP. To get more intuition about the economic implications of our structural estimates, Figure 1 plots the cross price-elasticity in equation (33) with respect to a change in Chinese trade costs. While this elasticity is identically equal to zero in the CES system of Panel A, it does not have to be the case for the other specifications. In fact, the parameters estimated in Panel C imply that the elasticity of relative demand to the relative price of Chinese factor is decreasing in per-capita GDP, being statistically different from zero even

\footnotetext{
${ }^{34}$ We obtain the same conclusion if all coefficients are allowed to vary by industry: the hypothesis that $\gamma_{l}^{k}=0$ for all $l$ and $k$ is rejected at the one percent level.

${ }^{35}$ As noted by Stock and Yogo (2002), research on tests for weak instruments in the non-linear GMM case is still "quite incomplete." In principle, one could calculate the nonlinear Anderson-Rubin statistic proposed by these authors. Given the large number of fixed effects in equation (35), computing this statistic has proven too computationally demanding in practice.

${ }^{36}$ The estimates are not identical because they are based on two consistent, but distinct estimators of the same parameter.
} 
Table 2: GMM estimates of mixed CES demand

\begin{tabular}{lccc}
\hline & $\bar{\epsilon}$ & $\sigma_{\alpha}$ & $\sigma_{\epsilon}$ \\
\hline Panel A: CES & & & \\
& $-5.955^{* *}$ & & \\
& $(0.671)$ & & \\
Panel B: Mixed CES (restricted heterogeneity) & & & \\
& $-6.115^{* *}$ & $2.075^{* *}$ & \\
& $(0.649)$ & $(0.578)$ & \\
Panel C: Mixed CES (unrestricted heterogeneity) & & & \\
& $-6.116^{* *}$ & $2.063^{* *}$ & 0.003 \\
& $(0.671)$ & $(0.647)$ & $(0.175)$ \\
\hline
\end{tabular}

Notes: Sample of 1,152 exporter-importer-year triples between 1995 and 2010 (normalizing country is the USA). Importers: Australia and USA. All models include a full set of dummies for importer-exporter and exporter-year. Standard errors (consistent, one-step standard errors, following the procedure in Appendix B) in parentheses clustered by 72 exporter-importer pairs are reported in parentheses. ${ }^{* *} p<0.01$.

for low-income countries like China.

\section{Application: China's Integration in the World Economy}

We conclude by applying our methodology to study the consequences of one particular counterfactual: China's integration into the world economy. To shed light on this issue, we proceed in two steps. First, we use the demand system estimated in Section 6 to infer the trade costs faced by China, both as an exporter and an importer, at different points in time. Given estimates of Chinese trade costs, we then ask: "For any country $j$, how much higher (or lower) would welfare have been at a given year $t \geq 1995$ if Chinese trade costs were those of 1995 rather than those of year $t$ ?" The next subsection focuses on the estimation of trade costs. Counterfactual predictions will be discussed in Section 7.2. ${ }^{37}$

\footnotetext{
${ }^{37}$ We follow a two-step procedure because we are interested in quantifying the welfare consequences of China's observed integration-interpreted as changes in iceberg trade costs within our theoretical framework - over the last two decades. Of course, one could dispense with the first step and directly study the effects of arbitrarily chosen changes in trade costs, including those not featuring the normalizations imposed in Section 7.1. This is the approach followed in most recent quantitative papers; see e.g. Costinot and Rodríguez-Clare (2013). Note also that our exercise is related to, but distinct from, the simulations in Hanson and Robertson (2010) and Hsieh and Ossa (2011), which evaluate the global consequences of China's sector-wise productivity growth using gravity models.
} 


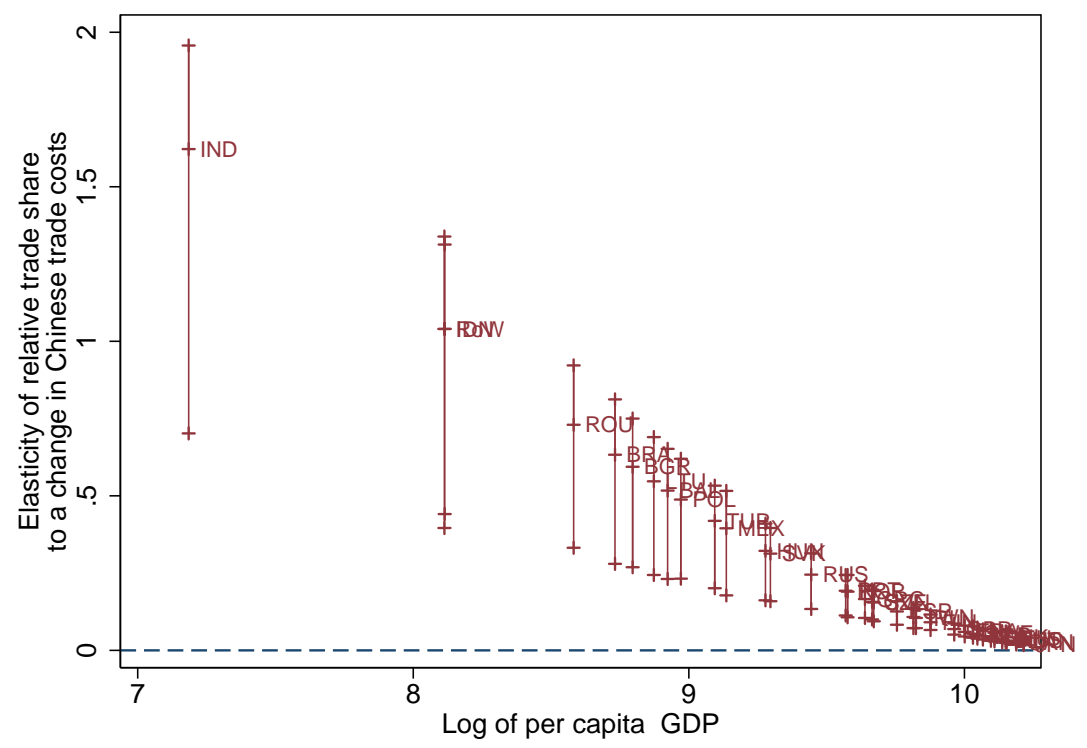

Figure 1: Elasticity of demand relative to the U.S. with respect to Chinese factor price.

Notes: Elasticity of U.S. demand for factors from any country relative to U.S. demand for U.S. factors with respect to a change in the Chinese factor price. Elasticities are computed using the estimates of the Mixed CES demand system in Panel C of Table 2. 95\% confidence intervals shown are computed using the bootstrap procedure described in Appendix D. Dashed blue line corresponds to the CES case.

\subsection{Trade Costs}

We measure trade costs as follows. For each importer $i$ and each year $t$ in our sample, we start by inverting our demand system, $\bar{\chi}$, to go from the vector of expenditure shares, $x_{i, t}$, to the vector of effective factor prices, $\omega_{i, t}=\bar{\chi}^{-1}\left(x_{i, t}\right)$, up to a normalization. We then use the time series of effective factor prices, $\left\{\omega_{j i, t}=\bar{\chi}_{j}^{-1}\left(x_{i, t}\right)\right\}$, and the identity, $\omega_{j i, t} \equiv \tau_{j i, t} c_{i, t}$, to construct the time series of iceberg trade costs, $\left\{\tau_{j i, t}\right\}$, such that

$$
\left(\tau_{j i, t} / \tau_{i i, t}\right) /\left(\tau_{j j, t} / \tau_{i j, t}\right)=\left(\bar{\chi}_{j}^{-1}\left(\boldsymbol{x}_{i, t}\right) / \bar{\chi}_{i}^{-1}\left(\boldsymbol{x}_{i, t}\right)\right) /\left(\bar{\chi}_{j}^{-1}\left(\boldsymbol{x}_{j, t}\right) / \bar{\chi}_{i}^{-1}\left(\boldsymbol{x}_{j, t}\right)\right), \text { for all } i, j, \text { and } t \text {. }
$$

This (log-)difference-in-differences provides a nonparametric generalization of the Head and Ries's (2001) index used to measure trade costs in gravity models. Compared to the case of a CES demand system, the only distinction is that one cannot directly read the difference-in-differences in effective prices from the difference-in-differences in expenditure shares. Inverting demand now requires a computer.

In order to go from a difference-in-differences to the level of Chinese trade costs, we 
follow the same approach as Head and Ries (2001) and further assume that

$$
\begin{aligned}
\tau_{i i, t} / \tau_{i i, 95} & =1 \text { for all } i \text { and } t \\
\tau_{i j, t} / \tau_{i j, 95} & =\tau_{j i, t} / \tau_{j i, 95} \text { for all } t \text { if } i \text { or } j \text { is China. }
\end{aligned}
$$

The first condition rules out differential changes in domestic trade costs around the world, whereas the second condition rules out asymmetric changes in Chinese trade costs. ${ }^{38}$ Given equations (37)-(39), we can then measure the proportional changes in Chinese trade costs between 1995 and any period $t$ as

$$
\tau_{j i, t} / \tau_{j i, 95}=\sqrt{\frac{\left(\bar{\chi}_{j}^{-1}\left(\boldsymbol{x}_{i, t}\right) / \bar{\chi}_{i}^{-1}\left(\boldsymbol{x}_{i, t}\right)\right) /\left(\bar{\chi}_{j}^{-1}\left(\boldsymbol{x}_{j, t}\right) / \bar{\chi}_{i}^{-1}\left(\boldsymbol{x}_{j, t}\right)\right)}{\left(\bar{\chi}_{j}^{-1}\left(\boldsymbol{x}_{i, 95}\right) / \bar{\chi}_{i}^{-1}\left(\boldsymbol{x}_{i, 95}\right)\right) /\left(\bar{\chi}_{j}^{-1}\left(\boldsymbol{x}_{j, 95}\right) / \bar{\chi}_{i}^{-1}\left(\boldsymbol{x}_{j, 95}\right)\right)}} \text {, if } i \text { or } j \text { is China. }
$$

By construction, changes in exporting and importing costs from China are the same, though they may vary across trading partners and over time.

Figure 2 reports the arithmetic average of changes in Chinese trade costs across all trading partners. The solid red line corresponds to our baseline estimates, obtained under mixed CES (Table 2, Panel C). As can be seen, these are substantial changes in trade costs. Between 1995 and 2007, we estimate that Chinese trade costs decreased by 20.2\% on average. If we were to restrict ourselves to a CES demand system (the dashed blue line), the decrease in Chinese trade costs would be equal to $16.7 \%$ instead.

\subsection{Counterfactual predictions}

In any year $t$, we are interested in counterfactual changes in trade costs, $\hat{\tau}_{j i, t}$, such that Chinese trade costs are brought back to their 1995 levels:

$$
\begin{aligned}
& \hat{\tau}_{j i, t}=\tau_{j i, 95} / \tau_{j i, t}, \text { if } i \text { or } j \text { is China, } \\
& \hat{\tau}_{j i, t}=1, \text { otherwise. }
\end{aligned}
$$

Given estimates of the factor demand system, obtained in Section 6, and estimates of trade costs, obtained in Section 7.1, we can use Corollary 1 to compute the welfare changes

\footnotetext{
${ }^{38}$ Our focus on symmetric changes in Chinese trade costs is partly motivated by the desire stay as close as possible to existing practices in the gravity literature. It should be clear, however, that while some normalization is required to go from differences-in-differences to the levels of trade costs, equations (38) and (39) provide only one of many possibilities. For example, an alternative would be to allow bilaterally asymmetric changes in Chinese trade costs under the assumption that some reference country's trade costs are constant over time. This is akin to focusing on counterfactuals in which one asks what would have happened if China had integrated with the rest of the world to the same extent as that reference country.
} 


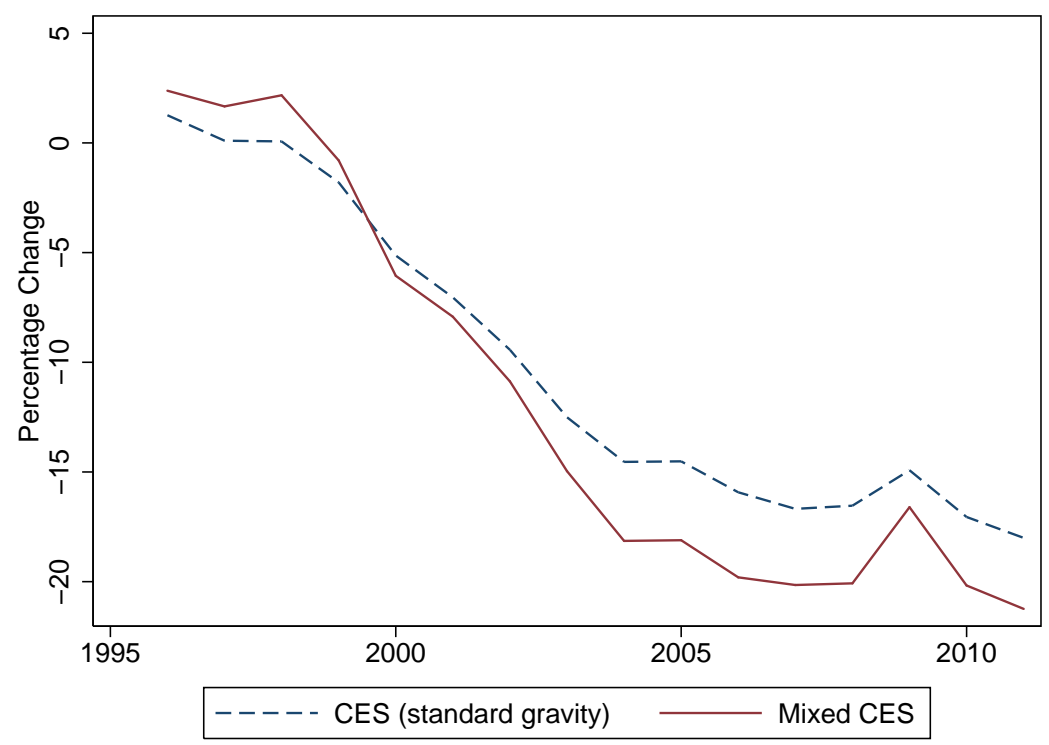

Figure 2: Average trade cost changes since 1995: China, 1996-2011.

Notes: Arithmetic average across all trading partners in the percentage reduction in Chinese trade costs between 1995 and each year $t=1996, \ldots, 2011$. "CES (standard gravity)" and "Mixed CES" plot the estimates of trade costs obtained using the factor demand system in Panels A and C, respectively, of Table 2.

associated with this counterfactual scenario. ${ }^{39}$

Figure 3 reports the negative of the welfare changes in China for all years in our sample. A positive number in year $t$ corresponds to the gains from economic integration for China between 1995 and year $t$. Before the great trade collapse in 2007, we see that the gains from economic integration for China are equal to $1.54 \%$. In line with our estimates of trade costs, we see that imposing CES would instead lead to gains from economic integration equal to $1.04 \%$.

What about China's trading partners? Figure 4 reports the welfare change from bringing Chinese trade costs back to their 1995 levels for all other countries in 2007. The bootstrapped $95 \%$ confidence intervals corresponding to each of these estimates (as well as those for China) can be found in Table A2 in Appendix D. Under our preferred estimates (red circles), we see that rich countries tend to gain relatively more from China's integration, with both Indonesia and Romania experiencing statistically significant losses. The previous pattern gets muted if one forces factor demand to be CES instead (blue triangles).

\footnotetext{
${ }^{39}$ Our counterfactual calculations allow for lump-sum transfers between countries to rationalize trade imbalances in the initial equilibrium. We then hold these lump-sum transfers constant across the initial and counterfactual equilibria. Details on the algorithm for the computation of the counterfactual exercise are described in Appendix D.
} 


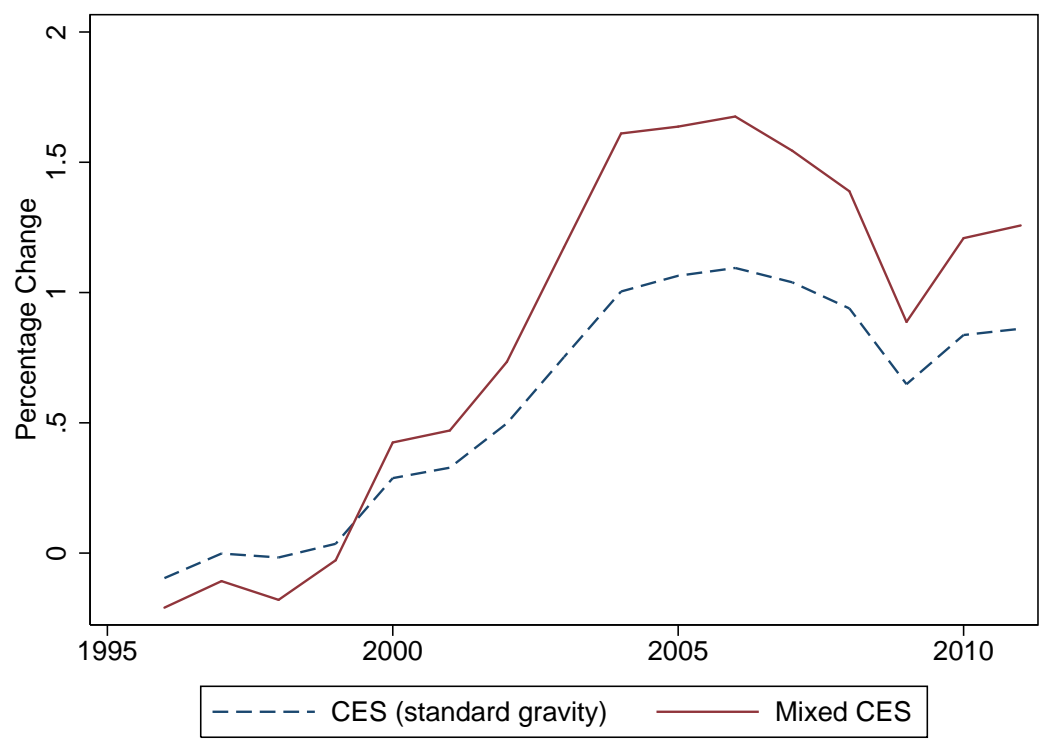

Figure 3: Welfare gains from Chinese integration since 1995: China, 1996-2011.

Notes: Welfare gains in China from reduction in Chinese trade costs relative to 1995 in each year $t=$ 1996, .., 2011. CES (standard gravity) and Mixed CES plot the estimates of welfare changes obtained using the factor demand system in Panels A and C, respectively, of Table 2.

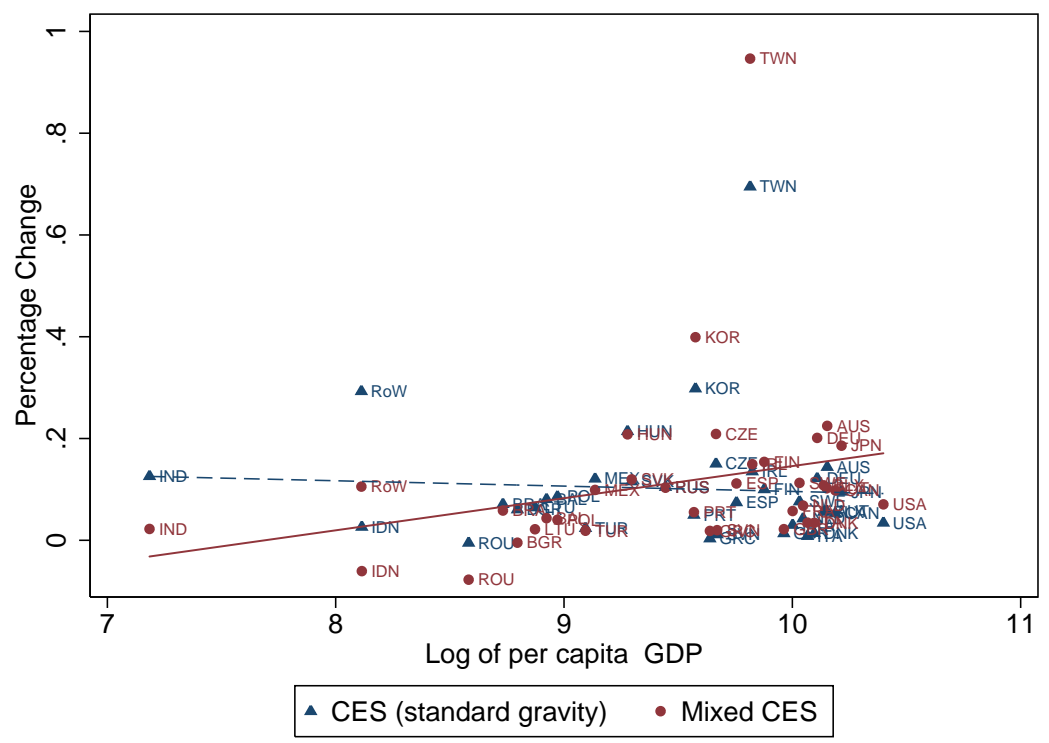

Figure 4: Welfare gains from Chinese integration since 1995: other countries, 2007.

Notes: Welfare gains in other countries from reduction in Chinese trade costs relative to 1995 in year $t=$ 2007. "CES (standard gravity)" and "Mixed CES" plot the estimates of welfare changes obtained using the factor demand system in Panels A and C, respectively, of Table 2. The solid red line shows the line of best fit through the Mixed CES points, and the dashed blue line the equivalent for the CES case. Bootstrapped $95 \%$ confidence intervals for these estimates are reported in Table A2. 


\section{Concluding Remarks}

This paper starts from a simple observation. If neoclassical trade models are like exchange economies in which countries trade factor services, then the shape of these countries' reduced factor demand must be sufficient for answering many counterfactual questions.

Motivated by this observation, we have developed tools to conduct counterfactual and welfare analysis given knowledge of any factor demand system. Then, we have provided sufficient conditions under which estimates of this system can be recovered nonparametrically. Lastly, we have applied our tools to study a particular counterfactual question: What would have happened to other countries if China had remained closed? Since the answer to this question hinges on how substitutable factors of production from around the world are, we have introduced a parsimonious generalization of the CES demand system that allows for rich patterns of substitution across factors from different countries. The counterfactual results based on estimates of this system illustrate the feasibility and potential benefits of allowing trade data to speak with added flexibility.

Clearly, our emphasis on reduced factor demand also has costs. The demand system in our empirical application remains high-dimensional-we consider a world economy with 37 exporters-but data are limited—freight costs for these 37 exporters are only available for 16 years and 2 importers. So parametric restrictions need to be imposed. The typical approach is to impose such restrictions on deeper primitives of the model, like preferences and technology, and then to use various data sources to estimate or calibrate each of those fundamentals. ${ }^{40}$ Here, we propose instead to impose restrictions directly on the factor demand system, while building estimation on precisely the moment conditions under which we have shown this system to be nonparametrically identified. Given data constraints, we do not view our approach as a panacea. But we believe that the tight connection between theory and data that it offers makes it worthy of further investigation.

An important open question concerns the extent to which one could combine the approach in this paper with additional, more disaggregated data sources. The answer is likely to depend on the additional assumptions that one is willing to impose, with costs and benefits that will need to be weighed. Consider, for instance, the differences in patterns of specialization across sectors and countries. Intuitively, there is a lot of information to be gained from such sector-level data. But if one is interested in aggregate questions, such data never come for free-disaggregated data will need to be aggregated ultimately. One possibility would be to use sector-level data, say in the pre-sample period, to con-

\footnotetext{
${ }^{40}$ Bas, Mayer and Thoenig (2015) provides an interesting example of this approach in the context of monopolistically competitive models of international trade.
} 
struct additional observed country characteristics in a factor demand system akin to the one introduced in Section 6. Another possibility, closer to existing work, would be to maintain strong functional forms on the way that sector-level factor demands are aggregated, but allow for mixed CES demand systems to deal flexibly with the substantial unobserved heterogeneity across goods within narrowly defined sectors; see Schott (2004).

Regardless of the methodology that one chooses, we hope that our theoretical results can make more transparent how CGE models map data into counterfactual predictions. One cannot escape Manski's (2003) "Law of Decreasing Credibility," that "the credibility of inference decreases with the strength of the assumptions maintained" (p. 1). But identifying the critical assumptions upon which counterfactual predictions rely in complex general equilibrium environments can help evaluate their credibility. Once it is established that assumptions about the shape of factor demand-and only the shape of factor demand-determine counterfactual predictions, it becomes easier to ask whether the moments chosen for structural estimation are related to the economic relation of interest and to explore whether functional form assumptions rather than data drive particular results.

In terms of applications, two lines of research seem particularly promising. The first concerns the distributional consequences of international trade. By assuming the same factor intensity in all sectors, our empirical application assumes away distributional issues. None of the theoretical results in Sections 3 and 4, however, rely on this assumption. Hence the same nonparametric approach could be used to study the impact of globalization on the skill premium or the relative return to capital. The second line of research concerns the consequences of factor mobility, either migration or foreign direct investment. Although factor supply is inelastic in Section 3, it would be easy to incorporate such considerations by introducing intermediate goods, as we did in Section 4.3.3. Then either migration or foreign direct investment would be equivalent to trade in intermediate goods, which may be subject to different frictions than trade in final goods.

Finally, while we have emphasized counterfactual and welfare analysis in this paper, the tools that we have developed could be applied more generally. Many questions concerning international trade can be reduced to estimating and inverting a demand system. But this system does not have to be CES. In Section 7.1, we have already mentioned the measurement of trade costs, which is an important application of gravity models; see e.g. Anderson and Van Wincoop (2004) and Jacks, Meissner and Novy (2011). Another natural application is the measurement of comparative advantage; see e.g. Costinot, Donaldson and Komunjer (2012) and Levchenko and Zhang (2011). Measures of revealed comparative advantage (RCA) aim to uncover which countries can produce and sell goods relatively more cheaply, and this boils down to a difference-in-differences of (log-)prices. 
Away from CES, this difference-in-differences will not be proportional to a difference-indifferences of (log-)expenditures. But given estimates of any invertible demand system, RCA remains an easy object to compute. 


\section{References}

Allen, Treb, Costas Arkolakis, and Yuta Takahashi, "Universal Gravity," Northwestern working paper, 2014.

Alvarez, Fernando and Robert E. Lucas, "General Equilibrium Analysis of the EatonKortum Model of International Trade," Journal of Monetary Economics, 2007, 54 (6), 17261768.

Anderson, James E. and Eric Van Wincoop, "Gravity with Gravitas: A Solution to the Border Puzzle," The American Economic Review, 2003, 93 (1), 170-192.

_ and _ , "Trade Costs," Journal of Economic Literature, 2004, 42 (3), 691-751.

Arkolakis, Costas, Arnaud Costinot, and Andres Rodríguez-Clare, "New Trade Models, Same Old Gains?," American Economic Review, 2012, 102 (1), 94-130.

_, - , Dave Donaldson, and Andres Rodriguez-Clare, "The Elusive Pro-Competitive Effects of Trade," mimeo, 2012.

Arrow, K.J. and F.H. Hahn, General competitive analysis, San Francisco: Holden-Day, 1971.

— , H.B. Chenery, B.S. Minhas, and R.M. Solow, "Capital-labor substitution and economic efficiency," Review of Economics and Statistics, 1961, 3, 225-250.

Baldwin, Richard E. and Anthony J. Venables, "Regional economic integration," in Gene M. Grossman and Kenneth Rogoff, eds., Handbook of International Economics, Vol. 3 New York: Elsevier 1995.

Bas, Maria, Thierry Mayer, and Mathias Thoenig, "From Micro to Macro: Demand, Supply, and Heterogeneity in the Trade Elasticity," mimeo, 2015.

Bernard, Andrew B. and J. Bradford Jensen, "Exceptional Exporter Performance: Cause, Effect, or Both," Journal of International Economics, 1999, 47, 1-25.

Berry, Steven, "Estimating Discrete-Choice Models of Product Differentiation," RAND Journal of Economics, 1994, 25 (2), 242-262.

—, James Levinsohn, and Ariel Pakes, "Automobile Prices in Market Equilibrium," Econometrica, 1995, 63 (4), 841-890.

Berry, Steven T., Amit Gandhi, and Philip A. Haile, "Connected substitutes and invertibility of demand," Econometrica, 2013, 81 (5), 2087-2111. 
- and Philip A. Haile, "Identification in differentiated products markets using market level data," Econometrica, 2014, 82 (5), 1749-1797.

Bowen, Harry P., Edward E. Leamer, and Leo Sveikauskas, "Multicountry, Multifactor Tests of the Factor Abundance Theory," American Economic Review, 1987, 77 (5), 791-809.

Bresnahan, Timothy F. and Robert J. Gordon, The economics of new goods, Chicago: University of Chicago Press, 2008.

Burstein, Ariel and Gita Gopinath, "International prices and exchange rates," in Gita Gopinath, Elhanan Helpman, and Kenneth Rogoff, eds., Handbook of International Economics, Vol. 4 New York: Elsevier 2013.

- and Jonathan Vogel, "Globalization, Technology, and the Skill Premium," 2010. Manuscript, Columbia University and UCLA.

_ , Joao C. Neves, and Sergio Rebelo, "Distribution costs and real exchange-rate dynamics during exchange-rate-based stabilizations," Journal of Monetary Economics, 2003, 50 (6), 1189-1214.

Caliendo, Lorenzo and Fernando Parro, "Estimates of the Trade and Welfare Effects of NAFTA," Review of Economic Studies, 2015, 82 (1), 1-44.

Cameron, A. Colin and Douglas L. Miller, "Robust inference with clustered data," 2010. UC Davis working paper.

Canay, Ivan A., Andres Santos, and Azeem M. Shaikh, "On the Testability of Identification in some Nonparametric Models with Endogeneity," Econometrica, 2013, 81 (6), 2535-2559.

Chiappori, P.A. and Ivar Ekeland, The Economics and Mathematics of Aggregation: Formal Models of Efficient Group Behavior, Boston: Now, 2009.

Costinot, Arnaud and Andres Rodríguez-Clare, "Trade Theory with Numbers: Quantifying the Consequences of Globalization," in Gita Gopinath, Elhanan Helpman, and Kenneth Rogoff, eds., Handbook of International Economics, Vol. 4, New York: Elsevier, 2013.

_ , Dave Donaldson, and Cory Smith, "Evolving Comparative Advantage and the Impact of Climate Change in Agricultural Markets: Evidence from a 1.7 Million Fields Around the World," Journal of Political Economy. In press, 2015. 
_ , _ , and Ivana Komunjer, "What Goods Do Countries Trade? A Quantitative Exploration of Ricardo's Ideas," Review of Economic Studies, 2012, 79 (2), 581-608.

Davis, Donald R. and David Weinstein, "An Account of Global Factor Trade," American Economic Review, 2001, 91 (5), 1423-1453.

Deardorff, Alan V. and Robert W. Staiger, "An Interpretation of the Factor Content of Trade," Journal of International Economics, 1988, 24 (1), 93-107.

Dekle, Robert, Jonathan Eaton, and Samuel Kortum, "Global Rebalancing with Gravity: Measuring the Burden of Adjustment," IMF Staff Papers, 2008, 55 (3), 511-540.

Dixit, Avinash K. and Victor Norman, Theory of International Trade, Cambridge University Press, 1980.

Eaton, Jonathan and Samuel Kortum, "Technology, Geography and Trade," Econometrica, 2002, 70 (5), 1741-1779.

Fajgelbaum, Pablo and Amit Khandelwal, "Measuring the Unequal Gains from Trade," UCLA working paper, 2014.

Goldberg, Pinelopi K., "Product Differentiation and Oligopoly in International Markets: The Case of the U.S. Automobile Industry," Econometrica, 1995, 63 (4), 891-951.

Grossman, Gene M. and Esteban Rossi-Hansberg, "Trading Tasks: A Simple Theory of Offshoring," American Economic Review, 2008, 98 (5), 1978-1997.

H., Jonathan H. Wright Stock James and Motohiro Yogo, "A survey of weak instruments and weak identification in generalized method of moments," Journal of Business and Economic Statistics, 2002, 20 (4).

Hanson, Gordon H. and Raymond Robertson, "China and the Manufacturing Exports of Other Developing Countries," in Robert C. Feenstra and Shang-Jin Wei, eds., China's Growing Role in World Trade, University of Chicago Press, 2010.

_, Nels Lind, and Marc-Andreas Muendler, "The Dynamics of Comparative Advantage," mimeo UCSD, 2014.

Hausman, J., "Exact Consumer's Surplus and Deadweight Loss," American Economic Review, 1981, 71, 662-676.

- and W. Newey, "Nonparametric estimation of exact consumers surplus and deadweight loss," Econometrica, 1995, 63 (6), 1445-1476. 
Head, Keith and John Ries, "Increasing Returns versus National Product Differentiation as an Explanation for the Pattern of U.S.-Canada Trade," American Economic Review, 2001, 91 (4), 858-876.

- and Thierry Mayer, "Gravity Equations: Toolkit, Cookbook, Workhorse," in Gita Gopinath, Elhanan Helpman, and Kenneth Rogoff, eds., Handbook of International Economics, Vol. 4, New York: Elsevier, 2013.

Helpman, Elhanan, "Solutions of General Equilibrium Problems for a Trading World," Econometrica, 1976, 44 (3), 547-559.

Hertel, Thomas, "Global Applied General Equilibrium Analysis Using the Global Trade Analysis Project Framework," in Peter B. Dixon and Dale W. Jorgenson, eds., Handbook of Computable General Equilibrium Modeling, Vol. 1, New York: Elsevier, 2013.

Hertel, Thomas W., Robert A. McDougall, Badri G. Narayanan, and Angel H. Aguiar, "Behavioral Parameters," in Badri G. Narayanan, Angel H. Aguiar, and Robert A. McDougall, eds., Global Trade, Assistance, and Production: The GTAP 8 Data Base, Center for Global Trade Analysis, Purdue University, 2012.

Howitt, Peter, "Gross substitutability with multi-valued excess demand functions," Econometrica, 1980, 48 (6), 1567-1573.

Hsieh, Chang-Tai and Ralph Ossa, "A Global View of Productivity Growth in China and India," NBER Working Paper, 2011.

Jacks, David S., Christopher M. Meissner, and Dennis Novy, “Trade booms, trade busts, and trade costs," Journal of International Economics, 2011, 83 (2), 185-201.

Johnson, Robert C. and Guillermo Noguera, "Accounting for Intermediates: Production Sharing and Trade in Value Added," Journal of International Economics, 2012, 86 (2), 224236.

Krugman, Paul, "Technology, trade and factor prices," Journal of International Economics, 2000, 50, 51-71.

Leamer, Edward E., "What's the use of factor contents?," Journal of International Economics, 2000, 50, 17-49.

_ , "Tantalus on the Road to Asymptopia," Journal of Economic Perspectives, 2010, 24 (2), $31-46$. 
Leontief, Wassily, "Domestic production and foreign trade; the American capital position re-examined," Proceedings of the American philosophical Society, 1953, pp. 332-349.

Levchenko, Andrei A. and Jing Zhang, "The Evolution of Comparative Advantage: Measurement and Welfare Implications," 2011. Michigan working paper.

Manski, Charles F., Partial Identification of Probability Distributions, New York: SpringerVerlag, 2003.

Mas-Colell, Andreu, "On the uniqueness of equilibrium once again," in W.A. Barnett, B. Cornet, C. d'Aspremont, J. Gabszewicz, and A. Mas-Colell, eds., Proceedings of the sixth international symposium in economic theory and econometrics, Cambridge: Cambridge University Press, 1991.

_ , Michael D. Whinston, and Jerry R. Green, Microeconomic Theory, Oxford University Press, 1995.

Matsuyama, Kiminori, "Beyond Icebergs: Towards a Theory of Biased Globalization," Review of Economic Studies, 2007, 74, 237-253.

Meade, J.E., A Geometry of International Trade, London: George Allen and Unwin, 1952.

Milgrom, Paul and Ilya Segal, "Envelope Theorems for Arbitrary Choice Sets," Econometrica, 2002, 70 (2), 583-601.

Neary, Peter and Albert Schweinberger, "Factor Content Functions and the Theory of International Trade," Review of Economic Studies, 1986, 53 (3), 421-432.

Nevo, Aviv, "A Practitioner's Guide to Estimation of Random Coefficients Logit Models of Demand," Journal of Economics and Management Strategy, 2000, 9 (4), 513-548.

_ , "Empirical Models of Consumer Behavior," Annual Review of Economics, 09 2011, 3 (1), $51-75$.

Newey, Whitney K., "Nonparametric Instrumental Variables Estimation," MIT working paper, 2013.

Newey, W.K. and J.L. Powell, "Instrumental Variable Estimation in Nonparametric Models," Econometrica, 2003, 71 (5), 1565-1578.

Novy, Dennis, "International Trade Without CES: Estimating Translog Gravity," Journal of International Economics, 2013, 89 (2), 271-282. 
Oberfield, Ezra and Devesh Raval, “Micro Data and Macro Technology,” 2014. Princeton working paper.

Pollak, Robert A., Robin C. Sickles, and Terence J. Wales, "The CES-Translog: Specification and estimation of a new cost function," Review of Economics and Statistics, 1984, $66(4), 602-607$.

Rader, Trout, Theory of General Economic Equilibrium, Academic Press, 1972.

Ramondo, Natalia and Andres Rodríguez-Clare, "Trade, Multinational Production, and the Gains from Openness," Journal of Political Economy, 2013, 121 (2), 273-322.

Scarf, Herbert E. and Charles A. Wilson, "Uniqueness of Equilibrium in the MultiCountry Ricardo Model," in Timothy J. Kehoe, T. N. Srinivasan, and John Whalley, eds., Frontiers in Applied General Equilibrium Modeling, Cambridge: Cambridge University PressCambridge University Press, 2005.

Schott, Peter K., "Across-Product versus Within-Product Specialization in International Trade," Quarterly Journal of Economics, 2004, 119 (2), 647-678.

Shapiro, Joseph, "Trade, CO2, and the Environment," Yale working paper, 2012.

Taylor, F.M., The guidance of production in a socialist state, Minneapolis: University of Minnesota Press, 1938.

Trefler, Daniel, “International Factor Price Differences: Leontief Was Right!," Journal of Political Economy, 1993, 101 (6), 961-987.

_ , "The Case of the Missing Trade and Other Mysteries," American Economic Review, 1995, 85 (5), 1029-46.

Wilson, Charles A., "On the General Structure of Ricardian Models with a Continuum of Goods: Applications to Growth, Tariff Theory, and Technical Change," Econometrica, 1980, 48 (7), 1675-1702.

Woodland, A.D., "Direct and Indirect Trade Utility Functions," Review of Economic Studies, 1980, 47, 907-926.

Yi, Kei-Mu, "Can Vertical Specialization Explain the Growth of World Trade?," Journal of Political Economy, 2003, 111 (1), 52-102. 


\section{A Proofs (for online publication)}

\section{A.1 Proposition 1}

Proof of Proposition 1. $(\Rightarrow)$ Suppose that $(\boldsymbol{q}, \boldsymbol{l}, \boldsymbol{p}, \boldsymbol{w})$ is a competitive equilibrium. For any country $i$, let us construct $L_{i} \equiv\left\{L_{j i}^{n}\right\}$ such that

$$
L_{j i}^{n}=\sum_{k} l_{j i}^{n k} \text { for all } i, j, \text { and } n
$$

Together with the factors market clearing condition (5), the previous expression immediately implies

$$
\sum_{j} L_{i j}^{n}=v_{i}^{n} \text { for all } i \text { and } n
$$

In order to show that $(L, w)$ is a reduced equilibrium, we therefore only need to show

$$
\begin{aligned}
& \boldsymbol{L}_{i} \in \operatorname{argmax}_{\tilde{\boldsymbol{L}}_{i}} U_{i}\left(\tilde{\boldsymbol{L}}_{i}\right) \\
& \qquad \sum_{j, n} w_{j}^{n} \tilde{L}_{j i}^{n} \leq \sum_{n} w_{i}^{n} v_{i}^{n} \text { for all } i .
\end{aligned}
$$

We proceed by contradiction. Suppose that there exists a country $i$ such that condition (42) does not hold. Since profits are zero in a competitive equilibrium with constant returns to scale, we must have $\sum_{j, k} p_{j i}^{k} q_{j i}^{k}=\sum_{j, n} w_{j}^{n} L_{j i}^{n}$. The budget constraint of the representative agent in the competitive equilibrium, in turn, implies $\sum_{j, n} w_{j}^{n} L_{j i}^{n}=\sum_{n} w_{i}^{n} v_{i}^{n}$. Accordingly, if condition (42) does not hold, there must be $\boldsymbol{L}_{i}^{\prime}$ such that $U_{i}\left(\boldsymbol{L}_{i}^{\prime}\right)>U_{i}\left(\boldsymbol{L}_{i}\right)$ and $\sum_{j, n} w_{j}^{n}\left(L_{j i}^{n}\right)^{\prime} \leq \sum_{n} w_{i}^{n} v_{i}^{n}$. Now consider $\left(\boldsymbol{q}_{i}^{\prime}, \boldsymbol{l}_{i}^{\prime}\right)$ such that

$$
\begin{aligned}
& \left(\boldsymbol{q}_{i}^{\prime}, \boldsymbol{l}_{i}^{\prime}\right) \in \operatorname{argmax}_{\tilde{\boldsymbol{q}}_{i}, \tilde{\boldsymbol{l}}_{i}} u_{i}\left(\tilde{\boldsymbol{q}}_{i}\right) \\
& \sum_{k} \tilde{l}_{j i}^{n k} \leq\left(L_{j i}^{n}\right)^{\prime} \text { for all } j \text { and } f, \\
& \tilde{\boldsymbol{q}}_{j i}^{k} \leq f_{j i}^{k}\left(\tilde{\boldsymbol{l}}_{j i}^{k}\right) \text { for all } j \text { and } k .
\end{aligned}
$$

We must have

$$
u_{i}\left(\boldsymbol{q}_{i}^{\prime}\right)=U_{i}\left(\boldsymbol{L}_{i}^{\prime}\right)>U_{i}\left(\boldsymbol{L}_{i}\right) \geq u_{i}\left(\boldsymbol{q}_{i}\right),
$$

where the last inequality derives from the fact that, by construction, $\boldsymbol{L}_{i}$ is sufficient to produce $\boldsymbol{q}_{i}$. Utility maximization in the competitive equilibrium therefore implies

$$
\sum_{j, k} p_{j i}^{k}\left(q_{j i}^{k}\right)^{\prime}>\sum_{n} w_{i}^{n} v_{i}^{n}
$$


Combining this inequality with $\sum_{j, n} w_{j}^{n}\left(L_{j i}^{n}\right)^{\prime} \leq \sum_{n} w_{i}^{n} v_{i}^{n}$, we obtain

$$
\sum_{j, k} p_{j i}^{k}\left(q_{j i}^{k}\right)^{\prime}>\sum_{j, n} w_{j}^{n}\left(L_{j i}^{n}\right)^{\prime}
$$

Hence, firms could make strictly positive profits by using $L_{i}^{\prime}$, to produce $\boldsymbol{q}_{i}^{\prime}$, which cannot be true in a competitive equilibrium. This establishes that $(L, w)$ is a reduced equilibrium with the same factor prices and the same factor content of trade as the competitive equilibrium. The fact that $U_{i}\left(\boldsymbol{L}_{i}\right)=u_{i}\left(\boldsymbol{q}_{i}\right)$ can be established in a similar manner. If there were $\boldsymbol{q}_{i}^{\prime}$ such that $u_{i}\left(\boldsymbol{q}_{i}^{\prime}\right)=$ $U_{i}\left(\boldsymbol{L}_{i}\right)>u_{i}\left(\boldsymbol{q}_{i}\right)$, then utility maximization would imply

$$
\sum_{j, k} p_{j i}^{k}\left(q_{j i}^{k}\right)^{\prime}>\sum_{n} w_{i}^{n} v_{i}^{n}=\sum_{j, n} w_{j}^{n} L_{j i}^{n}
$$

which would in turn violate profit maximization in the competitive equilibrium.

$(\Leftarrow)$ Suppose that $(\boldsymbol{L}, \boldsymbol{w})$ is a reduced equilibrium. For any positive of vector of output delivered in country $i, \boldsymbol{q}_{i} \equiv\left\{q_{j i}^{k}\right\}$, let $C_{i}\left(\boldsymbol{w}, \boldsymbol{q}_{i}\right)$ denote the minimum cost of producing $\boldsymbol{q}_{i}$

$$
\begin{aligned}
& C_{i}\left(\boldsymbol{w}, \boldsymbol{q}_{i}\right) \equiv \min _{\tilde{l}} \sum_{j, k, n} w_{j}^{n} \tilde{l}_{j i}^{n k} \\
& q_{j i}^{k} \leq f_{j i}^{k}\left(\tilde{l}_{j i}^{k}\right) \text { for all } j \text { and } k .
\end{aligned}
$$

The first step of our proof characterizes basic properties of $C_{i}$. The last two steps use these properties to construct a competitive equilibrium that replicates the factor content of trade and the utility levels in the reduced equilibrium.

Step 1. For any country $i$, there exists $\boldsymbol{p}_{i} \equiv\left\{p_{j i}^{k}\right\}$ positive such that the two following conditions hold: $(i)$

$$
C_{i}\left(\boldsymbol{w}, \boldsymbol{q}_{i}\right)=\sum_{j, k} p_{j i}^{k} q_{j i}^{k}, \text { for all } \boldsymbol{q}_{i}>0
$$

and (ii) if $\boldsymbol{l}_{i}$ solves (43), then $\boldsymbol{l}_{i}$ solves

$$
\max _{\tilde{l}_{j i}^{k}} p_{j i}^{k} f_{j i}^{k}\left(\tilde{l}_{j i}^{k}\right)-\sum_{n} w_{j}^{n} \tilde{l}_{j i}^{n k} \text { for all } j \text { and } k
$$

For any $i, j$, and $k$, let us construct $p_{j i}^{k}$ such that

$$
p_{j i}^{k}=\min _{\tilde{l}_{j i}^{k}}\left\{\sum_{n} w_{j}^{n} \tilde{l}_{j i}^{n k} \mid f_{j i}^{k}\left(\tilde{\boldsymbol{l}}_{j i}^{k}\right) \geq 1\right\}
$$

Take $\boldsymbol{l}_{j i}^{k}(1)$ that solves the previous unit cost minimization problem. Since $f_{j i}^{k}$ is homogeneous of degree one, we must have $f_{j i}^{k}\left(q_{j i}^{k} l_{j i}^{k}(1)\right) \geq q_{j i}^{k}$. By definition of $C_{i}$, we must also have $C_{i}\left(\boldsymbol{w}, \boldsymbol{q}_{i}\right) \leq$ $\sum_{j, k, n} q_{j i}^{k} w_{j}^{n} l_{j i}^{n k}(1)=\sum_{j, k} p_{j i}^{k} q_{j i}^{k}$. To show that equation (45) holds, we therefore only need to show 
that $C_{i}\left(w, q_{i}\right) \geq \sum_{j, k} p_{j i}^{k} q_{j i}^{k}$. We proceed by contradiction. Suppose that $C_{i}\left(\boldsymbol{w}, \boldsymbol{q}_{i}\right)<\sum_{j, k} p_{j i}^{k} q_{j i}^{k}$. Then there must be $q_{j i}^{k}>0$ such that

$$
\sum_{n} w_{j}^{n} l_{j i}^{n k}<q_{j i}^{k} \sum_{n} w_{j}^{n} l_{j i}^{n k}(1),
$$

where $\boldsymbol{l}_{j i}^{k}$ is part of the solution of (43). Since $f_{j i}^{k}$ is homogeneous of degree one, $\boldsymbol{l}_{j i}^{k} / q_{j i}^{k}$ would then lead to strictly lower unit cost then $l_{j i}^{k}(1)$, which cannot be. This establishes condition $(i)$.

To establish condition $(i i)$, we proceed again by contradiction. Suppose that there exists $\left(\boldsymbol{l}_{j i}^{k}\right)^{\prime}$ such that

$$
p_{j i}^{k} f_{j i}^{k}\left(\left(\boldsymbol{l}_{j i}^{k}\right)^{\prime}\right)-\sum_{n} w_{j}^{n}\left(l_{j i}^{n k}\right)^{\prime}>p_{j i}^{k} f_{j i}^{k}\left(\boldsymbol{l}_{j i}^{k}\right)-\sum_{n} w_{j}^{n} l_{j i}^{n k}
$$

Take the vector of output $\boldsymbol{q}_{i}$ such that $q_{j i}^{k}=f_{j i}^{k}\left(\boldsymbol{l}_{j i}^{k}\right)$ and zero otherwise. Condition $(i)$ applied to that vector immediately implies

$$
p_{j i}^{k} f_{j i}^{k}\left(\boldsymbol{l}_{j i}^{k}\right)=\sum_{n} w_{j}^{n} l_{j i}^{n k} .
$$

Combining this observation with inequality (48), we get $p_{j i}^{k}>\sum_{n} w_{j}^{n}\left(l_{j i}^{n k}\right)^{\prime} / f_{j i}^{k}\left(\left(\boldsymbol{l}_{i j}^{k}\right)^{\prime}\right)$, which contradicts the fact that $p_{j i}^{k}$ is the minimum unit cost.

Step 2. Suppose that $\left(\boldsymbol{q}_{i}, \boldsymbol{l}_{i}\right)$ solves

$$
\begin{aligned}
\max _{\tilde{\boldsymbol{q}}_{i}, \tilde{\boldsymbol{l}}_{i}} u_{i}\left(\tilde{\boldsymbol{q}}_{i}\right) & \\
\tilde{\boldsymbol{q}}_{j i}^{k} & \leq f_{j i}^{k}\left(\tilde{\boldsymbol{l}}_{j i}^{k}\right) \text { for all } j \text { and } k, \\
\sum_{k} w_{j}^{n} \tilde{l}_{j i}^{n k} & \leq \sum_{n} w_{i}^{n} v_{i}^{n} .
\end{aligned}
$$

Then $\boldsymbol{q}_{i}$ solves

$$
\begin{gathered}
\max _{\tilde{\boldsymbol{q}}_{i}} u_{i}\left(\tilde{\boldsymbol{q}}_{i}\right) \\
\sum_{j, k} p_{j i}^{k} \tilde{\tilde{q}}_{j i}^{k} \leq \sum_{n} w_{i}^{n} v_{i}^{n},
\end{gathered}
$$

and $\boldsymbol{l}_{i}$ solves

$$
\max _{\tilde{l}_{j i}^{k}} p_{j i}^{k} f_{j i}^{k}\left(\tilde{l}_{j i}^{k}\right)-\sum_{n} w_{j}^{n} \tilde{l}_{j i}^{n k} \text { for all } j \text { and } k
$$

If $\left(\boldsymbol{q}_{i}, \boldsymbol{l}_{i}\right)$ solves $(49)$, then

$$
\begin{aligned}
& \boldsymbol{q}_{i} \in \operatorname{argmax}_{\tilde{\boldsymbol{q}}_{i}} u_{i}\left(\tilde{\boldsymbol{q}}_{i}\right) \\
& \quad C_{i}\left(\boldsymbol{w}, \tilde{\boldsymbol{q}}_{i}\right) \leq \sum_{n} w_{i}^{n} v_{i}^{n} .
\end{aligned}
$$

Combining this observation with Step 1 condition $(i)$, we obtain that $\boldsymbol{q}_{i}$ solves (50). Likewise, if 
$\left(\boldsymbol{q}_{i}, \boldsymbol{l}_{i}\right)$ solves $(49)$, then

$$
\begin{aligned}
& \boldsymbol{l}_{i} \in \operatorname{argmin}_{\tilde{l}} \sum_{j, k, n} w_{j}^{n} \tilde{l}_{j i}^{n k}, \\
& q_{j i}^{k} \leq f_{j i}^{k}\left(\tilde{l}_{j i}^{k}\right) \text { for all } j \text { and } k .
\end{aligned}
$$

Combining this observation with Step 1 condition (ii), we obtain that $\boldsymbol{l}_{i}$ solves (51).

Step 3. For all $i$, take $\left(\boldsymbol{q}_{i}, \boldsymbol{l}_{i}\right)$ that solves

$$
\begin{aligned}
& \max _{\tilde{\boldsymbol{q}}_{i}, \tilde{l}_{i}} u_{i}\left(\tilde{\boldsymbol{q}}_{i}\right) \\
& \tilde{\boldsymbol{q}}_{j i}^{k} \leq f_{j i}^{k}\left(\tilde{\boldsymbol{l}}_{j i}^{k}\right) \text { for all } j \text { and } k, \\
& \sum_{k} \tilde{l}_{j i}^{n k} \leq L_{j i}^{n} \text { for all } j \text { and } n,
\end{aligned}
$$

and set $\boldsymbol{q}=\sum_{i} \boldsymbol{q}_{i}$ and $\boldsymbol{l}=\sum_{i} \boldsymbol{l}_{i}$. Then $(\boldsymbol{q}, \boldsymbol{l}, \boldsymbol{p}, \boldsymbol{w})$ is a competitive equilibrium with the same factor prices, $w$; (ii) the same factor content of trade, $L_{j i}^{n}=\sum_{k} l_{j i}^{n k}$ for all $i, j$, and $n$; and (iii) the same welfare levels, $U_{i}\left(\boldsymbol{L}_{i}\right)=u_{i}\left(\boldsymbol{q}_{i}\right)$ for all $i$.

Since $(\boldsymbol{L}, \boldsymbol{w})$ is a reduced equilibrium, if $\left(\boldsymbol{q}_{\boldsymbol{i}}, \boldsymbol{l}_{\boldsymbol{i}}\right)$ solves (52), then $\left(\boldsymbol{q}_{\boldsymbol{i}}, \boldsymbol{l}_{\boldsymbol{i}}\right)$ solves (49). By Step $2, \boldsymbol{q}_{i}$ and $\boldsymbol{l}_{i}$ must therefore solve (50) and (51), respectively. Hence, the utility maximization and profit maximization conditions (1) and (3) are satisfied. Since the constraint $\tilde{q}_{j i}^{k} \leq f_{j i}^{k}\left(\tilde{l}_{j i}^{k}\right)$ must be binding for all $j$ and $k$ in any country $i$, the good market clearing condition (4) is satisfied as well. The factor market clearing condition directly derives from the fact that $(\boldsymbol{L}, \boldsymbol{w})$ is a reduced equilibrium and the constraint, $\sum_{k} \tilde{l}_{j i}^{n k} \leq L_{j i}^{n}$, must be binding for all $j$ and $n$ in any country $i$. By construction, conditions (i)-(iii) necessarily hold.

\section{A.2 Lemma 1}

Proof of Lemma 1. We proceed in two steps.

Step 1. In a Ricardian economy, if good expenditure shares satisfy the connected substitute property, then factor expenditure shares satisfy the connected substitute property.

Our goal is to establish that factor demand, $\bar{\chi}$, satisfies the connected substitute propertyexpressed in terms of the effective prices of the composite factors, $\boldsymbol{\omega}_{j} \equiv\left\{\tau_{i j} c_{i}\right\}$-if good demand, $\bar{\sigma}$, satisfies the connected substitute property, with

$$
\overline{\boldsymbol{\sigma}}\left(\boldsymbol{p}_{j}\right) \equiv\left\{\left\{s_{j}^{k}\right\} \mid s_{j}^{k}=p_{j}^{k} q_{j}^{k} / y_{j} \text { for some } \boldsymbol{q}_{j} \in \operatorname{argmax}_{\tilde{\boldsymbol{q}}}\left\{\bar{u}(\tilde{\boldsymbol{q}}) \mid \sum_{k} p_{j}^{k} \tilde{q}_{j}^{k} \leq y_{j}\right\}\right\}
$$

Note that since $\bar{u}$ is homothetic, $\bar{\sigma}$ does not depend on income in country $j$. For notational convenience, we omit the importer's index, $j$, in the rest of this proof. 
Consider a change in effective factor prices from $\omega$ to $\omega^{\prime}$ and a partition of countries $\left\{M_{1}, M_{2}\right\}$ such that $\omega_{i}^{\prime}>\omega_{i}$ for all $i \in M_{1}$ and $\omega_{i}^{\prime}=\omega_{i}$ for all $i \in M_{2}$. Now take $x, x^{\prime}>0$ such that $x \in \bar{\chi}(\boldsymbol{\omega})$ and $x^{\prime} \in \bar{\chi}\left(\omega^{\prime}\right)$. For each exporting country $i$, we can decompose total expenditure shares into the sum of expenditure shares across all sectors $k$,

$$
x_{i}=\sum_{k} s^{k} x_{i}^{k}
$$

where $s^{k}$ denotes the share of expenditure on good $k$ at the initial prices,

$$
\begin{aligned}
\left\{s^{k}\right\} & \in \bar{\sigma}\left(\left\{p^{k}(\boldsymbol{\omega})\right\}\right), \\
p^{k}(\boldsymbol{\omega}) & =\min _{i}\left\{\omega_{i} / \alpha_{i}^{k}\right\} .
\end{aligned}
$$

For any good $k$, there are two possible cases. If no country $i \in M_{2}$ has the minimum cost for good $k$ at the initial factor prices, $\omega$, then

$$
\begin{aligned}
& \sum_{i \in M_{2}} x_{i}^{k}=0, \\
& p^{k}(\boldsymbol{\omega})<p^{k}\left(\boldsymbol{\omega}^{\prime}\right) .
\end{aligned}
$$

Let us call this set of good $K_{1}$. If at least one country $i \in M_{2}$ has the minimum cost for good $k$, then

$$
\begin{aligned}
\sum_{i \in M_{2}}\left(x_{i}^{k}\right)^{\prime} & =1, \\
p^{k}(\boldsymbol{\omega}) & =p^{k}\left(\boldsymbol{\omega}^{\prime}\right) .
\end{aligned}
$$

Let us call this second set of good $K_{2}$. Since $x, x^{\prime}>0$, we know that both $K_{1}$ and $K_{2}$ are non-empty.

Now consider the total expenditure on factors from countries $i \in M_{2}$ when factor prices are equal to $\omega^{\prime}$. It must satisfy

$$
\sum_{i \in M_{2}}\left(x_{i}\right)^{\prime} \geq \sum_{i \in M_{2}} \sum_{k \in K_{2}}\left(s^{k}\right)^{\prime}\left(x_{i}^{k}\right)^{\prime}=\sum_{k \in K_{2}}\left(s^{k}\right)^{\prime}\left[\sum_{i \in M_{2}}\left(x_{i}^{k}\right)^{\prime}\right]
$$

Combining the previous inequality with (55), we obtain

$$
\sum_{i \in M_{2}}\left(x_{i}\right)^{\prime} \geq \sum_{k \in K_{2}}\left(s^{k}\right)^{\prime}
$$

By the Inada conditions, all goods are consumed. Thus, we can invoke the connected substitute property for goods in $K_{1}$ and $K_{2}$. Conditions (54) and (56) imply

$$
\sum_{k \in K_{2}}\left(s^{k}\right)^{\prime}>\sum_{k \in K_{2}} s^{k}
$$


Since $\sum_{i \in M_{2}} x_{i}^{k} \leq 1$, the two previous inequalities further imply

$$
\sum_{i \in M_{2}}\left(x_{i}\right)^{\prime}>\sum_{k \in K_{2}} s^{k}\left[\sum_{i \in M_{2}} x_{i}^{k}\right]=\sum_{i \in M_{2}} \sum_{k \in K_{2}} s^{k} x_{i}^{k}
$$

Finally, using (53) and the fact that $\left\{K_{1}, K_{2}\right\}$ is a partition, we get

$$
\sum_{i \in M_{2}}\left(x_{i}\right)^{\prime}>\sum_{i \in M_{2}} \sum_{k \in K_{1}} s^{k} x_{i}^{k}+\sum_{i \in M_{2}} \sum_{k \in K_{2}} s^{k} x_{i}^{k}=\sum_{i \in M_{2}} x_{i}
$$

This establishes that $\bar{\chi}$ satisfies the connected substitute property.

Step 2. If factor demand $\bar{\chi}$ satisfies the connected substitute property, then for any vector of factor expenditure shares, $x>0$, there is at most one vector (up to a normalization) of effective factor prices, $\omega$, such that $x \in \bar{\chi}(\omega)$.

We proceed by contradiction. Suppose that there exist $\omega, \omega^{\prime}$, and $x_{0}>0$ such that $x_{0} \in \bar{\chi}(\omega)$, $x_{0} \in \bar{\chi}\left(\omega^{\prime}\right)$, and $\omega$ and $\omega^{\prime}$ are not collinear. Since $\bar{\chi}$ is homogeneous of degree zero in all factor prices, we can assume without loss of generality that $\omega_{i} \geq \omega_{i}^{\prime}$ for all $i$, with at least one strict inequality and one equality. Now let us partition all countries into two groups, $M_{1}$ and $M_{2}$, such that

$$
\begin{aligned}
& \omega_{i}^{\prime}>\omega_{i} \text { if } i \in M_{1}, \\
& \omega_{i}^{\prime}=\omega_{i} \text { if } i \in M_{2} .
\end{aligned}
$$

Since $\bar{\chi}$ satisfies the connected substitute property, conditions (57) and (58) imply that for any $x, x^{\prime}>0$ such that $x \in \bar{\chi}(\omega)$ and $x^{\prime} \in \bar{\chi}\left(\omega^{\prime}\right)$, we must have

$$
\sum_{i \in M_{2}} x_{i}^{\prime}>\sum_{i \in M_{2}} x_{i}
$$

which contradicts the existence of $x_{0} \in \bar{\chi}(\omega) \cap \bar{\chi}\left(\omega^{\prime}\right)$. Lemma 1 follows from Steps 1 and 2 .

\section{A.3 Lemma 2}

Proof of Lemma 2. We proceed by contradiction. Suppose that there exist two equilibrium vectors of factor prices, $c \equiv\left(c_{1}, \ldots, c_{I}\right)$ and $c^{\prime} \equiv\left(c_{1}^{\prime}, \ldots, c_{I}^{\prime}\right)$, that are not collinear. By Proposition 1 , we know that $c$ and $c^{\prime}$ must be equilibrium vectors of the reduced exchange model. So they must satisfy

$$
\begin{aligned}
\sum_{j} L_{i j} & =\bar{f}_{i}\left(\boldsymbol{v}_{i}\right), \text { for all } i, \\
\sum_{j} L_{i j}^{\prime} & =\bar{f}_{i}\left(\boldsymbol{v}_{i}\right), \text { for all } i,
\end{aligned}
$$


where $\left\{L_{i j}\right\}$ and $\left\{L_{i j}^{\prime}\right\}$ are the optimal factor demands in the two equilibria,

$$
\begin{aligned}
& \left\{L_{i j}\right\} \in \overline{\boldsymbol{L}}\left(\boldsymbol{\omega}_{j}\right), \text { for all } j, \\
& \left\{L_{i j}^{\prime}\right\} \in \overline{\boldsymbol{L}}\left(\boldsymbol{\omega}_{j}^{\prime}\right), \text { for all } j,
\end{aligned}
$$

where $\omega_{j} \equiv\left\{\tau_{i j} c_{i}\right\}$ and $\omega_{j}^{\prime} \equiv\left\{\tau_{i j} c_{i}^{\prime}\right\}$ are the associated vectors of effective factor prices.

We can follow the same strategy as in Step 2 of the proof of Lemma A.3. Without loss of generality, let us assume that $c_{i}^{\prime} \geq c_{i}$ for all $i$, with at least one strict inequality and one equality. We can again partition all countries into two groups, $M_{1}$ and $M_{2}$, such that

$$
\begin{gathered}
c_{i}^{\prime}>c_{i} \text { if } i \in M_{1}, \\
c_{i}^{\prime}=c_{i} \text { if } i \in M_{2} .
\end{gathered}
$$

The same argument then implies that in any country $j$,

$$
\sum_{i \in M_{2}} x_{i j}^{\prime}>\sum_{i \in M_{2}} x_{i j}
$$

where $\left\{x_{i j}\right\}$ and $\left\{x_{i j}^{\prime}\right\}$ are the expenditure shares associated with $\left\{L_{i j}\right\}$ and $\left\{L_{i j}^{\prime}\right\}$, respectively. By definition of the factor expenditure shares, the previous inequality can can be rearranged as

$$
\sum_{i \in M_{2}} c_{i}^{\prime} L_{i j}^{\prime} /\left(c_{j}^{\prime} \bar{f}_{j}\left(\boldsymbol{v}_{j}\right)\right)>\sum_{i \in M_{2}} c_{i} L_{i j} /\left(c_{j} \bar{f}_{j}\left(\boldsymbol{v}_{j}\right)\right)
$$

Since $c_{i} \geq c_{i}^{\prime}$ for all $i$, this implies

$$
\sum_{i \in M_{2}} c_{i}^{\prime} L_{i j}^{\prime}>\sum_{i \in M_{2}} c_{i} L_{i j}
$$

Summing across all importers $j$, we therefore have

$$
\sum_{i \in M_{2}} c_{i}^{\prime} \sum_{j} L_{i j}^{\prime}>\sum_{i \in M_{2}} c_{i} \sum_{j} L_{i j}
$$

By equations (59) and (60), this further implies

$$
\sum_{i \in M_{2}} c_{i}^{\prime} \bar{f}_{i}\left(\boldsymbol{v}_{i}\right)>\sum_{i \in M_{2}} c_{i} \bar{f}_{i}\left(\boldsymbol{v}_{i}\right)
$$

which contradicts (62).

\section{B Estimation (for online publication)}

In this section we discuss further details of the estimation procedure outlined in Section 6.2. 


\section{B.1 GMM Estimator}

As in Section 6.2, define the stacked matrix of instruments, $\mathbf{Z} \equiv\left[\mathbf{Z}^{\mathbf{1}} \mid \mathbf{Z}^{\mathbf{2}}\right]$, and the stacked vector of errors, $\mathbf{e}(\boldsymbol{\theta}) \equiv \bar{\chi}^{-1}\left(\boldsymbol{x} \mid \boldsymbol{\theta}_{2}\right)-\boldsymbol{Z}^{1} \cdot \boldsymbol{\theta}_{1}$. The GMM estimator is

$$
\widehat{\boldsymbol{\theta}}=\arg \min _{\theta} \mathbf{e}(\boldsymbol{\theta})^{\prime} \mathbf{Z} \Phi \mathbf{Z}^{\prime} \mathbf{e}(\boldsymbol{\theta})
$$

where $\Phi$ is the GMM weight. We confine attention to the consistent one-step procedure by setting $\Phi=\left(\mathbf{Z}^{\prime} \mathbf{Z}\right)^{-1} \cdot{ }^{41}$

\section{B.2 Standard Errors}

In our baseline specification, we acknowledge the possibility of autocorrelation in the error term. In particular, we assume that observations are independent across exporter-importer pairs, but there is arbitrary autocorrelation across periods for the same pair. Following Cameron and Miller (2010), we have that

$$
\sqrt{M}(\widehat{\boldsymbol{\theta}}-\boldsymbol{\theta}) \rightarrow N\left[0,\left(B^{\prime} \Phi B\right)^{-1}\left(B^{\prime} \Phi \Lambda \Phi B\right)\left(B^{\prime} \Phi B\right)^{-1}\right]
$$

where $B \equiv E\left[Z_{j i, t}^{\prime} \nabla_{\theta} e_{j i, t}(\boldsymbol{\theta})\right]$ and $\Lambda \equiv E\left[\left(Z_{j i}^{\prime} e_{j i}\right)\left(Z_{j i}^{\prime} e_{j i}\right)^{\prime}\right]$, with $Z_{j i}=\left[Z_{j i, t}\right]_{t=1}^{T}$ and $e_{j i} \equiv\left[e_{j i, t}\right]_{t=1}^{T}$ being matrices of stacked periods for exporter-importer pair $(j, i)$.

The covariance matrix can be consistently estimated using

$$
\widehat{\operatorname{Avar}}(\widehat{\boldsymbol{\theta}}) \equiv\left(\hat{B}^{\prime} \Phi \hat{B}\right)^{-1}\left(\hat{B}^{\prime} \Phi \hat{\Lambda} \Phi \hat{B}\right)\left(\hat{B}^{\prime} \Phi \hat{B}\right)^{-1}
$$

where $\hat{B} \equiv\left(\mathbf{Z}^{\prime} \nabla_{\theta} \mathbf{e}(\widehat{\boldsymbol{\theta}})\right), \nabla_{\theta} \mathbf{e}(\widehat{\boldsymbol{\theta}}) \equiv\left[D_{\boldsymbol{\theta}_{2}} \bar{\chi}^{-1}\left(\boldsymbol{x} \mid \boldsymbol{\theta}_{2}\right) \mid-\mathbf{Z}^{\mathbf{1}}\right]$, and $\hat{\Lambda} \equiv \Gamma^{\prime} \Gamma$ such that $\Gamma \equiv\left[e_{j i}(\widehat{\boldsymbol{\theta}})^{\prime} Z_{j i}\right]_{j i}$. This analysis ignored the fact that we take draws of $\left(\alpha_{s}, \epsilon_{s}\right)$ to compute simulated moment conditions in the algorithm described below. Although this simulation step affects standard errors, the asymptotic distribution of the estimator is the same as the number of simulated draws goes to infinite. Thus, we compute the covariance matrix according to expression (63) which is assumed to be an appropriate approximation for the large number of simulations (discussed below) used in the empirical implementation.

\section{B.3 Estimation Algorithm}

The simulated GMM procedure is implemented with the following steps.

Step 0. Draw $S$ simulated pairs $\left(\alpha_{s}, \ln \epsilon_{S}\right) \sim N(0, I)$. We set $S=4,000$ and use the same draws for all markets.

\footnotetext{
${ }^{41}$ This is the efficient estimator under homoskedasticity, however this weight matrix leads to an inneficient estimator under a more general covariance structure of errors.
} 
Step 1. Conditional on $\boldsymbol{\theta}_{2}$, compute the vector $\bar{\chi}^{-1}\left(\boldsymbol{x}_{i, t} \mid \boldsymbol{\theta}_{2}\right) \equiv\left\{\delta_{j i, t}\right\}_{j=2}^{N}$ that solves the following system:

$$
\left\{\bar{\chi}_{j}\left(\delta_{i, t} \mid \boldsymbol{\theta}_{2}\right)\right\}_{j=2}^{N}=\left\{x_{j i, t}\right\}_{j=2}^{N}
$$

where $x_{j i, t}$ is the expenditure share of importer $i$ on exports of $j$ at year $t$ and

$$
\bar{\chi}_{j}\left(\boldsymbol{\delta}_{i, t} \mid \boldsymbol{\theta}_{2}\right)=\frac{1}{S} \sum_{s=1}^{S} \frac{\exp \left[\alpha_{s} \sigma_{\alpha} \ln \kappa_{j}+\left(\epsilon_{S}\right)^{\sigma_{\epsilon}} \delta_{j i, t}\right]}{1+\sum_{l=2}^{N} \exp \left[\alpha_{S} \sigma_{\alpha} \ln \kappa_{l}+\left(\epsilon_{S}\right)^{\sigma_{\epsilon}} \delta_{l i, t}\right]} .
$$

Uniqueness and existence of the solution is guaranteed by the fixed point argument in Berry, Levinsohn and Pakes (1995). To solve the system, consider the fixed point of the following function:

$$
G\left(\delta_{i, t}\right)=\left[\delta_{j i, t}+\lambda\left(\ln x_{j i, t}-\ln \bar{\chi}_{j}\left(\delta_{i, t} \mid \theta_{2}\right)\right)\right]_{j=2}^{N}
$$

where $\lambda$ is a parameter controlling the adjustment speed. This fixed point is obtained as the limit of the sequence: $\delta_{i, t}^{n+1}=G\left(\delta_{i, t}^{n}\right)$. Numerically, we compute the sequence until $\max _{j}\left|\ln x_{j i, t}-\ln \bar{\chi}_{j}\left(\delta_{i, t} \mid \theta_{2}\right)\right|<$ tol, where tol is some small number that we discuss further below.

This step is implemented as follows. First, the initial guess $\delta_{i j, t}^{0}$ in the initial iteration is set to be the logit solution $\delta_{j i, t}^{0}=\ln x_{j i, t}-\ln x_{1 i, t}$. In subsequent iterations, we use the following rule. If $\boldsymbol{\theta}_{2}$ is close to the parameter vector of the previous iteration, we use the system solution in the last iteration. Otherwise, we use the vector that solved the system for the same importer in the previous year (if it is the first year, we use the logit solution). Second, the speed of adjustment is initially set to $\lambda=3$. If distance increases in iteration $n$, then we reduce $\lambda$ by $5 \%$ and compute $\delta_{i, t}^{n+1}$ again until distance decreases in the step and use the new value of $\lambda$ until the solution is found. If $\lambda$ falls below a minimum $(\underline{\lambda}=.001)$, then we assume no solution for the system and set the objective function to a high value. Lastly, we set $t o l=10^{-8}$ and, every 20,000 iterations, we increase tolerance by a factor of two. This guarantees that the algorithm does not waste time on convergence for parameter values far away from the real ones. ${ }^{42}$

Step 2. Conditional on $\boldsymbol{\theta}_{2}$, solve analytically for linear parameters directly from the minimization

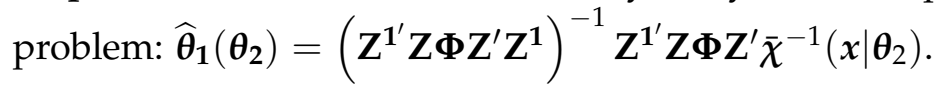

Step 3. Conditional on $\boldsymbol{\theta}_{2}$, compute the vector of structural errors: $\mathbf{e}\left(\boldsymbol{\theta}_{2}\right)=\bar{\chi}^{-1}\left(\boldsymbol{x} \mid \boldsymbol{\theta}_{2}\right)-\mathbf{Z}^{1} \cdot \widehat{\boldsymbol{\theta}}_{\mathbf{1}}\left(\boldsymbol{\theta}_{\mathbf{2}}\right)$

Step 4. Numerically minimize the objective function to obtain estimates of $\boldsymbol{\theta}_{2}$ :

$$
\hat{\boldsymbol{\theta}}_{\mathbf{2}} \equiv \arg \min _{\theta_{2}} H\left(\boldsymbol{\theta}_{\mathbf{2}}\right) \equiv \mathbf{e}\left(\boldsymbol{\theta}_{2}\right)^{\prime} \mathbf{Z} \Phi \mathbf{Z}^{\prime} \mathbf{e}\left(\boldsymbol{\theta}_{2}\right)
$$

The numerical minimization is implemented using the "trust-region-reflective" algorithm that re-

\footnotetext{
${ }^{42}$ This adjustment procedure follows closely the suggestions in Nevo (2000).
} 
quires an analytical gradient of the objective function (described below). This algorithm is intended to be more efficient in finding the local minimum within a particular attraction region. First, we solve the minimization problem using a grid of ten initial conditions randomly drawn from a uniform distribution in the parameter space. Second, we solve a final minimization problem using as initial condition the minimum solution obtained from the first-round minimization. Here, we impose a stricter convergence criteria and we reduce the tolerance level of the system solution in Step 1 to tol $=10^{-12}$.

Objective Function Gradient. The Jacobian of $H\left(\boldsymbol{\theta}_{\mathbf{2}}\right)$ is $\nabla H\left(\boldsymbol{\theta}_{2}\right)=2 \cdot \operatorname{De}\left(\boldsymbol{\theta}_{2}\right)^{\prime} \mathbf{Z} \Phi \mathbf{Z}^{\prime} \mathbf{e}\left(\boldsymbol{\theta}_{2}\right)$ where

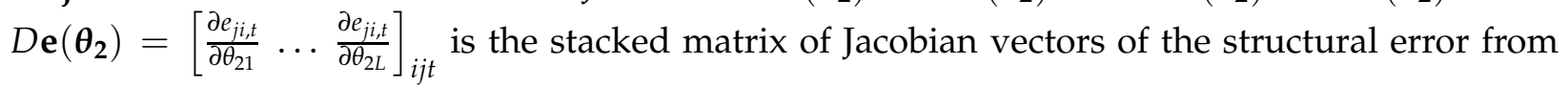
Step 5. By the envelope theorem, the Jacobian is $D \mathbf{e}\left(\boldsymbol{\theta}_{\mathbf{2}}\right)=D \boldsymbol{\delta}\left(\boldsymbol{\theta}_{\mathbf{2}}\right)$ because $\widehat{\boldsymbol{\theta}}_{\mathbf{1}}\left(\boldsymbol{\theta}_{\mathbf{2}}\right)$ is obtained from the analytical minimization of the inner problem restricted to a particular level of $\boldsymbol{\theta}_{2}$. For each importer-year, the implicit function theorem implies that

$$
D \boldsymbol{\delta}_{i, t}\left(\boldsymbol{\theta}_{2}\right)=\left[\begin{array}{ccc}
\frac{\partial \delta_{2 i, t}}{\partial \theta_{21}} & \ldots & \frac{\partial \delta_{2 i, t}}{\partial \theta_{2 L}} \\
\vdots & \ddots & \vdots \\
\frac{\partial \delta_{N i, t}}{\partial \theta_{21}} & \cdots & \frac{\partial \delta_{N i, t}}{\partial \theta_{2 L}}
\end{array}\right]=-\left[\begin{array}{ccc}
\frac{\partial \bar{\chi}_{2}}{\partial \delta_{2 i, t}} & \cdots & \frac{\partial \bar{\chi}_{2}}{\partial \delta_{N i, t}} \\
\vdots & \ddots & \vdots \\
\frac{\partial \bar{\chi}_{N}}{\partial \delta_{2 i, t}} & \cdots & \frac{\partial \bar{\chi}_{N}}{\partial \delta_{N i, t}}
\end{array}\right]^{-1}\left[\begin{array}{ccc}
\frac{\partial \bar{\chi}_{2}}{\partial \theta_{21}} & \cdots & \frac{\partial \bar{\chi}_{2}}{\partial \theta_{2 L}} \\
\vdots & \ddots & \vdots \\
\frac{\partial \bar{\chi}_{N}}{\partial \theta_{21}} & \cdots & \frac{\partial \bar{\chi}_{N}}{\partial \theta_{2 L}}
\end{array}\right]
$$

where

$$
\begin{gathered}
\frac{\partial \bar{\chi}_{j}}{\partial \delta_{l i, t}}=\left\{\begin{array}{cc}
-\frac{1}{S} \sum_{s=1}^{S}\left(\epsilon_{s}\right)^{\sigma_{\epsilon}} \cdot x_{j i, t}\left(\alpha_{s}, \epsilon_{s}\right) x_{l i, t}\left(\alpha_{s}, \epsilon_{s}\right) & \text { if } l \neq j \\
\frac{1}{S} \sum_{s=1}^{S}\left(\epsilon_{s}\right)^{\sigma_{\epsilon}} \cdot x_{j i, t}\left(\alpha_{s}, \epsilon_{s}\right)\left(1-x_{j i, t}\left(\alpha_{s}, \epsilon_{s}\right)\right) & \text { if } l=j
\end{array}\right. \\
\frac{\partial \bar{\chi}_{j}}{\partial \sigma_{\epsilon}}=\frac{1}{S} \sum_{s=1}^{S}\left(\ln \epsilon_{s}\right)\left(\epsilon_{s}\right)^{\sigma_{\epsilon}} \cdot x_{j i, t}\left(\alpha_{s}, \epsilon_{s}\right) \cdot\left[\delta_{j i, t}-\sum_{l=2}^{N} x_{l i, t}\left(\alpha_{s}, \epsilon_{s}\right) \cdot \delta_{l i, t}\right] \\
\frac{\partial \bar{\chi}_{j}}{\partial \sigma_{\alpha}}=\frac{1}{S} \sum_{s=1}^{S} \alpha_{s} \cdot x_{j i, t}\left(\alpha_{s}, \epsilon_{s}\right) \cdot\left[\kappa_{i}-\sum_{l=2}^{N} x_{l i, t}\left(\alpha_{s}, \epsilon_{s}\right) \cdot \kappa_{l}\right] .
\end{gathered}
$$




\section{Sample of Countries (for online publication)}

Table A1: List of exporting countries

\begin{tabular}{|c|c|c|}
\hline Abbreviation & Exporter & $\begin{array}{c}\log (\text { p.c. GDP }) \\
{[\mathrm{USA}=0]}\end{array}$ \\
\hline AUS & Australia & -0.246 \\
\hline AUT & Austria & -0.249 \\
\hline BLX & Belgium-Luxembourg & -0.261 \\
\hline BRA & Brazil & -1.666 \\
\hline BGR & Bulgaria & -1.603 \\
\hline CAN & Canada & -0.211 \\
\hline $\mathrm{CHN}$ & China & -2.536 \\
\hline CZE & Czech Republic & -0.733 \\
\hline DNK & Denmark & -0.303 \\
\hline BAL & Estonia-Latvia & -1.475 \\
\hline FIN & Finland & -0.522 \\
\hline FRA & France & -0.398 \\
\hline DEU & Germany & -0.290 \\
\hline GRC & Greece & -0.760 \\
\hline HUN & Hungary & -1.121 \\
\hline IND & India & -3.214 \\
\hline IDN & Indonesia & -2.284 \\
\hline IRL & Ireland & -0.574 \\
\hline ITA & Italy & -0.332 \\
\hline JPN & Japan & -0.183 \\
\hline LTU & Lithuania & -1.526 \\
\hline MEX & Mexico & -1.263 \\
\hline NLD & Netherlands & -0.352 \\
\hline POL & Poland & -1.428 \\
\hline PRT & Portugal & -0.830 \\
\hline KOR & Republic of Korea & -0.823 \\
\hline RoW & Rest of the World & -2.286 \\
\hline $\mathrm{ROU}$ & Romania & -1.816 \\
\hline RUS & Russia & -0.954 \\
\hline SVK & Slovak Republic & -1.102 \\
\hline SVN & Slovenia & -0.728 \\
\hline ESP & Spain & -0.644 \\
\hline SWE & Sweden & -0.367 \\
\hline TWN & Taiwan & -0.584 \\
\hline TUR & Turkey & -1.305 \\
\hline GBR & United Kingdom & -0.436 \\
\hline USA & United States & 0.000 \\
\hline
\end{tabular}




\section{Counterfactual Analysis (for online publication)}

\section{D.1 Preliminaries}

In the counterfactual analysis of Section 7, we use the complete trade matrix for the 37 exporters listed in Table A1. In order to reconcile theory and data, we incorporate trade imbalances as follows. For each country, we define $\rho_{j, t}$ as the difference between aggregate gross expenditure and aggregate gross production. We proceed under the assumption that trade imbalances remain constant at their observed level in terms of the factor price of the reference country. Here, the reference country is the United States $(j=1)$ such that its factor price is normalized to one, $\hat{w}_{1}=1$. In particular, the market clearing condition in (16) becomes

$$
\sum_{i=1}^{N} \hat{x}_{j i, t} x_{j i, t}\left(\left(\hat{w}_{i} \hat{v}_{i}\right) y_{i, t}+\rho_{i, t}\right)=\left(\hat{w}_{j} \hat{v}_{j}\right) y_{j, t}, \quad \text { for } j=2, \ldots, N
$$

where

$$
\hat{x}_{j i, t} x_{j i, t}=\frac{1}{S} \sum_{s=1}^{S} \frac{\exp \left[\alpha_{s} \sigma_{\alpha} \ln \kappa_{j}+\left(\epsilon_{s}\right)^{\sigma_{\epsilon}}\left(\bar{\chi}_{j}^{-1}\left(\boldsymbol{x}_{i, t} \mid \boldsymbol{\theta}_{2}\right)-\bar{\epsilon} \ln \left(\hat{w}_{j} \hat{\tau}_{j i}\right)\right)\right]}{1+\sum_{l=2}^{N} \exp \left[\alpha_{s} \sigma_{\alpha} \ln \kappa_{l}+\left(\epsilon_{s}\right)^{\sigma_{\epsilon}}\left(\bar{\chi}_{l}^{-1}\left(\boldsymbol{x}_{i, t} \mid \boldsymbol{\theta}_{2}\right)-\bar{\epsilon} \ln \left(\hat{w}_{l} \hat{\imath}_{l i}\right)\right)\right]} .
$$

Notice that, by construction, $\sum_{i=1}^{N} \rho_{i, t}=0$. Thus, the solution of the system of $N-1$ equations above implies that the market clearing condition for the reference country is automatically satisfied.

\section{D.2 Algorithm}

To compute the vector $\hat{\boldsymbol{v}}=\left\{\hat{w}_{j}\right\}_{j=2}^{N}$ that solves system (64), we use the same algorithm as in Alvarez and Lucas (2007).

Step 0. Initial guess: $\hat{\boldsymbol{w}}^{k}=[1, \ldots, 1]$ if $k=0$.

Step 1. Conditional on $\hat{w}^{k}$, compute $\hat{x}_{j i, t} x_{j i, t}$ according to (65).

Step 2. Compute the excess labor demand as

$$
F_{j}\left(\hat{\boldsymbol{w}}^{k}\right) \equiv \frac{1}{y_{j, t}}\left[-\left(\hat{w}_{j} \hat{v}_{j}\right) y_{j, t}+\sum_{i=1}^{N} \hat{x}_{j i, t} x_{j i, t}\left(\left(\hat{w}_{i} \hat{v}_{i}\right) y_{i, t}+\rho_{i, t}\right)\right]
$$

where we divide by $y_{j, t}$ to scale excess demand by country size.

Step 3. If $\max _{j}\left|F_{j}\left(\hat{\boldsymbol{w}}^{k}\right)\right|<t o l$, then stop the algorithm. (In practice we set tol $=10^{-8}$ here.) 
Otherwise, return to Step 1 with new factor prices computed as

$$
\hat{w}_{j}^{k+1}=\hat{w}_{j}^{k}+\mu F_{j}\left(\hat{\boldsymbol{w}}^{k}\right)
$$

where $\mu$ is a positive constant. Intuitively, this updating rule increases the price of those factors with a positive excess demand.

\section{D.3 Welfare}

By Proposition 3, we can compute welfare changes in any country $i$ by solving for $e\left(\cdot, U_{i}^{\prime}\right)$. To do so, we guess that for all $\omega \equiv\left\{\omega_{l}\right\}$,

$$
e\left(\omega, U_{i}^{\prime}\right)=\left(y_{i}^{\prime}\right) \frac{\exp \left(\int \frac{1}{-\left(\bar{\epsilon} \epsilon^{\sigma_{\epsilon}}\right)} \ln \left[\sum_{l=1}^{N}\left(\kappa_{l}\right)^{\sigma_{\alpha} \alpha}\left(\omega_{l}\right)^{-\left(\bar{\epsilon} \epsilon^{\sigma_{\epsilon}}\right)}\right] d F(\alpha, \epsilon)\right)}{\exp \left(\int \frac{1}{-\left(\bar{\epsilon} \epsilon^{\sigma \epsilon}\right)} \ln \left[\sum_{l=1}^{N}\left(\kappa_{l}\right)^{\sigma_{\alpha} \alpha}\left(\left(\omega_{l, t,}\right)^{\prime}\right)^{-\left(\bar{\epsilon} \epsilon^{\sigma_{\epsilon}}\right)}\right] d F(\alpha, \epsilon)\right)} .
$$

We then check that our guess satisfies (18) and (19) if $\bar{\chi}$ satisfies (31). By equations (20) and (66), welfare changes must therefore satisfy

$$
\Delta W_{i}=\frac{\left(y_{i}^{\prime}\right) / \exp \left(\int \frac{1}{-\left(\bar{\epsilon} \epsilon^{\sigma_{\epsilon}}\right)} \ln \left[\sum_{l=1}^{N}\left(\kappa_{l}\right)^{\sigma_{\alpha} \alpha}\left(\left(\omega_{l i, t}\right)^{\prime}\right)^{-\left(\bar{\epsilon} \epsilon^{\sigma_{\epsilon}}\right)}\right] d F(\alpha, \epsilon)\right)}{y_{i} / \exp \left(\int \frac{1}{-\left(\bar{\epsilon} \epsilon^{\sigma_{\epsilon}}\right)} \ln \left[\sum_{l=1}^{N}\left(\kappa_{l}\right)^{\sigma_{\alpha} \alpha}\left(\bar{\chi}_{l}^{-1}\left(\boldsymbol{x}_{i, t}\right)\right)^{-\left(\bar{\epsilon} \epsilon^{\sigma_{\epsilon}}\right)}\right] d F(\alpha, \epsilon)\right)}-1 .
$$

Using the fact that $\left(y_{i}\right)^{\prime} / y_{i}=\hat{w}_{i}$ and $\left(\omega_{l i, t}\right)^{\prime}=\hat{w}_{l} \hat{\tau}_{l i} \bar{\chi}_{l}^{-1}\left(x_{i, t}\right)$, this finally leads to

$$
\Delta W_{i}=\left(\hat{w}_{i}\right) \frac{\exp \left(\int \frac{1}{-\left(\bar{\epsilon} \epsilon^{\sigma_{\epsilon}}\right)} \ln \left[\sum_{l=1}^{N}\left(\kappa_{l}\right)^{\sigma_{\alpha} \alpha}\left(\bar{\chi}_{l}^{-1}\left(\boldsymbol{x}_{i, t}\right)\right)^{-\left(\bar{\epsilon} \epsilon^{\sigma_{\epsilon}}\right)}\right] d F(\alpha, \epsilon)\right)}{\exp \left(\int \frac{1}{-\left(\bar{\epsilon} \epsilon^{\sigma_{\epsilon}}\right)} \ln \left[\sum_{l=1}^{N}\left(\kappa_{l}\right)^{\sigma_{\alpha} \alpha}\left(\hat{w}_{l} \hat{\tau}_{l i} \bar{\chi}_{l}^{-1}\left(\boldsymbol{x}_{i, t}\right)\right)^{-\left(\bar{\epsilon} \epsilon^{\sigma_{\epsilon}}\right)}\right] d F(\alpha, \epsilon)\right)}-1,
$$

with $\left\{\hat{w}_{l}\right\}$ obtained from the algorithm in Section D.2.

\section{D.4 Confidence Intervals}

The confidence intervals for the counterfactual analysis are computed with the following bootstrap procedure. First, draw parameter values from the asymptotic distribution of the GMM estimator: $\boldsymbol{\theta}(b) \sim N(\hat{\boldsymbol{\theta}}, \widehat{A \operatorname{Var}}(\hat{\boldsymbol{\theta}}))$. Second, compute $\bar{\chi}^{-1}\left(\boldsymbol{x}_{i, t} \mid \boldsymbol{\theta}_{2}(b)\right)$ using the algorithm described in Step 1 of Section B.3. Third, compute the counterfactual exercise with $\boldsymbol{\theta}(b)$ and $\bar{\chi}^{-1}\left(\boldsymbol{x}_{i, t} \mid \boldsymbol{\theta}_{2}(b)\right)$ using the algorithm described in Section D.2. Lastly, repeat these three steps for $b=1, \ldots, 200$. The bootstrap confidence interval corresponds to $\left[E V^{(.025)}, E V^{(.975)}\right]$ where $E V^{(\alpha)}$ denotes the $\alpha$-th quantile value of the equivalent variation obtained across the set of 200 parameter draws. 


\section{D.5 Additional Results}

Table A2: Welfare gains from Chinese integration since 1995: all countries, 2007

\begin{tabular}{|c|c|c|c|c|}
\hline \multirow[b]{2}{*}{ Exporter } & \multicolumn{2}{|c|}{ CES (standard gravity) } & \multicolumn{2}{|c|}{ Mixed CES } \\
\hline & Welfare Gains & 95\% Confidence Interval & Welfare Gains & $95 \%$ Confidence Interval \\
\hline Australia & 0.144 & $(0.120,0.176)$ & 0.225 & $(0.163,0.384)$ \\
\hline Austria & 0.058 & $(0.048,0.071)$ & 0.102 & $(0.069,0.187)$ \\
\hline Belgium-Luxembourg & 0.056 & $(0.046,0.069)$ & 0.108 & $(0.064,0.195)$ \\
\hline Brazil & 0.071 & $(0.059,0.087)$ & 0.058 & $(0.051,0.104)$ \\
\hline Bulgaria & 0.061 & $(0.050,0.075)$ & -0.005 & $(-0.050,0.040)$ \\
\hline Canada & 0.053 & $(0.043,0.065)$ & 0.098 & $(0.059,0.176)$ \\
\hline China & 1.039 & $(0.866,1.268)$ & 1.544 & $(1.195,2.812)$ \\
\hline Czech Republic & 0.151 & $(0.124,0.186)$ & 0.209 & $(0.163,0.374)$ \\
\hline Denmark & 0.014 & $(0.012,0.018)$ & 0.034 & $(0.014,0.076)$ \\
\hline Estonia-Latvia & 0.081 & $(0.067,0.100)$ & 0.043 & $(0.029,0.085)$ \\
\hline Finland & 0.100 & $(0.083,0.123)$ & 0.154 & $(0.109,0.279)$ \\
\hline France & 0.030 & $(0.025,0.037)$ & 0.057 & $(0.037,0.125)$ \\
\hline Germany & 0.122 & $(0.101,0.150)$ & 0.201 & $(0.144,0.347)$ \\
\hline Greece & 0.004 & $(0.003,0.004)$ & 0.018 & $(0.004,0.061)$ \\
\hline Hungary & 0.214 & $(0.177,0.264)$ & 0.208 & $(0.178,0.352)$ \\
\hline India & 0.126 & $(0.104,0.155)$ & 0.022 & $(-0.064,0.101)$ \\
\hline Indonesia & 0.026 & $(0.022,0.033)$ & -0.061 & $(-0.222,-0.004)$ \\
\hline Ireland & 0.135 & $(0.112,0.167)$ & 0.150 & $(0.128,0.241)$ \\
\hline Italy & 0.008 & $(0.007,0.010)$ & 0.035 & $(0.012,0.089)$ \\
\hline Japan & 0.095 & $(0.079,0.117)$ & 0.186 & $(0.120,0.368)$ \\
\hline Lithuania & 0.065 & $(0.054,0.079)$ & 0.022 & $(-0.001,0.052)$ \\
\hline Mexico & 0.121 & $(0.100,0.150)$ & 0.099 & $(0.086,0.204)$ \\
\hline Netherlands & 0.043 & $(0.035,0.053)$ & 0.068 & $(0.042,0.116)$ \\
\hline Poland & 0.086 & $(0.071,0.107)$ & 0.040 & $(0.026,0.096)$ \\
\hline Portugal & 0.050 & $(0.042,0.060)$ & 0.055 & $(0.047,0.093)$ \\
\hline Republic of Korea & 0.298 & $(0.248,0.364)$ & 0.399 & $(0.311,0.654)$ \\
\hline Rest of the World & 0.293 & $(0.244,0.358)$ & 0.105 & $(-0.039,0.246)$ \\
\hline Romania & -0.005 & $(-0.006,-0.004)$ & -0.077 & $(-0.215,-0.029)$ \\
\hline Russia & 0.105 & $(0.087,0.129)$ & 0.103 & $(0.089,0.157)$ \\
\hline Slovak Republic & 0.116 & $(0.096,0.143)$ & 0.120 & $(0.101,0.207)$ \\
\hline Slovenia & 0.012 & $(0.009,0.015)$ & 0.020 & $(0.010,0.045)$ \\
\hline Spain & 0.075 & $(0.062,0.092)$ & 0.112 & $(0.085,0.213)$ \\
\hline Sweden & 0.076 & $(0.063,0.094)$ & 0.113 & $(0.085,0.205)$ \\
\hline Taiwan & 0.695 & $(0.582,0.843)$ & 0.946 & $(0.743,1.520)$ \\
\hline Turkey & 0.024 & $(0.020,0.030)$ & 0.019 & $(0.016,0.042)$ \\
\hline United Kingdom & 0.014 & $(0.011,0.017)$ & 0.022 & $(0.013,0.049)$ \\
\hline United States & 0.034 & $(0.028,0.043)$ & 0.071 & $(0.046,0.136)$ \\
\hline
\end{tabular}

Notes: Estimates of welfare changes (computed as the minus of the equivalent variation) from replacing China's trade costs to all other countries in 2007 at their 1995 levels. "CES (standard gravity)" and "Mixed CES" report these welfare changes obtained using the factor demand system in Panels A and C, respectively, of Table 2. 95\% confidence intervals computed using the bootstrap procedure documented in Appendix D. 